\title{
Regulation of Sterol Regulatory Element Binding Protein-1 in Bovine Mammary Epithelial Cells \\ Liang Chen
}

\author{
Dissertation submitted to the faculty of the Virginia Polytechnic Institute and State \\ University in partial fulfillment of the requirements for the degree of \\ Doctor of Philosophy \\ In \\ Animal Sciences, Dairy
}

\author{
Committee: \\ Benjamin A. Corl, Chair \\ Robert M. Akers \\ Honglin Jiang \\ Gonzalo Ferreira
}

$8 / 11 / 2012$

Blacksburg, Virginia

Keywords: SREBP1, t10, c12-CLA, Insig1, mTOR

Copyright 2016, Liang Chen 


\title{
Regulation of Sterol Regulatory Element Binding Protein-1 in Bovine Mammary Epithelial Cells
}

\author{
Liang Chen
}

\begin{abstract}
The key transcription factor sterol regulatory element binding protein-1 (SREBP1) plays a central role in milk fat synthesis. SREBP1 stimulates the transcription of genes encoding lipogenic enzymes. The overall objective of these studies was to investigate the mechanisms of SREBP1 regulation by nutrients. In the first study, chromatin immunoprecipitation (ChIP) accompanied with deep-sequencing was employed to investigate the potential sterol regulatory elements (SRE) in the promoter of SREBP1target genes. The SRE in three known SREBP1-target genes SREBP1, fatty acid synthase (FASN) and stearoyl-CoA desaturase (SCD) were first validated in a bovine mammary epithelial cell line (MacT) and in bovine mammary tissues. At least one or two SRE binding sites in 24 selected lipogenic genes were identified within 50,000 base pair to the 5'-transcription start site through ChIP-seq. The genes closest to the highest enriched peaks were involved in cell integrity, defense or signal transduction whereas lipogenic genes were not among the top enrichment leading to the questions about the success of the ChIP. The second study was conducted to determine the effect of t10, c12-conjugated linoleic acid (CLA) on insulin induced gene-1 (Insig1), an endoplasmic reticulum (ER) protein that anchors SREBP1 and prevents proteolytic activation of SREBP1. MacT cells were treated with increasing levels of t10, c12-CLA. High concentration of t10, c12-CLA inhibited Insig1 degradation therefore decreased SREBP1 maturation. Furthermore, immunoprecipitation (IP) confirmed that t10, c12-CLA reduced Insig1 proteasomal
\end{abstract}


degradation by disrupting the interaction between Insig 1 and UBX domain-containing protein 8 (Ubxd8), which is part of a degradation complex that removes Insig1 from the ER. In the third study, three potential regulators of SREBP1 activation and their pathways were investigated in insulin, t10, c12-CLA or glucose treated MacT cells. Insulin-induced mammalian target of rapamycin (mTOR) signaling stimulated lipogenesis via activation of SREBP1 and the stimulatory effect was based on the regulation on cAMP response element binding protein coactivator 2 (CRTC2) phosphorylation, Lipin1 translocation and glycogen synthase kinase-3 (GSK3)-dependent proteasomal degradation. t10, c12-CLA inhibited SREBP1 through AMP-activated protein kinase (AMPK) phosphorylation, a key protein kinase in energy homeostasis. Glucose stabilized the SREBP1 chaperone protein SCAP and facilitated SREBP1 activation. Overall, SREBP1 activation is under specific regulation of t10, c12-CLA and interacts with multiple major cellular signaling pathways in response to hormonal stimulation and nutrient availability. 


\section{Dedication}

I dedicate the dissertation to my wife Han Mou and my son Ian 


\section{Acknowledgement}

I thanks Dr. Benjamin Corl, my advisor and my mentor for my three-year study. Your guidance, patience and trust provide me the optimal environment and confidence to take on every challenge. I also thank you for rendering the opportunity to pursue my degree in Virginia Tech. I am truly grateful for the wonderful experience here in Blacksburg. I thank my committee members Dr. Mike Akers, Dr. Honglin Jiang and Dr. Ganzalo Ferreira for helping me design my study plan, prepare preliminary exam and dissertation writing. My special thanks to Andrea Lengi for her technical support in the lab, without you I cannot get all the experiments done smoothly. I also thank all the former students in Corl lab for the protocols, reagents and labnotes to help me get to my goal faster.

I thank all the dairy science faculty, staff and fellow graduate students for your encouragement and support. It has been a great pleasure to work with you.

I thank my family, my parents, my grandparents, my uncle and my aunt, who are always there to provide everything to achieve my goal.

Lastly, I thank my wife for your enormous sacrifices and encouragement to support me every each day in last five years. I thank you for making my dream come true. 


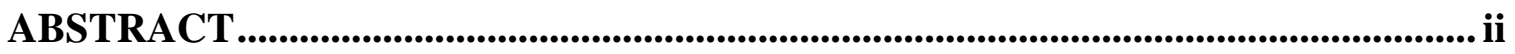

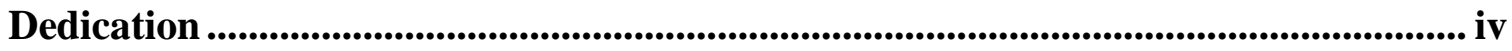

Acknowledgement ............................................................................................................................. v

Table of Contents ............................................................................................... vi

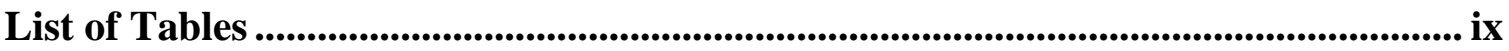

List of Figures................................................................................................................. $\mathrm{x}$

List of Abbreviations ...................................................................................................... xii

Chapter 1 General introduction ........................................................................... 1

Chapter 2 Literature review ......................................................................................................... 4

Milk fat synthesis....................................................................................................................... 4

Milk fat depression........................................................................................................... 5

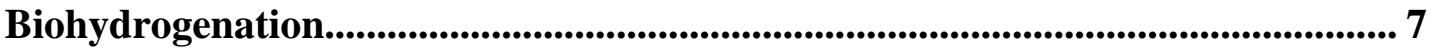

T10, c12-CLA-induced MFD ........................................................................................ 10

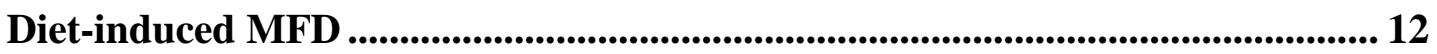

Lipogenic enzymes ....................................................................................................... 14

SREBP1 ................................................................................................................. 19

Regulation of SREBP1 ................................................................................................ 23

Regulation of SREBP1 by mTOR signaling.............................................................. 28

Regulation of SREBP1 by other factors ....................................................................... 30

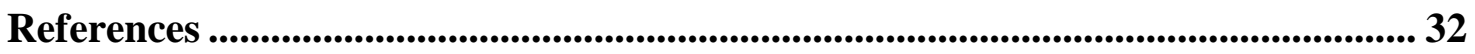

Chapter 3 Analysis of chromatin immunoprecipitation of SREBP1 in bovine mammary epithelial cells.......................................................................................................... 42

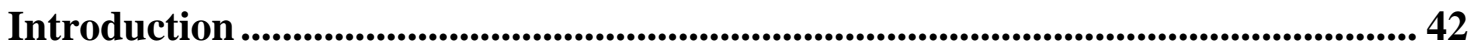

Methods and materials............................................................................................................ 44

Reagents...................................................................................................................... 44

Preparation of samples for CHIP assay .......................................................................... 44

PCR and real-time PCR analysis of SREBP1-target gene promoter ................... 46

ChIP sequencing library construction and data processing .................................... 47

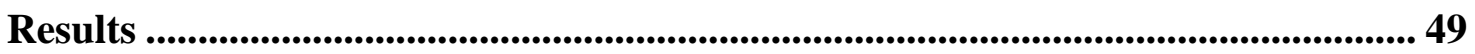

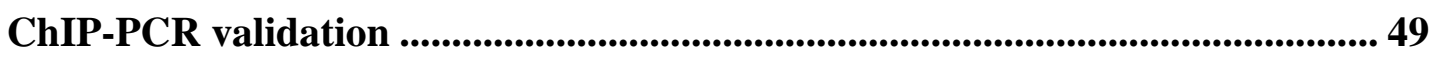

ChIP-QPCR enrichment test .................................................................................................5 50 
ChIP-Seq data analysis ........................................................................................................... 50

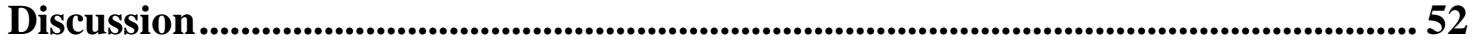

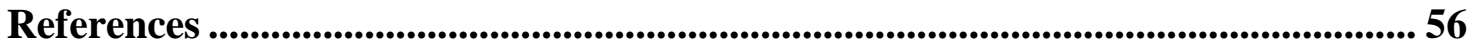

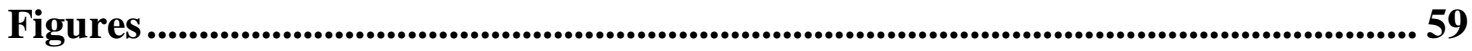

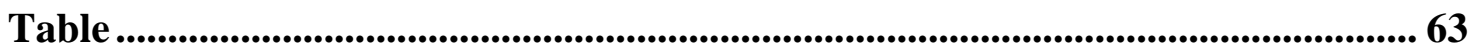

Chapter 4 Trans10, cis12-CLA regulates SREBP1 activation through proteasomal degradation of Insig1 ......................................................................................... 65

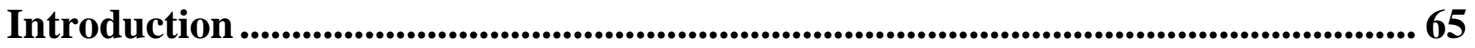

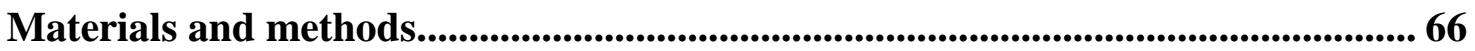

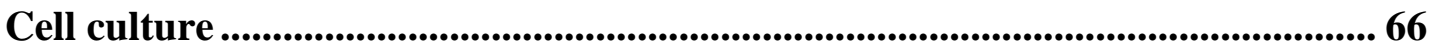

Fatty acid treatments.................................................................................................. 67

Expression vector construction and transfection .................................................... 67

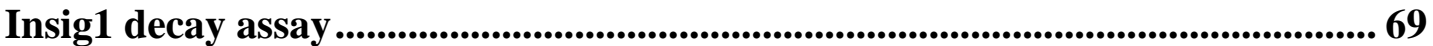

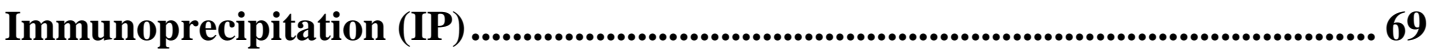

RT-PCR and real-time PCR (qPCR) .................................................................. 70

Protein extraction and Immunoblotting..................................................................... 70

Statistical Analysis .............................................................................................................. 71

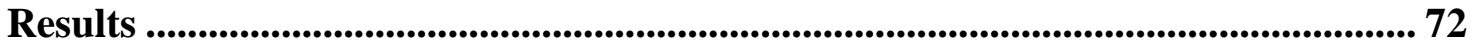

Increasing t10, c12-CLA reduced SREBP1 and lipogenic gene expression ....... 72

t10, c12-CLA increased Insig1 protein expression ................................................ 73

t10, c12-CLA reduced Insig1 degradation ................................................................ 73

CLA reduced interaction between Insig1 and Ubxd8 ...................................... 74

Discussion ................................................................................................................................... 75

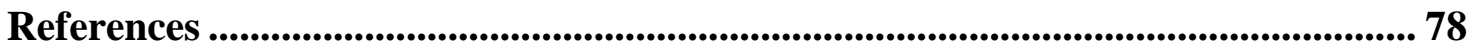

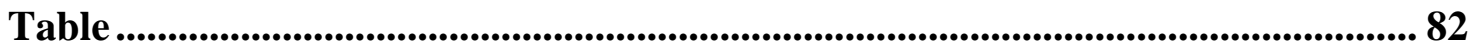

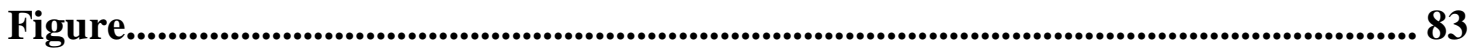

Chapter 5 Regulation of SREBP1 activation through mTOR signaling, AMPK and glucose availability in bovine mammary epithelial cells .......................................90 90

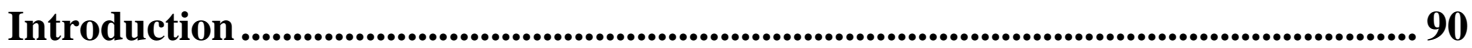

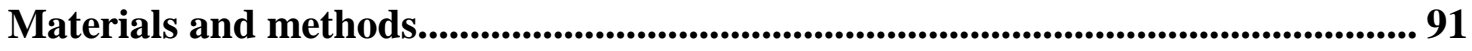

Reagents........................................................................................................................... 91

Cell culture and Treatments ...................................................................................... 92

Gene Knockdown by siRNA .......................................................................... 93 
Protein preparation and Western blot analysis ........................................................... 94

RT-PCR and real-time PCR (qPCR) ................................................................ 95

Statistical Analysis .................................................................................... 96

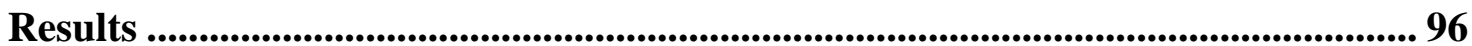

mTOR kinase affects SREBP1 levels in MacT .............................................. 96

mTOR kinase affects lipogenic gene expression in MacT...................................... 97

mTOR kinase affects lipogenic gene transcription via SREBP1 .......................... 97

mTOR kinase affects cytoplasmic CRTC2 phosphorylation, Lipin1 cellular redistribution and GSK3-dependent proteasomal degradation............................ 98

Glucose activated SREBP1 through SCAP .................................................... 99

t10, c12-CLA increases AMPK activity .................................................................. 99

Discussion .................................................................................................................................... 100

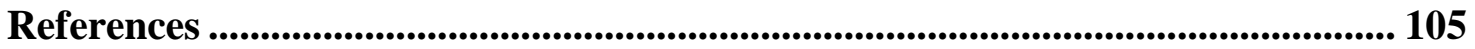

Table ............................................................................................................................. 109

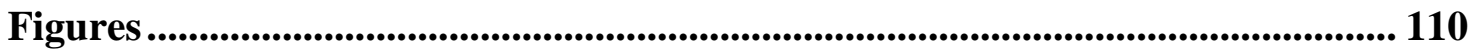

Chapter 6 General Conclusions ............................................................................................... 125 


\section{List of Tables}

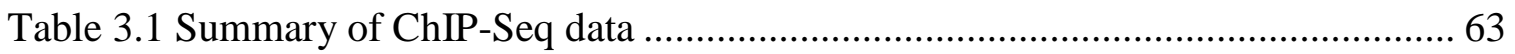

Table 3.2 List of potential SRE binding site in selected lipogenic gene promoters ......... 63

Table 4.1 Primer sequences for transcripts used in real-time quantitative PCR.............. 82

Table 5.1 Primer sequences for transcripts used in real-time quantitative PCR............ 109 


\section{List of Figures}

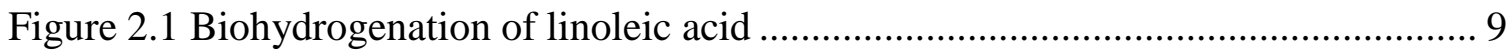

Figure 2.2 The role of key lipogenic enzymes in milk fat synthesis pathways ............... 18

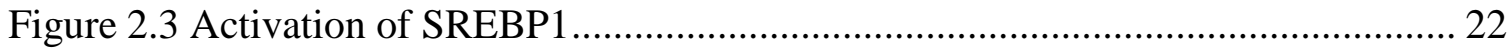

Figure 2.4 Unsaturated fatty acids-mediated Insig1 proteasomal degradation................ 27

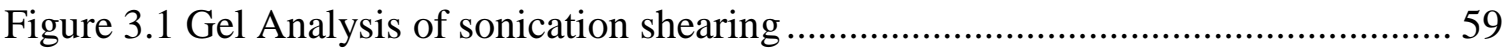

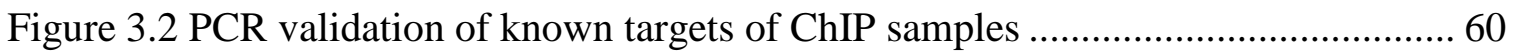

Figure 3.3 QPCR validation of fold-enrichment of SREBP1 binding ............................ 62

Figure 4.1 t10, c12-CLA reduced SREBP1 protein expression.................................... 83

Figure 4.2 t10, c12-CLA reduced lipogenic gene expression.................................... 84

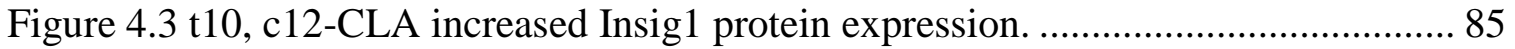

Figure 4.4 Unsaturated fatty acids increased Insig1 protein expression........................ 86

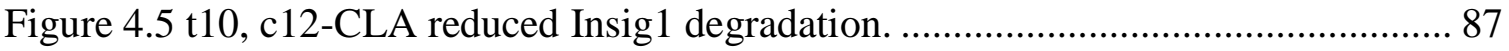

Figure 4.6 CLA reduced interaction between Insig1 and Ubxd8. .............................. 89

Figure 5.1 mTOR kinase affected SREBP1 levels in MacT..................................... 110

Figure 5.2 mTOR kinase affected lipogenic gene expression in MacT....................... 112

Figure 5.3 mTOR kinase affected lipogenic gene transcription through SREBP1....... 113

Figure 5.4 mTOR kinase affected GSK3-dependent SREBP1 degradation.................. 116

Figure 5.5 mTOR kinase affected cytoplasmic CRTC2 phosphorylation and Lipin1

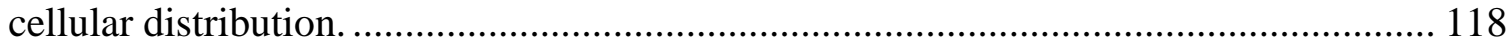

Figure 5.6 Glucose regulated SREBP1 through activation of SCAP. ......................... 120

Figure 5.7 t10, c12-CLA induced SREBP1 inhibition through AMPK ....................... 122 
Figure 5.8 Summary diagram for proposed effects of insulin, glucose and t10, c12-CLA and their regulatory pathways on SREBP1 activation in MacT. ............................... 124 


\section{List of Abbreviations}

\begin{tabular}{|l|l|}
\hline ACC & acetyl-CoA carboxylase \\
\hline ACSL & acyl-CoA synthetase long-chain family \\
\hline ACSS & acyl-CoA synthetase short-chain family \\
\hline ADPH & adipophilin \\
\hline AGPAT & acylglycerol-3-phosphate acyltransferase \\
\hline B2M & beta-2-microglobulin \\
\hline BH & biohydrogenation \\
\hline bHLHLZ & basic helix-loop-helix leucine zipper \\
\hline bp & Base pair \\
\hline CLA & Conjugated linoleic acid \\
\hline ChIP & coat protein complex \\
\hline COP & cAMP response element binding protein \\
\hline CREB & CREB-regulated transcription coactivator 2 \\
\hline CRTC2 & diacylglycerol \\
\hline DAG & diacylglycerol acyltransferase \\
\hline DGAT & eukaryotic translation initiation factor 3 subunit K \\
\hline EIF3K & electrophoretic mobility shift assay \\
\hline EMSA & endoplasmic reticulum \\
\hline ER & fatty acid \\
\hline FA & fatty acid binding protein \\
\hline FABP3 & fatty acid synthase \\
\hline FASN & mitochondrial glycerol-3-phosphate acyltransferase \\
\hline GPAM & Glycerol-3-phosphate acyltransferase \\
\hline GPAT & isocitrate dehydrogenase \\
\hline GSK3 & Insulin induced gene \\
\hline Insig & \\
\hline
\end{tabular}




\begin{tabular}{|l|l|}
\hline IP & immunoprecipitation \\
\hline LPA & lysophosphatidic acid \\
\hline LPIN & Lipin1 \\
\hline LPL & lipoprotein lipase \\
\hline LXR & liver $X$ receptor \\
\hline LXRE & liver $X$ receptor response element \\
\hline MFD & milk fat depression \\
\hline NADPH & nicotinamide adenine dinucleotide phosphate \\
\hline NCBI & National Center for Biotechnology Information \\
\hline PA & phosphatidic acid \\
\hline PLIN & perilipin \\
\hline PPAR & peroxisome proliferator-activated receptor \\
\hline PUFA & Polyunsaturated fatty acid \\
\hline RPS15 & ribosomal protein S15 \\
\hline S14 & spot 14 \\
\hline S1P & site 1 protease \\
\hline S2P & site 2 protease \\
\hline SCAP & SREBP-cleavage activating protein \\
\hline SCD & stearoyl-CoA desaturase \\
\hline siRNA & small interfering RNA \\
\hline SRE & sterol response element \\
\hline SREBP & sterol regulatory element binding protein \\
\hline TAG & triacylglycerol \\
\hline & \\
\hline
\end{tabular}




\section{Chapter 1}

\section{General introduction}

Milk fat is the most variable component in milk, both in concentration and composition. Milk fat ranges from 1.77 to $5.98 \%$ with an average of $3.76 \%$ in measurements from cows (Mansson, 2008). In dairy cows, the concentration of milk fat is greatly influenced by the diet. When large proportions of readily-fermentable carbohydrates (starch) and unsaturated fat are incorporated into the diet, milk fat percentage can decrease up to 50\% (Palmquist, 2006a). This situation is commonly referred to as milk fat depression (MFD). The basis of diet-induced MFD is the inhibition of FA synthesis in the mammary gland by specific biohydrogenation $(\mathbf{B H})$ intermediates arising from rumen BH of polyunsaturated FAs (PUFA) (Bauman and Griinari, 2000). The first of these bioactive FAs identified was trans10, cis12-conjugated linoleic acid (t10, c12-CLA) through abomasal infusion of t10, c12-CLA (Baumgard et al., 2000). Diet-induced MFD (25:75\% forage/concentrate, supplemented with 5\% soybean oils) decreased milk fat by $43 \%$ and increased t10, c12-CLA concentration in milk fat (Piperova et al., 2000). To be noted, the effect is most pronounced on those FAs synthesized de novo (Chouinard et al., 1999).

Milk fat is derived equally from two origins: de novo fatty acid synthesis (DNS) in mammary epithelial cells, and preformed FA uptake from circulation. Multiple lipogenic enzymes are involved in the pathways for FA uptake, DNS, FA activation, transport and desaturation, triaglycerol (TAG) synthesis, milk fat globule formation and secretion (Chilliard et al., 2000). The reduction in milk fat corresponds to the reduction of the mRNA expression and activity of the key enzymes, such as acetyl-CoA carboxylase 
(ACC), fatty acid synthase (FASN), lipoprotein lipase (LPL) and glycerol-3-phosphate acyltransferase (GPAT) (Baumgard et al., 2002b, Peterson et al., 2003). Sterol regulatory element binding protein 1 (SREBP1) has been implicated as the key transcription factor exerting coordinate control over transcription of the lipogenic genes in the bovine mammary gland (Harvatine et al., 2009). The specific regions in the promoter of these lipogenic genes can be recognized by SREBP1 is called sterol regulatory elements (SRE) (Shimano, 2001). However, the potential SRE binding sites of SREBP1-target genes, especially lipogenic genes, have not been investigated in bovine mammary gland.

The precursor of SREBP1 is synthesized in the endoplasmic reticulum (ER) in a complex with SREBP cleavage activating protein (SCAP). Activation of SREBP1 requires SCAP-mediated transport to the Golgi apparatus and cleavage to the mature form. The mature SREBP1 (mSREBP1) migrates to the nucleus and promotes transcription of target genes (Eberle et al., 2004). When sufficient sterols are present in the cell, SCAP-SREBP1 complex is retained in the ER by a third protein called insulininduced gene 1 (Insig1) (Yang et al., 2002). When sterol concentrations fall, Insig1 is degraded through a two-step process. First, Insig1 is ubiquitinated by ubiquitin ligase gp78. Then UBX domain-containing protein 8 (Ubxd8) binds to the ubiquitinated Insig1 protein and valosin-containing protein $(\mathrm{VCP})$ mediates the removal of Insig1 from ER membrane for proteasomal degradation (Lee et al., 2008). Unsaturated FAs (UFAs) block the maturation of SREBP1 (Hannah et al., 2001). This is analogous to the inhibition of SREBP1 observed with MFD.

SREBP1 activation is also regulated by the mammalian target of rapamycin kinase (mTOR), which participates in two different complexes by interacting with two 
mTOR subunits raptor (mTORC1) and rictor (mTORC2), at multiple levels (Bakan and Laplante, 2012). Loss of tuberous sclerosis complex (TSC)1/2, a mTORC1 suppressor, promotes SREBP1 processing in mouse embryonic fibroblasts (MEFs) and this effect is blocked by rapamycin, a mTORC1 inhibitor (Duvel et al., 2010). AMP-activated protein kinase (AMPK), the upstream regulator of mTOR, is involved in the t10, c12-CLAmediated lowering of TAG content in adipocytes (Jiang et al., 2012). Cheng et al. (Cheng et al., 2015) reported that minimal glucose concentration was sufficient to stabilize SCAP through N-glycosylation and facilitate the SCAP-SREBP1 complex trafficking to the Golgi. However, the specific roles of those regulators on SREBP1 activation and the potential regulatory pathways have not yet been determined in milk fat synthesis.

Therefore, I hypothesized that 1) SRE binding sites in SREBP1-target genes can be identified in bovine mammary tissue and characterized through chromatin immunoprecipitation (ChIP) coupled with deep sequencing. 2) t10, c12-CLA inhibits SREBP1 activation by blocking the removal of Insig1 from the ER membrane. 3) Three potential regulators mTOR signaling, AMPK as well as the glucose availability regulate SREBP1 activation in bovine mammary epithelial cells. The overall objectives of this study was to better understand the molecular mechanism of milk fat synthesis through SREBP1 activation. 


\section{Chapter 2}

\section{Literature review}

\section{Milk fat synthesis}

Milk fat is an important component in dairy product consumption. Up to $75 \%$ of total fat consumption from ruminal animal source is milk fat. $15-25 \%$ of the total fat in the human diet is dairy origin (Chilliard et al., 2000). Fat is not only attributed to the energy density in whole milk, different fatty acids (FA) play positive roles in human health. For example, n-3 polyunsaturated FAs (PUFA) and conjugated linoleic acids (CLA) could lower the risk of cardiovascular diseases (Lopez-Huertas, 2010). In dairy cows, the mammary gland has evolved to produce exceptionally large quantity of milk through years of genetic selection and improved nutrition and management. However, fat is the most variable component of milk with the amount and composition affected by nutritional, environmental and genetic factors (Bauman et al., 2011). A better understanding of milk fat regulation is crucial to sustain milk fat production thus secure the benefits for producers, processors and consumers.

Milk fat is comprised of preformed FAs uptake from circulation and de novo synthesis (DNS) in the mammary gland. Short chain FAs (4 to 8 carbons) and medium chain FAs (10 to 14 carbons) almost exclusively arise from DNS. Long chain FAs (> 16 carbons) are derived from blood lipids. The 16-carbon FA (palmitate) originates from both (Palmquist, 2006b). In ruminants, DNS fatty acids make up one-half of milk fat synthesis. Acetate and 3- $\beta$-hydroxylbutyrate (3-HB) are the primary carbon source for DNS. Glucose and acetate are also the primary source of reducing equivalents in the form of nicotinamide adenine dinucleotide phosphate (NADPH) (Chaiyabutr et al., 1980). The 
proportion of palmitate from DNS decreases as dietary fat intake increases (Bauman and Griinari, 2003). Another half of FAs comes from triglyceride (TAG)-rich lipoproteins (very low density lipoproteins (VLDL) and chylomicrons) and albumin-bound nonesterified fatty acids (NEFA) that are absorbed from the small intestine or mobilized from body fat reserves, respectively (Neville and Picciano, 1997). NEFA increase in proportion to fat mobilization from adipose tissues when cows are in negative energy balance (Adewuyi et al., 2005). Contrary to other tissues, little elongation of C16:0 to C18:0 occurred in the mammary gland of cows. However, there is a high delta-9 desaturase activity that converts stearic acid (C18:0) to oleic acid (cis-9 C18:1) (Chilliard et al., 2000). What is more, rumenic acid (cis9, trans11 C18:2), the major CLA in the milk, can also be generated from desaturation of vaccenic acid (trans11 C18:1) (Griinari et al., 2000). Milk fat synthesis, uptake and desaturation make up the FAs pool for esterification of glycerol to produce TAG (98\% of total milk fat) and complex lipids including of phospholipids (1\%) (Jensen, 2002).

\section{Milk fat depression}

Milk fat depression (MFD) is characterized by a reduction in milk fat up to $50 \%$ with no change in other milk components or milk yield (Chaiyabutr et al., 1980). This low milk fat syndrome in response to diet composition can be categorized into two broad groups (Bauman and Griinari, 2000). One is diets providing large amounts of readilyfermentable carbohydrates and reduced amounts of fiber. These low-fiber diets (LF) fail to maintain the normal rumen functions to support milk fat synthesis (Bauman and Griinari, 2003). The second group is diets supplemented with PUFAs, either from plant oils (such as soybean oil) or marine oils (fish oil). The latter will induce MFD even with 
adequate fiber inclusion (Doreau and Chilliard, 1997). Among the theories proposed to explain MFD, three based on altered rumen microbial metabolism were supported by research.

One theory is that there is inadequate rumen production of acetate and 3-HB. LF diets causes a decrease in milk fat precursors production to support milk fat synthesis thus leading to MFD. However, comparable rumen production of acetate was observed in LF diet that induced pronounced MFD (Bauman et al., 1971). Another experiment with infused exogenous acetate failed to elicit a milk fat response (Davis et al., 1970). VFA production is also important for energy production. A decrease in acetate production is expected when milk fat synthesis is inhibited with LF diets rather than the cause of it (Bauman and Griinari, 2003). Therefore, it is over-simplified to ascribe LF-induced MFD to lower rumen acetate production.

Another theory is based on the nutrient competition between mammary glands and other tissues (such as adipose tissue) (Jenny et al., 1974). LF diets increase rumen propionate production (Bauman et al., 1971), and thus could facilitate hepatic gluconeogenesis (Annison et al., 1974). Increased glucose levels elicit insulin to induce adipose tissue utilization of acetate, 3-HB for fat deposition and reduced mobilization of long-chain fatty acids from fat reserve (Bauman and Griinari, 2003). By using the hyperinsulinemic-euglucemic clamp technique, in which circulating insulin level was increased over four-fold by exogenous insulin infusion while plasma glucose was maintained with infusion as well, only 5-15\% reduction in milk fat was observed, indicating a marginal milk fat response to increased insulin (McGuire et al., 1995, Griinari et al., 1997). In addition, the reduction of NEFA by $68 \%$ revealed the reduction 
in milk fat was due to the inhibition of lipolysis limiting preformed fatty acids mobilized from body reserves (Corl et al., 2006). However, elevated insulin most likely occurs during mid-lactation, when cows were in positive energy balance and NEFAs represent only a minor contribution to milk fat synthesis as the milk fat yield only decreased by $6 \%$ using a hyperinsulinemic-euglycemic clamp (Andersen et al., 2002). Based on these data, glucogenic-insulin theory cannot fully explain the cause of MFD.

The third theory is about the relationship between rumen fermentation and mammary fatty acid synthesis. Increased trans18:1 in milk fat content was observed in various diets that caused MFD (Bauman and Griinari, 2000). Trans11 18:1 is an intermediate in the biohydrogenation $(\mathbf{B H})$ of linoleic acid. However, no effect on milk fat yield or percentage was observed by direct abomasal infusion of $25 \mathrm{~g} / \mathrm{d}$ of elaidic acid (trans11 18:1) for 7d (Rindsig and Schultz, 1974). Further investigation discovered that the increase of one specific isomer trans10 18:1 in milk fat was associated with MFD rather than tran18:1 fatty acids in general (Grinari, 1999). Trans10 18:1 is formed from reduction of trans10, cis12-CLA (t10, c12-CLA). A curvilinear relationship between increased t10, c12-CLA in milk fat and decrease in milk fat percentage was summarized by Bauman \& Griinari (Bauman and Griinari, 2000) just as with trans fatty acids. Baumgard et al. (Baumgard et al., 2000) first reported that direct infusion of pure t10, c12-CLA inhibited milk fat synthesis. Given the lack of direct evidence for trans fatty acids on MFD and t10, c12-CLA as a putative rumen BH intermediate under condition of MFD, a close examination of the mechanism of t10, c12-CLA on MFD was warranted (Bauman and Griinari, 2003).

\section{Biohydrogenation}


Biohydrogenation is a process where unsaturated fatty acids (UFA) consumed by dairy cows are metabolized by rumen microorganisms to more saturated end-products (Bauman et al., 2011). For example, corn is highest in linoleic acid. Linoleic acid is converted to $\mathrm{c} 9, \mathrm{t} 11-\mathrm{CLA}$, then hydrogenated to trans $11 \mathrm{C} 18: 1$, and finally becomes stearic acid (C18:0) under normal rumen conditions (Jenkins and Harvatine, 2014). During MFD, BH pathways were altered and resulted in more $\mathrm{BH}$ intermediates in the rumen outflow. CLA isomers that arise from this incomplete $\mathrm{BH}$ requires two critical conditions. First, decreased rumen $\mathrm{pH}$ that causes a change in rumen environment and microbial population. Second, the increased supply of PUFAs from dietary sources (Bauman and Griinari, 2003). Under this “alternative” BH pathway, supply of PUFAs results in incomplete $\mathrm{BH}$ and generates an array of trans-C18:1 and CLA isomers. Among them, t10, c12-CLA is recognized as a primary CLA isomers responsible for MFD demonstrated by abomasal infusion of pure t10, c12-CLA (Baumgard et al., 2000). The biohydrogenation pathways are shown in Figure 2.1.

Lee and Jenkins (Lee and Jenkins, 2011) confirmed 8 CLA isomers were enriched through continuous culture of mixed ruminal microbes from linoleic acid, in which t10, c12-CLA isomer exhibited the highest enrichment. Compared to t10, c12-CLA, other CLA isomers exerts antilipogenic effects to a lower efficacy. Perfield et al. (Perfield et al., 2007) reported t9, c11-CLA reduced milk fat by $15 \%$ compared to t10, c12-CLA, which reduced milk fat by $27 \%$. Similar effect was observed using c10, t12-CLA (Saebo et al., 2005). T7, c9-CLA, originated from rumen-derived trans-7 18:1 via $\Delta$ 9-desaturase activity in mammary gland, also inhibited milk fat synthesis (Kadegowda et al., 2008). Inhibition of $\Delta 9$-desaturase failed to change milk fat content (Corl et al., 2002). By far, 
the biohydrogenation theory directly illustrates the generation of bioactive CLA isomers, that potently and specifically inhibit milk fat synthesis and cause MFD.

\section{Figure 2.1 Biohydrogenation of linoleic acid}

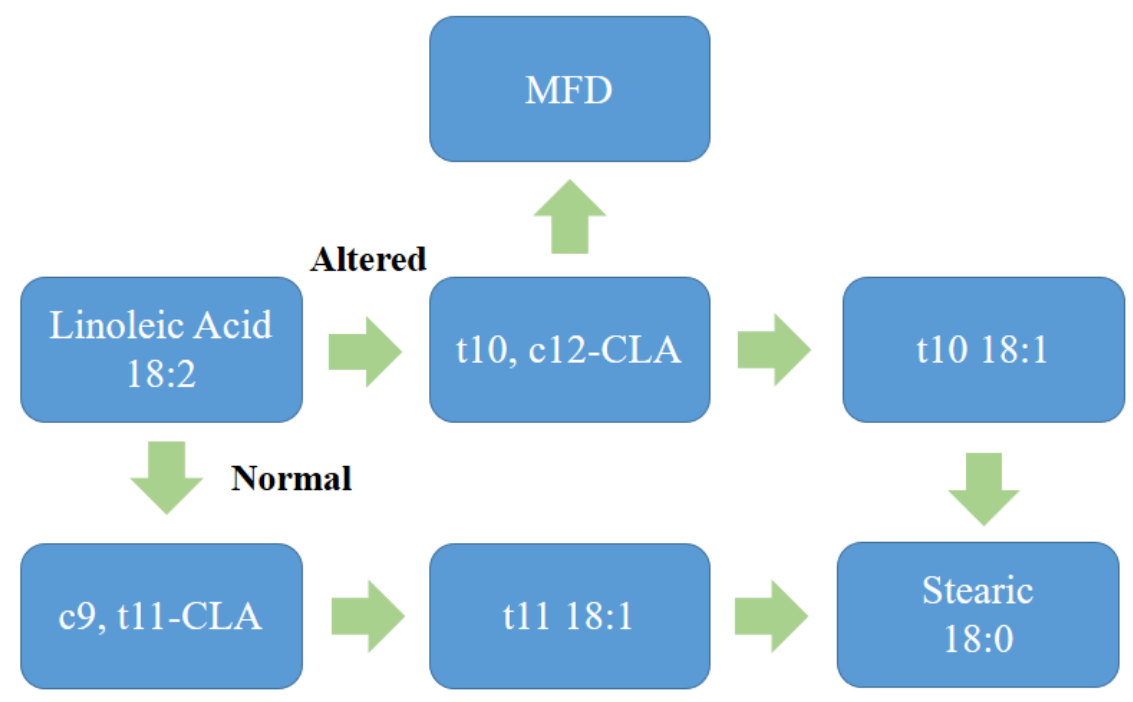

Under normal rumen condition, linoleic acid (18:2) is converted to biohydrogenation intermediate c9, t11CLA, and then biohydrogenated into Elaidic acid (t11 18:1), finally saturated to end-product stearic acid (18:0) in the rumen outflow. However, dietary polyunsaturated fatty acids (PUFAs) and decrease in rumen $\mathrm{pH}$ cause change in rumen environment and shift in rumen microbial population to favor production of an alternative biohydrogenation intermediate $\mathrm{t} 10, \mathrm{c} 12$-CLA, part of $\mathrm{t} 10, \mathrm{c} 12$-CLA will be saturated into stearic acid, but increase in t10, c12-CLA concentration in the rumen outflow eventually induced milk fat depression (MFD). Modified from Jenkins and Harvatine (Jenkins and Harvatine, 2014). 


\section{T10, c12-CLA-induced MFD}

T10, c12-CLA was first identified as the specific CLA isomer to cause MFD (Baumgard et al., 2000). T10, c12-CLA as a primary CLA isomer responsible for reduction in milk fat synthesis was observed in other mammals including mice, rats, pigs, sheep and human (Bauman et al., 2011). The use of lipid-encapsulated and Ca-salts of CLA supplements are effective approaches to examine the CLA effect and avoid rumen alteration (Perfield et al., 2002, Moallem et al., 2010). Recently rumen-unprotected CLA supplement supplied as methyl esters used to cause MFD was also reported in grazing dairy ewes (Oliveira et al., 2012) and lactating goats (Baldin et al., 2013). The reduction of milk fat yield displayed a dose-dependent response to abosomal infusion of $\mathrm{t} 10, \mathrm{c} 12$ CLA (de Veth et al., 2004). As low as $3.5 \mathrm{~g} / \mathrm{d}$ t10, c12-CLA effectively reduced milk fat yield by $25 \%$ (Peterson et al., 2002). While increasing dose to $7.0 \mathrm{~g} / \mathrm{d}$ and $14 \mathrm{~g} / \mathrm{d}$, milk fat yield decreased accordingly by 33 and 50\% (Baumgard et al., 2001).

The milk fat yield response to t10, c12-CLA infusion is rapid. A progressive decrease in milk fat following the initiation of infusion reached a significant level by 10 h, and achieved peak reduction (44\%) by $4 \mathrm{~d}$. Likewise, milk fat yield recovered as soon as the withdrawal of $\mathrm{t} 10, \mathrm{c} 12$-CLA treatment and returned to the original level by $\mathrm{d} 4$ post-infusion (Baumgard et al., 2000). In a long term of 20-week CLA treatment, the inhibitory effect of t10, c12-CLA persisted (Perfield et al., 2002) and the recovery rate was relatively slow about 4 to 5 weeks after the termination of CLA supplement (Moallem et al., 2010).

The apparent transfer efficiency of t10, c12-CLA from supplement to milk fat varies from $8-28 \%$ depending on the delivery methods and appears to be a dose- 
dependent response (Chouinard et al., 1999, de Veth et al., 2004). Reduction induced by CLA in overall FAs was observed but the effects are more profound in de novo synthesized FAs (Chouinard et al., 1999, Perfield et al., 2002), even though the effects distributed more uniformly among reduction of preformed FAs and DNS at low dose (Baumgard et al., 2001). The maximal reduction of milk fat yield was 50\% (Bauman and Griinari, 2003). The reasons why no further reduction was observed might be intricate. It might be only one-half of milk fat yield is responsive to CLA regulation, or the innate property of milk fat as an energy source in a priority to nurse neonates.

The effects of t10, c12-CLA on whole body metabolism and production performance were also extensively investigated. Supplementing CLA decreased milk fat synthesis and repartitioned nutrients towards milk yield and milk protein synthesis in grazing system (Hutchinson et al., 2012) and in an energy-limiting condition during early lactation (de Veth et al., 2006). During mid-, late-lactation, t10, c12-CLA has minimal effects on dry matter intake, body weight or energy balance (Perfield et al., 2002, Pappritz et al., 2011). CLA-induced MFD has no effects on plasma concentration of metabolites such as glucose and NEFAs or hormone secretion such as insulin, leptin and insulin-like growth factor-I during short-term (Baumgard et al., 2002a) or long-term treatment (Bernal-Santos et al., 2003). Infusion of t10, c12-CLA has no effect on plasma NEFA response to epinephrine challenge or glucose response to insulin challenge (Baumgard et al., 2002a, de Veth et al., 2006). Those results indicated that whole-body energy metabolism and glucose homeostasis were unaffected by t10, c12-CLA. However, less endogenous glucose production after CLA supplementation suggests that glucose utilization in mammary gland was spared for lactose synthesis since less glucose was 
used for milk fat synthesis (Hotger et al., 2013). Kramer et al. (Kramer et al., 2013)

reported that fatty acid synthesis in other tissues (e.g. liver and adipose tissues) was only marginally affected by CLA supplementation, while de novo synthesized FAs and C16 decreased significantly in milk fat, indicating a specific CLA effect in mammary gland.

\section{Diet-induced MFD}

Dietary fat from forage and grains typically ranges from 1 to $3 \% \mathrm{DM}$. Fat supplements for dairy rations are usually highly hydrogenated to avoid rumen fermentation and digestion problems (Jenkins and Harvatine, 2014). However, in intensive modern dairy operations that feed total mixed rations, diets that include higher levels of highly fermentable carbohydrates or diets that include PUFAs-rich plant oils or fish oils are often associated with MFD (Harvatine et al., 2009). MFD is also found on more extensively managed, pastured-based dairies due to the consumption of early growth stage forages (Rivero and Anrique, 2015). Dairy cows fed a MFD diet (25:70\% forage/concentrate and supplemented with $5 \%$ soybean oils) significantly decreased milk fat by $43 \%$ in a three-week period (Piperova et al., 2000). The increase in t10, c12-CLA and trans FAs in milk fat was the mark of specific modifications of rumen environment induced by a MFD diet (Loor et al., 2005). Furthermore, infusion of t10, c12-CLA to cows fed MFD diets led to a lower potential response in milk fat decrease, indicating a maximal response to t10, c12-CLA (Glasser et al., 2010). Dairy cows fed sunflower oil (rich in n-6) and linseed oil (rich in n-3) combined with DHA-rich algae diets for 10 weeks resulted in MFD by reducing milk fat yield over $30 \%$ and increased secretion of t10, c12-CLA and DHA, indicating rumen BH alteration by PUFAs of lipid supplements (Angulo et al., 2012). 
Continuing work reflects large variations of milk fat response to dietary manipulations. Since the MFD effect on DNS was more pronounced than on long chain fatty acids (LCFA) uptake, supply of dietary short and medium chain fatty acids (SMCFA) was proposed to rescue MFD (Vyas et al., 2012). Milk fat concentration increased linearly in response to butterfat (rich in SMCFA) infusion at the expense of milk yield but was insufficient to rescue MFD (Vyas et al., 2013). Along with the same idea, coconut oil (rich in medium chain FAs) were tested but failed to prevent MFD (Hollmann and Beede, 2012, Reveneau et al., 2012). Free fatty acids (FFA) rich in palmitic acid increased milk fat yield by increasing C16 in milk (Rico et al., 2014c). Different forms of UFAs supplement (FFA vs triglycerides) was investigated and UFArich FFAs decreased DNS to a great extent, but neither treatment was significant than from control. Low milk fat yield in basal diet disguised the treatment effect due to diet formulation (Boerman and Lock, 2014). Using corn distillers dried grains with soluble (DDGS) in the high producing diets to replace soybean meal and corn grain is impeded by the high PUFAs in corn oils (Havlin et al., 2014). Reduced-fat DDGS allows inclusion up to $30 \%$ DM in the diet without risk of MFD (Ramirez-Ramirez et al., 2016).

Potential measures to alleviate/recover milk fat yield from MFD were also explored. Diet-induced MFD and recovery appeared to have a similar pattern as CLAinduced MFD which occurred progressively after a short lag (Jenkins and Harvatine, 2014). Feeding a low fiber, high oil diet (29.5\% NDF, $6.9 \%$ oils) in the induction phase resulted in a $34 \%$ milk fat reduction by $\mathrm{d} 9$. After restoring adequate dietary NDF (36.8\%) and minimizing PUFAs in the diet, milk fat yield was fully recovered to normal levels by d 15 (Rico and Harvatine, 2013). Inoculation of rumen digesta from non-MFD 
cows showed slight improvement, to accelerate the recovery rate of DNS or normal $\mathrm{BH}$ (Rico et al., 2014a, Rico et al., 2014b). Monensin is likely to affect PUFAs-altering BH pathway because it is used to alter rumen bacterial population to lower ruminal methane production (Jenkins et al., 2003). However, supplementing monensin to MFD diet has no effect on milk fat yield (He et al., 2012). Supplementing vitamin E along with dietary fat was proposed to prevent the "trans11 to trans10 shift" in rumen BH pathway (Pottier et al., 2006). Administrating vitamin E after MFD developed failed to reverse the process toward trans11 pathway and did not restore milk fat content (Zened et al., 2012). A ratio of dietary starch to forage NDF > 1.4 was associated with reduced milk fat (Weiss, 2012). Partially replacing dietary starch with fiber and saturated fat successfully partitioned more energy toward milk and increased milk fat yield (Boerman et al., 2014).

\section{Lipogenic enzymes}

Milk fat synthesis requires concerted actions of multiple mammary lipogenic enzymes. These enzyme activities regulate the biochemical process involved in FA uptakes, fatty acid synthesis, transport, desaturation and esterification, and the formation, translocation and secretion of milk lipid droplet (Bauman et al., 2011). Acetyl-CoA carboxylase (ACC) and FA synthase (FASN) are two key enzymes for DNS in mammary epithelial cells. First, acetate is activated by Acyl-CoA synthase short-chain family member 2 (ACSS2) to acetyl-CoA (Bionaz and Loor, 2008b). The conversion of acetylCoA to malonyl-CoA is catalyzed by ACC, which is the rate-limiting step of DNS. FASN is a multi-functional protein that transfers one acetyl-CoA unit to malonyl-CoA in a sequential order to produce fatty acyl-CoA with chain lengths from $\mathrm{C} 4$ to $\mathrm{C} 16$, of which palmitate is the major product (Smith et al., 2003). On the other hand, preformed FAs 
uptake from plasma is mediated by lipoprotein lipase (LPL), which hydrolyzes TAG to release FAs. The transport of LCFAs across the mammary epithelial membrane is carried out by fatty acid binding protein $(\mathbf{F A B P})$ in conjunction with fatty acid translocator (FAT/CD36) (Barber et al., 1997). Acyl-CoA-binding proteins (ACBP) regulate intracellular FAs transport with a 10-fold higher affinity but much lower abundance than FABP (Mikkelsen and Knudsen, 1987). LCFAs are activated by acyl-CoA synthase longchain family isoforms (ACSL) and removed from FABP (Bionaz and Loor, 2008a). Stearoyl-CoA desaturase (SCD) introduces a double bond in the $\Delta 9$-position of the saturated FAs for the synthesis of monounsaturated FAs such as palmitoleoyl-CoA and primarily, oleoyl-CoA and production of c9, t11-CLA from t11 C18:1 (Corl et al., 2001). Fatty acyl-CoA synthesized from DNS and preformed FAs are esterified to the glycerol-3-phosphate (G3P) backbone to form TAG (Forsberg et al., 1985). Glycerol is from hydrolysis of TAG and also derived from glucose, which is taken up from plasma via an insulin-independent transporter GLUT1 (Zhao, 2014). One fatty acyl-CoA is acylated to G3P to form lysophosphatidate (LPA) by glycerol-3-phosphate acyltransferase (GPAT), which is the first committed step in TAG synthesis. Acylglycerolphosphate acyltransferase (AGPAT) adds another fatty acyl-CoA to lysophosphatidate to form phosphatidate (PA), then hydrolyzed to diacylglycerol (DAG) by Lipin1. Diacylglycerol acyltransferase 1 (DGAT1) esterifies the sn-3 position of G3P backbone with either LCFAs and SCFAs to form TAG. Milk fat globules (MFG) are formed in ER, transported to apical membrane and released to the lumen (Keenan and Mather, 2006). The pathways for milk fat synthesis are shown in Figure 2.2. 
Piperova et al. (Piperova et al., 2000) reported that mammary ACC and FASN enzyme activity decreased by $61 \%$ and $44 \%$ by feeding a MFD diet that reduced milk fat yield by $43 \%$. Feeding another high concentrate/low fiber diet for the same time frame, which reduced milk fat yield by $25 \%$, caused a reduction of mRNA abundance of lipogenic genes includes ACC, FASN, SCD (Peterson et al., 2003). These results supported the finding in MFD induced by 5-d t10, c12-CLA infusion, which observed $42 \%$ milk yield reduction as well as 39 to $54 \%$ reduction in mRNA abundance of above mentioned lipogenic enzymes (Baumgard et al., 2002b). The reduction in mRNA expression and enzyme activity were correlated with the increase in t10, c12-CLA level in these experiments. Mammary gland LPL activity was up-regulated at the onset of lactation and remained high through the lactation cycle compared with adipose tissues (Shirley et al., 1973). FABP3 was the most abundant FABP isomer in lactating mammary gland (Bionaz and Loor, 2008a). Gene expression of LPL and FABP3 were reduced by t10, c12-CLA in diet induced and CLA-induced-MFD (Baumgard et al., 2002b, Peterson et al., 2003). In addition to its FA trafficking role, FABP3 binding to activated FAs relieves the suppression of ACC and SCD (Bionaz and Loor, 2008b). Previous research has shown that the mRNA expression of GPAT and AGPAT was decreased significantly by t10, c12-CLA abomasal infusion or MFD diet (Baumgard et al., 2002b, Peterson et al., 2003), while DGAT1 mRNA expression failed to respond to t10, c12-CLA treatment but the enzyme activity decreased significantly, indicating a post-translational regulation by CLA (Sørensen et al., 2008). Diets supplemented with plant oils and DHA-rich algae for 10 weeks induced down-regulation of gene expression in bovine mammary tissues included: SCD1, FASN and SREBP1 but not LPL or GPAT. In addition, a positive 
relationship between mammary SCD1 and SREBP1 mRNA abundance was observed (Angulo et al., 2012).

Sterol response element binding protein-1 (SREBP1) has been implicated as the key transcription factor in the bovine mammary gland exerting coordinate control over transcription of the genes for milk fat synthesis (Harvatine et al., 2009, Bauman et al., 2011). Mammary SREBP1 was initially investigated as a candidate in the regulation of milk fat synthesis by t10, c12-CLA using a bovine mammary epithelial cell line (MacT). The transcriptionally active form of SREBP1 was reduced by $26 \%$ in MacT cells cultured in media containing $75 \mu \mathrm{M} \mathrm{t10,c12-CLA}$, and this reduction corresponded to $40-50 \%$ reductions in ACC and FASN mRNA abundance (Peterson et al., 2004). Subsequent to this work, an in vivo experiment documented reductions in gene expression for SREBP1 and proteins involved in its activation in mammary tissue during CLA infusion and dietinduced MFD (Harvatine and Bauman, 2006). Further experiments found that overexpression of SREBP1 in bovine MEC caused up-regulation of mRNA abundance of SREBP1, FASN, ACC and SCD1 and detected corresponding TAG accumulation (Li et al., 2014). The knockdown of SREBP1 in MacT cells led to the reduction in mRNA expression of lipogenic enzymes as well as FA uptake and synthesis (Ma and Corl, 2012). 
Figure 2.2 The role of key lipogenic enzymes in milk fat synthesis pathways

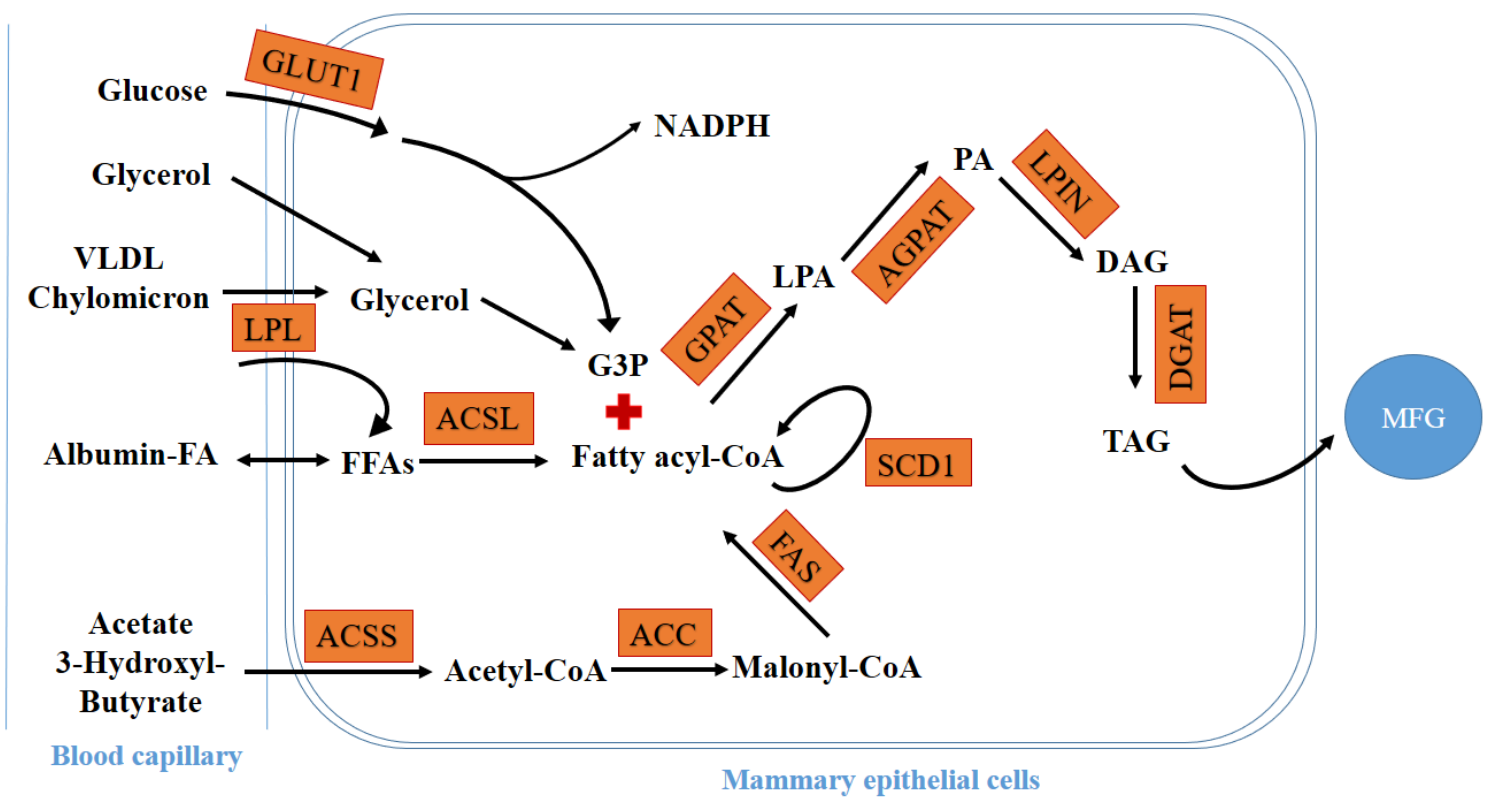

Diagram representing lipogenic enzyme-coordinated milk fat synthesis. Key proteins are shown in boxes: Acyl-CoA synthase short-chain family member 2 (ACSS2) activates acetate and 3-hydroxyl-butyrate (3HB), Acetyl-CoA carboxylase (ACC) carboxylates acetyl-CoA into malonyl-CoA and FA synthase (FASN) catalyzes the chain reaction of fatty acid. Stearoyl-CoA desaturase (SCD1) converts saturated FAs into monounsaturated FAs. lipoprotein lipase (LPL) mediates preform long chain FAs uptake from very low density lipoprotein (VLDL) and chylomicron as well as albumin bound FAs. Triglycerides (TAG) are hydrolyzed by LPL to release free FAs and glycerol. Small portion of glucose uptake via GLUT1 is transformed into glycerol-3-phosphate (G3P) as the backbone for TAG synthesis. One fatty acyl-CoA is esterified into G3P by glycerol-3-phosphate acyltransferase (GPAT) to produce lysophosphatidate (LPA). Acylglycerol-phosphate acyltransferase (AGPAT) add another fatty acyl-CoA to form phosphatidate (PA) then hydrolyzed to diacylglycerol (DAG) by Lipin1. TAG is produced by esterifying DAG with a third fatty acyl-CoA by diacylglycerol acyltransferase (DGAT). Milk fat is secreted from mammary epithelial cells as a lipid droplet called milk fat globule (MFG). 


\section{SREBP1}

SREBP proteins belong to the helix-loop-helix leucine zipper (bHLHLZ) family of transcription factors, which are first synthesized as 1150 amino acid (aa) inactive precursors bound to the ER membrane. Two SREBPs designated as SREBP1 and SREBP2, transcribed from two separate genes, regulate fatty acid synthesis and cholesterol synthesis, respectively (Brown and Goldstein, 1997). Two splice variants of SREBP1 result from alternative splicing of the 5 '-exons. The SREBP1c variant is expressed in tissues while the SREBP1a isoform is expressed in cultured cells (Eberle et al., 2004). All three SREBP precursors (pSREBP) contain three domains: 1) a 480-aa $\mathrm{NH}_{2}$-terminal domain; 2) a 90-aa membrane anchoring domain consisting of two membrane-spanning segments separated by a short hydrophilic loop of about 30 aa that projects into the ER lumen; 3) the third domain is a $\mathrm{COOH}$-terminal regulatory domain of 590 aa (Brown and Goldstein, 1997).

To stimulate gene transcription, SREBP1 must be activated through proteolytic processing (Eberle et al., 2004). A group of proteins are involved in its activation. After synthesis in the ER, SREBP1 forms complexes with SREBP cleavage-activating protein (SCAP), a polytopic membrane protein named coat protein complex II (COP II) escorts them to the Golgi apparatus (GA). SCAP is anchored in the ER through association with a third protein named insulin-induced gene (Insig), which retains the SCAP-SREBP1 complex in the ER membrane. Once the SCAP-SREBP1 complex dissociates from Insig, and translocates to GA, SREBP1 is proteolytically cleaved into the mature form $\left(\mathrm{NH}_{2}-\right.$ terminal domain) by site-1 (S1P) and site-2 proteases (S2P). The mature SREBP1 (MSREBP1) enters the nucleus and stimulates transcription of target genes by binding to 
the sterol responsive element (SRE) of their promoter regions (Eberle et al., 2004). The activation of SREBP1 is shown in Figure 2.3.

Binding to the classic palindromic E-box motif (5'-CANNTG-3') containing promoters is the hallmark of bHLHLZ transcription factors. However, there is another unique feature of SREBP1, that SREBP1 binds to non-palindromic sterol regulatory elements (5'-TCACNCCAC-3') (Kim et al., 1995). A well-conserved arginine residue is found in the basic domain of almost all other bHLHLZ proteins, is substituted by a tyrosine in SREBP1, which allowing SREBP1 to recognize not only the e-boxes but SREs as well. This dual binding specificity enables SREBP1 to bind to a broad spectrum of lipogenic genes (Shimano, 2001). Horton et a. (Horton et al., 2003) used oligonucleotide arrays hybridization with RNA and identified 33 direct target genes in mouse liver that met the criteria of significant increase in transgenic SREBP1 mice and SCAP-knockout mice, of which, 16 are connected to fatty acid metabolism. In a more recent investigation using chromatin immunoprecipitation-high-throughput DNA sequencing (CHIP-seq) and feeding a high carbohydrate diet to increase SREBP1 activity, 426 SREBP1 binding sites were characterized in chromatin from mouse liver (Seo et al., 2009). There could be more than one SRE in the promoters of SREBP1 target genes. A total of 5 binding sites for SREBP1 were found in the apoA- II promoter (Pissios et al., 1999). Two independent SREBP1 binding sites that flank the e-box in FASN promoter are required for maximal activation (Magana and Osborne, 1996). The nucleotide sequences of functional SREs varies enormously (Edwards et al., 2000). There could be multiple consensus binding sites to represent SREs. A novel sequence motif (5'ACTACANNTCCC-3') was present in $76 \%$ of the total peaks, might indicate a new SRE 
binding site (Seo et al., 2009). To date, three cofactors stimulating protein-1 (Sp-1), nuclear factor-Y (NF-Y) and CREB were identified for optimal transcriptional activation by SREBP1. In vitro studies showed that these proteins formed stable complexes to promote the active transcription (Edwards et al., 2000).

In dairy cows, a RNA-seq analysis summarized that 199 genes related to milk fat synthesis were significantly differentiated regulated (up- or down-regulated) of midlactating cows fed a diet supplemented with 5\% DM linseed oil or 5\% DM safflower oil, which are rich in unsaturated fatty acids for 28 days (Ibeagha-Awemu et al., 2016). Considering SREBP1 as the master transcription factor in milk fat synthesis, better understanding of the SREBP1 binding for lactating cows is necessary. However, a genome-wide analysis of SREBP1 binding sites in bovine mammary gland has never been revealed to-date. 


\section{Figure 2.3 Activation of SREBP1}

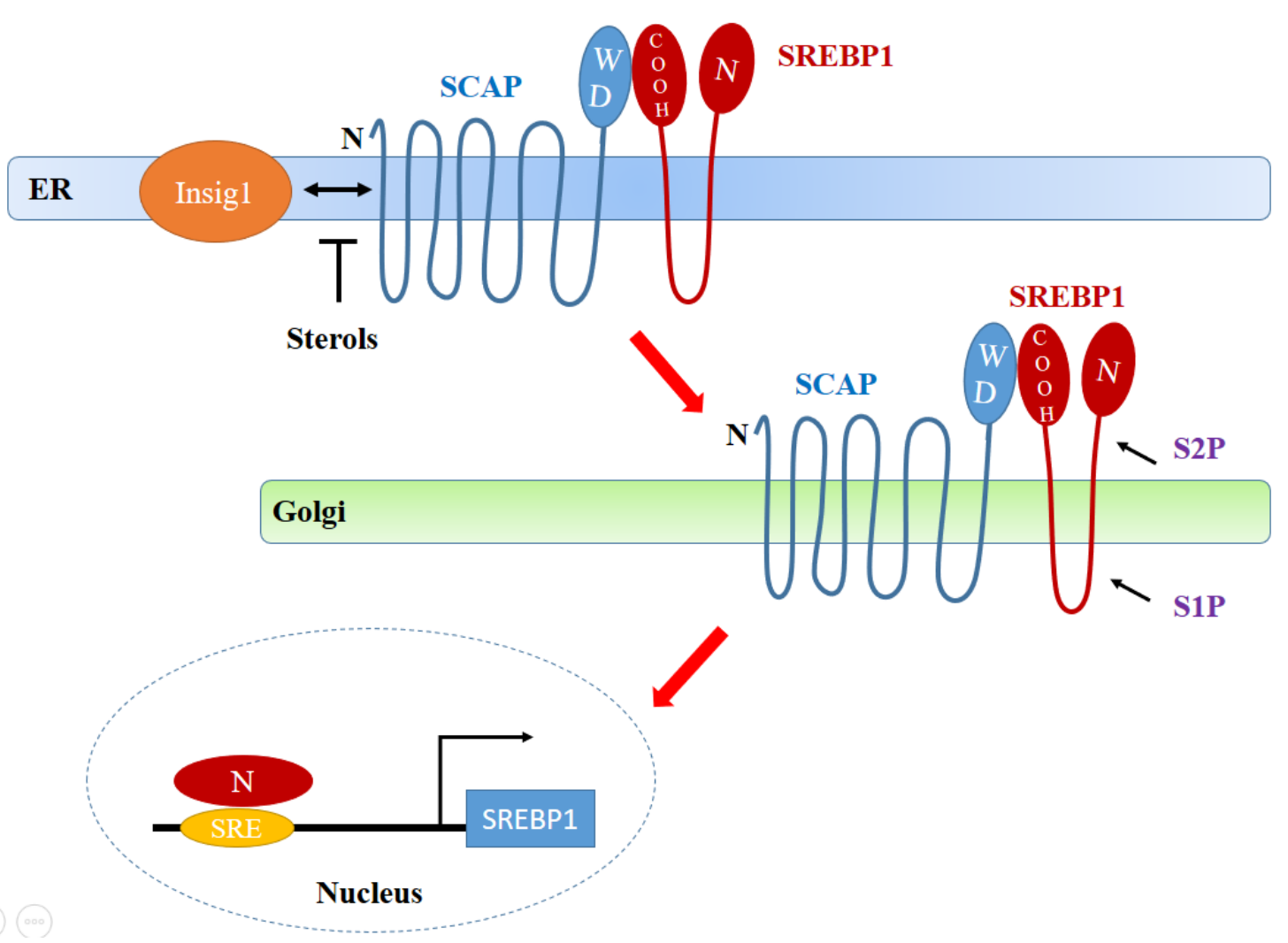

Sterol response element binding protein-1 (SREBP1) is synthesized as a precursor protein in endoplasmic reticulum (ER) membrane. SREBP1 is associated with SREBP cleavage activating protein (SCAP) by their COOH-terminal domains. SCAP-SREBP1 complex interacts with insulin-induced gene 1 (Insig1) when sufficient sterols are present. Decreased sterols concentration allows SCAP-SREBP1 complex to migrate to the Golgi, where SREBP1 is processed by site-1 $(\mathbf{S 1 P})$ and site-2 proteases $(\mathbf{S 2 P})$ and releases its $\mathrm{NH}_{2}$ terminal domain, the mature form of SREBP1 to enter nucleus. The nuclear SREBP1 (nSREBP1) activates its target genes (e.g. its own gene) transcription through binding to the sterol response elements (SRE) in their promoter regions. Modified from Cheng et al. (Cheng et al., 2015). 


\section{Regulation of SREBP1}

SCAP is critical for SREBP1 activation. The SCAP protein is divided into two domains. The $\mathrm{NH}_{2}$-terminal domain consists of eight membrane-spanning segments, followed by a COOH-terminal containing four or five tryptophan-aspartic acid (WD) repeats. SCAP-SREBP1 complex formation occurs between the $\mathrm{COOH}$-terminal domain of both proteins (Sakai et al., 1997). The COOH-terminal domain of SCAP is also important for recruiting S1P for initial SREBP proteolytic cleavage at site-1, which is a Leu-Ser bond in the middle of the luminal loop (Sakai et al., 1996). Fasting reduced mSREBP1 in the liver nuclei. SREBP1 increased to above nonfasted level after mice were refed a high concentrate/low fat diet, suggesting food consumption affects SREBP1 activation (Horton et al., 1998). Transgenic mice that overexpressed nuclear SREBP1 failed to show the decrease of gene expression of enzymes responsive for fatty acid synthesis upon fasting, indicating SREBP1 is the master regulator of lipogenic genes (Horton et al., 1998).

The proteolytic cleavage of SREBPs is subject to feedback control by cholesterol. When sterols accumulate in cells, the SCAP-SREBP complex fails to migrate to the Golgi, the nuclear SREBPs are rapidly degraded by a proteosomal process and the synthesis of sterols and fatty acids declines (Nohturfft et al., 2000). Unsaturated FAs decreased the nuclear SREBP1 but not SREBP2, to be noted, oleate, linoleate and arachidonate were effective but saturated FA palmitate and stearate was not effective. In the absence of fatty acids, sterols did not cause a sustained decrease of nuclear SREBP1(Hannah et al., 2001). When SREBP1 was expressed through an independent promoter, UFAs reduced nuclear SREBP1 without affecting its mRNA level (Hannah et 
al., 2001). These results revealed a specific inhibitory effect of UFAs on SREBP1 activation.

SCAP sense the excessive sterols in the cells through its sterol-sensing domain, thus change its conformation to prevent the SCAP-SREBP complex from incorporating into ER transport vesicles COP II. Mutant SCAP with a single aa substitution in the sterol-sensing domain (D443N) resulted in SCAP being resistant to sterol inhibition (Korn et al., 1998). Cheng et al. (Cheng et al., 2015) reported that minimal glucose concentration was sufficient to stabilize SCAP through N-glycosylation to facilitate SCAP-SREBP1 complex trafficking to the Golgi.

Another critical protein in SREBP activation is Insig. The discovery of Insig1 is from research of cholesterol metabolism. When sterols accumulate, they bind to SCAP to cause a conformational change that increases the affinity of SCAP to an ER protein, which was later designated as Insig1, and retained the SCAP-SREBP2 complex in the ER (Yang et al., 2002). When cells are depleted of sterols, SCAP dissociates from Insig and the SCAP-SREBP complex moves to the Golgi for processing and active cholesterol synthesis resumes (Brown et al., 2002). This feedback response was severely blunted in the Insigs knockout mice, resulting in over-accumulated cholesterol and TAG, as well as unchanged levels of mSREBP and mRNAs for SREBP-target genes (Engelking et al., 2005). When Insig1 protein is saturated by overexpression of SCAP, the migration of SCAP-SREBP complex is no longer blocked by sterols. When the expression of Insig1 exceeds the amount of SCAP, SREBP processing is blocked even in sterol-depleted cells (Yang et al., 2002). Interestingly, Insig1 is also a SREBP1-target gene (Kast-Woelbern et 
al., 2004). The increase of endogenous Insig1 is associated with SREBP1-mediated lipogenesis, but insufficient to block SREBP1 expression (Takaishi et al., 2004).

Insig2, a second ER protein that can block the processing of SREBP, is 59\% identical in human sequences with a much shorter $\mathrm{NH}_{2}$-terminal domain (Yabe et al., 2002). But it differs from Insig1 in two aspects: 1) The expression of Insig1, but not Insig2 depends on the presence of mSREBP; 2) the action of Insig2 requires sterols, even at high expression, Insig2 will not cause ER retention of the SCAP-SREBP complex (Yabe et al., 2002). Insig1 expression declines as mSREBP activity is low, Insig2 remains the inhibition on SREBP until sterol levels fall and Insig2 degrades. There is a liver-specific Insig2a, which can be down-regulated by insulin, allowing insulin to stimulate fatty acid synthesis even when hepatic cholesterol is high (Yabe et al., 2003). In combination of these two Insigs, lipid homeostasis is well maintained.

The level of Insig1 protein varies opposite to that of its mRNA (Gong et al., 2006). In sterol-depleted cells in which Insig1 mRNA levels are high, the Insig1 protein is ubiquitinated by the ER-resident ubiquitin ligase gp78, and rapidly degraded by a proteasome with a half-life $<30$ min (Lee et al., 2006b). When sterols are accumulated in cells, SCAP binds to Insig1 and blocks Insig1 ubiquitination, thereby extending its halflife to $>2 \mathrm{~h}$ (Gong et al., 2006). Therefore, the Insig1 mRNA declines with a lag in protein level. In contrast, Insig2 has a much longer half-life and is not regulated by SREBPs as well as a much lower affinity to SCAP or gp78 (Lee et al., 2006b). The removal of Insig1 from the ER for degradation is carried out by a complex between UBX domain containing protein 8 (Ubxd8) and valosin-containing protein (VCP). Ubxd8 binds to the ubiquitinated Insig1 protein and VCP mediates the removal of Insig1 from 
the membrane for proteosomal degradation (Lee et al., 2008). Unsaturated FAs altered the structure of Ubxd8 and block the removal of Insig1 from the ER by causing the dissociation of the Ubxd8-VCP complex from Insig1 (Lee et al., 2008, Lee et al., 2010). When the interaction of Ubxd8-VCP and ubiquitinated Insig1 is blocked, Insig1 is deubiquitinated and can resume its interaction with the SCAP-SREBP1 complex (Lee et al., 2008). Although ubiquitination of Insig1 is the required step of degradation, it is not required for the release of SCAP-SREBP1 complex (Lee et al., 2006a). The proteasomal degradation of Insig1 is shown in Figure 2.4. 
Figure 2.4 Unsaturated fatty acids-mediated Insig1 proteasomal degradation

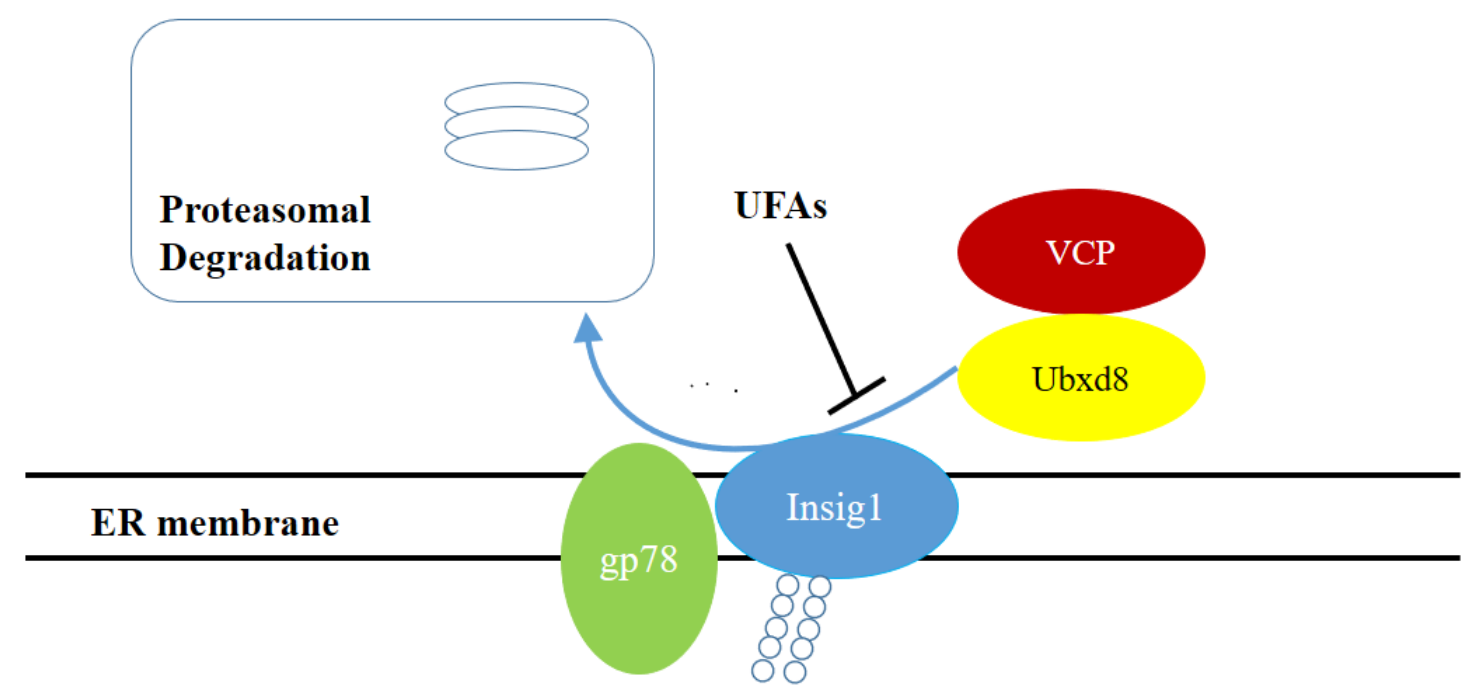

Firstly, Insulin-induced gene 1 (Insig1) is ubiquitinated by ubiquitin ligase gp78. A heterodimer formed by UBX domain containing protein 8 (Ubxd8) and valosin-containing protein (VCP) carries the ubiquitinated Insig1 out of endoplasmic reticulum (ER) and finally degraded by proteasome. However, the presence of unsaturated fatty acids (UFAs) blocks the interaction between ubiquitinated Insig1 and Ubxd8-VCP complex. Thus the degradation of Insig1 is disrupted and Insig1 retained in the ER membrane. 


\section{Regulation of SREBP1 by mTOR signaling}

The mammalian target of rapamycin kinase (mTOR) signaling regulates SREBP1 activation at multiple levels. mTOR regulates a variety of cellular metabolism by forming two complexes through interaction with different subunits: raptor (mTORC1) and rictor (mTORC2) (Bakan and Laplante, 2012). Porstmann et al (Porstmann et al., 2008) were the first to show that SREBP1 activation and lipogenesis were regulated through the major downstream effector of phosphatidylinositol 3-kinase (PI3K), mTOR complex 1 (mTORC1). Akt induced SREBP1 activation was blocked by rapamycin, a mTORC1 inhibitor, as well as the knockdown of raptor, the specific mTORC1 subunit, showed similar effect. Insulin induced-activation of PI3K/Akt leads to direct phosphorylation of tuberous sclerosis complex (TSC) $1 / 2$ and proline-rich Akt substrate $40 \mathrm{kDa}$ (PRAS40), which relieved their inhibition of mTORC1. In TSC1/2-null mouse embryonic fibroblasts, the expression of SREBP1 is activated and leads to increase of de novo lipid synthesis, indicating activation of mTORC1 is sufficient to stimulate SREBP1 activity (Duvel et al., 2010). Inhibition of S6 kinase, a downstream target of mTORC1, inhibits SREBP1 processing, suggesting that mTORC1 regulates SREBP1 through S6K (Duvel et al., 2010). SREBP1 activation is also inhibited by mTORC1 inhibitor rapamycin as well as the knockout of raptor, a mTORC1 subunit, prevented mice from developing hepatic steatosis by feeding a high fat diet (Peterson et al., 2011). Lipin1, a phosphatidic acid phosphatase responsible for DAG biosynthesis when present in cytosol, and a transcriptional coactivator in the nucleus, is a direct substrate of mTORC1 and regulates nuclear SREBP1 activity (Peterson et al., 2011). Lipin1 phosphorylation by mTORC1 blocks its nuclear localization and suppresses entry of nSREBPs, while unphosphorylated 
Lipin1 resides in the nuclear outer membrane, greatly reduced nSREBP1 levels.

Knockdown of Lipin1 in liver-specific raptor knockout mice restores SREBP1 activation. In addition, Lipin1 is also a SREBP1 target gene and its transcription is under direct SREBP1. Considered together, Lipin1 is a mTORC1-dependent downstream regulator of SREBP1 and a negative feedback mechanism exists between SREBP1 and Lipin1 (Peterson et al., 2011).

Another possible way that mTORC1 regulate SREBP1 is influencing the ER to the Golgi transport of pSREBP1. Insig2a is a liver specific Insig that respond to insulin regulation. Knockdown of Insig2a promotes association of SCAP-SREBP1 complex with COPII vesicles, while overexpressed Insig2a reduced nSREBP1 level (Yellaturu et al., 2009b). Phosphorylation of ER-bound pSREBP1 by mTORC1 increases its affinity of SCAP-SREBP1 complex for the Sec23/24 proteins of the COPII vesicles (Yellaturu et al., 2009a). However, further research showed that, it is Sec31, another COPII vesicles subunit, disassociates with the cAMP response element-binding protein (CREB) regulated transcription coactivators 2 (CRTC2), which becomes phosphorylated by mTORC1, and interacts instead with Sec23, thus promoting COPII dependent transport and processing of SREBP1 in the Golgi (Han et al., 2015a).

SREBP1 stability is also regulated by mTORC2. nSREBP1 was reduced in cells treated with INK128, a potent inhibitor against mTORC1 and mTORC2, or rictor knockdown, a mTORC2 subunit. Inhibition of Glycogen synthase kinase-3 (GSK3) prevented nSREBP1 reduction induced by mTORC2 inhibition (Li et al., 2015). GSK3 activation by insulin deprivation phosphorylates SREBP leading to ubiquitinylation by the $\mathrm{SCF}^{\mathrm{Fbw}}$ ubiquitin ligase and leads to proteasomal degradation (Dong et al., 2015). 


\section{Regulation of SREBP1 by other factors}

AMP-activated protein kinase (AMPK), phosphorylates SREBP1 at Ser372, inhibiting SREBP1 proteolytic processing (Li et al., 2011). PKA, another cAMP dependent protein kinase, phosphorylated nSREBP1 at Ser314 reduced DNA binding without affecting the cleavage processing of SREBP1 (Lu and Shyy, 2006). AMPK was activated in NEFA-treated bovine hepatocytes. SREBP1 expression and transcriptional activity were inhibited by activated AMPK, which also inhibited ACC activity and decreased TAG content in hepatocytes (Li et al., 2013). T10, c12-CLA directly or indirectly activated AMPK and increased ACC phosphorylation in 3T3-L1 adipocytes, suggesting a novel pathway that t10, c12-CLA inhibits SREBP1 activation through AMPK (Jiang et al., 2012). AMPK regulated FAs synthesis in MacT cells was also reported. Cells were treated with AICAR, a AMPK activator, dramatically reduced DNS by inactivating ACC through phosphorylation (McFadden and Corl, 2009).

Regulation of SREBP1 also occurs at transcriptional levels. SREBP1 is regulated by a feed-forward mechanism since SREs are present in the promoters of its gene. Through this feed-forward loop, nuclear SREBP1 (nSREBP1) activates the transcription

of its own gene leading to constitutive expression at low level in liver and other tissues of adult animals. On the other hand, when nSREBP1 declined, there is a secondary decrease in SREBP1 mRNA (Amemiya-Kudo et al., 2000). Liver X-receptors (LXRs) are involved in the transcriptional regulation of SREBP1. LXR, as a nuclear receptor, forms heterodimer with retinoid $\mathrm{X}$ receptor, and are activated by a variety of sterols. A LXRbinding site in the SREBP1 promoter was identified and LXR activates SREBP1 transcription at the presence of a synthetic LXR agonist (Repa et al., 2000). A blunted 
response of LXR agonist induced-lipogenic gene increase when SREBP1 is knocked out, indicating LXR increases fatty acid synthesis largely through SREBP1 (Liang et al., 2002). Furthermore, unsaturated FAs competitively blocked LXR-induced SREBP1 expression by antagonizing the ligand-dependent activation of LXR (Ou et al., 2001) and accelerating SREBP1 mRNA decay (Xu et al., 2001). LXR binding sites in the promoter of bovine SREBP1 was also identified (Lengi and Corl, 2010).However, t10, c12-CLA inhibited SREBP1 activation but not the ability of LXR binding to SREBP1 promoter. In addition, LXR activation was not altered by t10, c12-CLA infusion in lactating cows, indicating that the inhibition of SREBP1 transcription is not mediated by LXR in bovine mammary gland (Ma, 2012).

Thyroid hormone-responsive spot 14 (S14) was identified as a t10, c12-CLA responsive gene, which also contains a SRE, indicating it is a SREBP1-target gene(Harvatine and Bauman, 2006). Dairy cows producing high fat had high S14 mRNA, while over-expressed S14 increased FASN and SREBP1 expression in BMEC (Cui et al., 2015). S14-null mice produced milk deficient in de novo medium-chain fatty acids (MCFA) and overexpressed S14 produced equivalent amount of milk but greater MCFAs as well as enhanced FASN activity, indicating S14 a direct enhancer of FASN activity in mammary gland when maximal MCFAs production are needed (Rudolph et al., 2014). Acyl-coenzyme A binding domain containing 3 (ACBD3) is a Golgi-associated protein. ACBD3 attenuated SREBP1 maturation by directly binding to SREBP1 precursor (pSREBP1) rather than disrupted SCAP-SREBP1-Insig1 interaction, thus reduced the promoter activation on FASN and DNS of palmitate (Chen et al., 2012). Sirtuin1 (SirT1), 
a key NAD+-dependent deacetylase directly deacetylates SREBP1 and enhanced the ubiquitination and thus decrease the stability of SREBP1 (Ponugoti et al., 2010).

\section{References}

1. $\quad$ Mansson, H. L. (2008) Fatty Acids in Bovine Milk Fat. Food \& nutrition research 52

2. Palmquist, D. (2006) Milk Fat: Origin of Fatty Acids and Influence of Nutritional Factors Thereon. in Advanced Dairy Chemistry Volume 2 Lipids, Springer. pp 43-92

3. Bauman, D. E., and Griinari, J. M. (2000) Regulation and Nutritional Manipulation of Milk Fat. Low-Fat Milk Syndrome. Advances in experimental medicine and biology $\mathbf{4 8 0}$, 209-216

4. Baumgard, L. H., Corl, B. A., Dwyer, D. A., Saebo, A., and Bauman, D. E. (2000) Identification of the Conjugated Linoleic Acid Isomer That Inhibits Milk Fat Synthesis. American journal of physiology. Regulatory, integrative and comparative physiology 278, R179-184

5. Piperova, L. S., Teter, B. B., Bruckental, I., Sampugna, J., Mills, S. E., Yurawecz, M. P., Fritsche, J., Ku, K., and Erdman, R. A. (2000) Mammary Lipogenic Enzyme Activity, Trans Fatty Acids and Conjugated Linoleic Acids Are Altered in Lactating Dairy Cows Fed a Milk Fat-Depressing Diet. The Journal of Nutrition 130, 2568-2574

6. Chouinard, P. Y., Corneau, L., Barbano, D. M., Metzger, L. E., and Bauman, D. E. (1999) Conjugated Linoleic Acids Alter Milk Fatty Acid Composition and Inhibit Milk Fat Secretion in Dairy Cows. The Journal of Nutrition 129, 1579-1584

7. Chilliard, Y., Ferlay, A., Mansbridge, R. M., and Doreau, M. (2000) Ruminant Milk Fat Plasticity: Nutritional Control of Saturated, Polyunsaturated, Trans and Conjugated Fatty Acids. Ann. Zootech. 49, 181-205

8. Peterson, D. G., Matitashvili, E. A., and Bauman, D. E. (2003) Diet-Induced Milk Fat Depression in Dairy Cows Results in Increased Trans-10, Cis-12 Cla in Milk Fat and Coordinate Suppression of Mrna Abundance for Mammary Enzymes Involved in Milk Fat Synthesis. The Journal of Nutrition 133, 3098-3102

9. Baumgard, L. H., Matitashvili, E., Corl, B. A., Dwyer, D. A., and Bauman, D. E. (2002) Trans-10, Cis-12 Conjugated Linoleic Acid Decreases Lipogenic Rates and Expression of Genes Involved in Milk Lipid Synthesis in Dairy Cows. Journal of Dairy Science 85, 2155-2163

10. Harvatine, K. J., Boisclair, Y. R., and Bauman, D. E. (2009) Recent Advances in the Regulation of Milk Fat Synthesis. Animal : an international journal of animal bioscience 3, 40-54

11. Peterson, D. G., Matitashvili, E. A., and Bauman, D. E. (2004) The Inhibitory Effect of Trans-10, Cis-12 Cla on Lipid Synthesis in Bovine Mammary Epithelial Cells Involves Reduced Proteolytic Activation of the Transcription Factor Srebp-1. The Journal of Nutrition 134, 2523-2527

12. Harvatine, K. J., and Bauman, D. E. (2006) Srebp1 and Thyroid Hormone Responsive Spot 14 (S14) Are Involved in the Regulation of Bovine Mammary Lipid Synthesis During Diet-Induced Milk Fat Depression and Treatment with Cla. The Journal of Nutrition 136, 2468-2474

13. Eberle, D., Hegarty, B., Bossard, P., Ferre, P., and Foufelle, F. (2004) Srebp

Transcription Factors: Master Regulators of Lipid Homeostasis. Biochimie 86, 839-848 
14. Yang, T., Espenshade, P. J., Wright, M. E., Yabe, D., Gong, Y., Aebersold, R., Goldstein, J. L., and Brown, M. S. (2002) Crucial Step in Cholesterol Homeostasis: Sterols Promote Binding of Scap to Insig-1, a Membrane Protein That Facilitates Retention of Srebps in Er. Cell 110, 489-500

15. Lee, J. N., Zhang, X., Feramisco, J. D., Gong, Y., and Ye, J. (2008) Unsaturated Fatty Acids Inhibit Proteasomal Degradation of Insig-1 at a Postubiquitination Step. The Journal of Biological Chemistry 283, 33772-33783

16. Hannah, V. C., Ou, J., Luong, A., Goldstein, J. L., and Brown, M. S. (2001) Unsaturated Fatty Acids Down-Regulate Srebp Isoforms 1a and 1c by Two Mechanisms in Hek-293 Cells. The Journal of Biological Chemistry 276, 4365-4372

17. Lee, J. N., Kim, H., Yao, H., Chen, Y., Weng, K., and Ye, J. (2010) Identification of Ubxd8 Protein as a Sensor for Unsaturated Fatty Acids and Regulator of Triglyceride Synthesis. Proceedings of the National Academy of Sciences of the United States of America 107, 21424-21429

18. Bakan, I., and Laplante, M. (2012) Connecting Mtorc1 Signaling to Srebp-1 Activation. Current opinion in lipidology 23, 226-234

19. Duvel, K., Yecies, J. L., Menon, S., Raman, P., Lipovsky, A. I., Souza, A. L., Triantafellow, E., Ma, Q., Gorski, R., Cleaver, S., Vander Heiden, M. G., MacKeigan, J. P., Finan, P. M., Clish, C. B., Murphy, L. O., and Manning, B. D. (2010) Activation of a Metabolic Gene Regulatory Network Downstream of Mtor Complex 1. Molecular cell 39, 171-183

20. Peterson, T. R., Sengupta, S. S., Harris, T. E., Carmack, A. E., Kang, S. A., Balderas, E., Guertin, D. A., Madden, K. L., Carpenter, A. E., Finck, B. N., and Sabatini, D. M. (2011) Mtor Complex 1 Regulates Lipin 1 Localization to Control the Srebp Pathway. Cell 146, 408-420

21. Han, J., Li, E., Chen, L., Zhang, Y., Wei, F., Liu, J., Deng, H., and Wang, Y. (2015) The Creb Coactivator Crtc2 Controls Hepatic Lipid Metabolism by Regulating Srebp1. Nature 524, 243-246

22. Li, S., Oh, Y. T., Yue, P., Khuri, F. R., and Sun, S. Y. (2015) Inhibition of Mtor Complex 2 Induces Gsk3/Fbxw7-Dependent Degradation of Sterol Regulatory Element-Binding Protein 1 (Srebp1) and Suppresses Lipogenesis in Cancer Cells. Oncogene

23. Jiang, S., Wang, W., Miner, J., and Fromm, M. (2012) Cross Regulation of Sirtuin 1, Ampk, and Ppargamma in Conjugated Linoleic Acid Treated Adipocytes. PloS one 7, e48874

24. Li, Y., Xu, S., Mihaylova, M. M., Zheng, B., Hou, X., Jiang, B., Park, O., Luo, Z., Lefai, E., Shyy, J. Y., Gao, B., Wierzbicki, M., Verbeuren, T. J., Shaw, R. J., Cohen, R. A., and Zang, M. (2011) Ampk Phosphorylates and Inhibits Srebp Activity to Attenuate Hepatic Steatosis and Atherosclerosis in Diet-Induced Insulin-Resistant Mice. Cell metabolism 13, 376-388

25. Cheng, C., Ru, P., Geng, F., Liu, J., Yoo, J. Y., Wu, X., Cheng, X., Euthine, V., Hu, P., Guo, J. Y., Lefai, E., Kaur, B., Nohturfft, A., Ma, J., Chakravarti, A., and Guo, D. (2015) Glucose-Mediated N-Glycosylation of Scap Is Essential for Srebp-1 Activation and Tumor Growth. Cancer Cell 28, 569-581

26. Lopez-Huertas, E. (2010) Health Effects of Oleic Acid and Long Chain Omega-3 Fatty Acids (Epa and Dha) Enriched Milks. A Review of Intervention Studies.

Pharmacological research : the official journal of the Italian Pharmacological Society 61, 200-207

27. Bauman, D. E., Harvatine, K. J., and Lock, A. L. (2011) Nutrigenomics, Rumen-Derived Bioactive Fatty Acids, and the Regulation of Milk Fat Synthesis. Annual review of nutrition 31, 299-319 
28. Palmquist, D. L. (2006) Milk Fat: Origin of Fatty Acids and Influence of Nutritional Factors Thereon. in Advanced Dairy Chemistry Volume 2 Lipids (Fox, P. F., and McSweeney, P. L. H. eds.), Third Edition. Ed., Springer Science+Business Media, Inc.,, Boston, MA

29. Chaiyabutr, N., Faulkner, A., and Peaker, M. (1980) The Utilization of Glucose for the Synthesis of Milk Components in the Fed and Starved Lactating Goat in Vivo. The Biochemical journal 186, 301-308

30. Bauman, D. E., and Griinari, J. M. (2003) Nutritional Regulation of Milk Fat Synthesis. Annual review of nutrition 23, 203-227

31. Neville, M. C., and Picciano, M. F. (1997) Regulation of Milk Lipid Secretion and Composition. Annual review of nutrition 17, 159-183

32. Adewuyi, A. A., Gruys, E., and van Eerdenburg, F. J. (2005) Non Esterified Fatty Acids (Nefa) in Dairy Cattle. A Review. The Veterinary quarterly 27, 117-126

33. Griinari, J. M., Corl, B. A., Lacy, S. H., Chouinard, P. Y., Nurmela, K. V., and Bauman, D. E. (2000) Conjugated Linoleic Acid Is Synthesized Endogenously in Lactating Dairy Cows by Delta(9)-Desaturase. The Journal of Nutrition 130, 2285-2291

34. Jensen, R. G. (2002) The Composition of Bovine Milk Lipids: January 1995 to December 2000. Journal of Dairy Science 85, 295-350

35. Doreau, M., and Chilliard, Y. (1997) Effects of Ruminal or Postruminal Fish Oil Supplementation on Intake and Digestion in Dairy Cows. Reproduction, nutrition, development 37, 113-124

36. Bauman, D. E., Davis, C. L., and Bucholtz, H. F. (1971) Propionate Production in the Rumen of Cows Fed Either a Control or High-Grain, Low-Fiber Diet. Journal of Dairy Science 54, 1282-1287

37. Davis, C., Brown, R., and Phillipson, A. (1970) Low-Fat Milk Syndrome. in Physiology of digestion and metabolism in the ruminant. Proceedings of the third international symposium, Cambridge, England; August 1969., Newcastle-upon-Tyne: Oriel Press

38. Jenny, B. F., Polan, C. E., and Thye, F. W. (1974) Effects of High Grain Feeding and Stage of Lactation on Serum Insulin, Glucose and Milk Fat Percentage in Lactating Cows. The Journal of Nutrition 104, 379-385

39. Annison, E. F., Bickerstaffe, R., and Linzell, J. L. (1974) Glucose and Fatty Acid Metabolism in Cows Producing Milk of Low Fat Content. The Journal of Agricultural Science 82, 87-95

40. Griinari, J. M., McGuire, M. A., Dwyer, D. A., Bauman, D. E., and Palmquist, D. L. (1997) Role of Insulin in the Regulation of Milk Fat Synthesis in Dairy Cows. Journal of Dairy Science 80, 1076-1084

41. McGuire, M. A., Griinari, J. M., Dwyer, D. A., and Bauman, D. E. (1995) Role of Insulin in the Regulation of Mammary Synthesis of Fat and Protein. Journal of Dairy Science 78, 816-824

42. Corl, B. A., Butler, S. T., Butler, W. R., and Bauman, D. E. (2006) Short Communication: Regulation of Milk Fat Yield and Fatty Acid Composition by Insulin. Journal of Dairy Science 89, 4172-4175

43. Andersen, J. B., Mashek, D. G., Larsen, T., Nielsen, M. O., and Ingvartsen, K. L. (2002) Effects of Hyperinsulinaemia under Euglycaemic Condition on Liver Fat Metabolism in Dairy Cows in Early and Mid-Lactation. Journal of veterinary medicine. A, Physiology, pathology, clinical medicine 49, 65-71

44. Rindsig, R. B., and Schultz, L. H. (1974) Effects of Abomasal Infusions of Safflower Oil or Elaidic Acid on Blood Lipids and Milk Fat in Dairy Cows. Journal of Dairy Science 57, 1459-1466

45. Grinari, J., and Dale E. Bauman. (1999) Biosynthesis of Conjugated Linoleic Acid and Its Incorporation into Meat and Milk in Ruminants. 
46. Jenkins, T. C., and Harvatine, K. J. (2014) Lipid Feeding and Milk Fat Depression. The Veterinary clinics of North America. Food animal practice

47. Lee, Y. J., and Jenkins, T. C. (2011) Biohydrogenation of Linolenic Acid to Stearic Acid by the Rumen Microbial Population Yields Multiple Intermediate Conjugated Diene Isomers. The Journal of Nutrition 141, 1445-1450

48. Perfield, J. W., 2nd, Lock, A. L., Griinari, J. M., Saebo, A., Delmonte, P., Dwyer, D. A., and Bauman, D. E. (2007) Trans-9, Cis-11 Conjugated Linoleic Acid Reduces Milk Fat Synthesis in Lactating Dairy Cows. Journal of Dairy Science 90, 2211-2218

49. Saebo, A., Saebo, P. C., Griinari, J. M., and Shingfield, K. J. (2005) Effect of Abomasal Infusions of Geometric Isomers of 10,12 Conjugated Linoleic Acid on Milk Fat Synthesis in Dairy Cows. Lipids 40, 823-832

50. Kadegowda, A. K., Piperova, L. S., and Erdman, R. A. (2008) Principal Component and Multivariate Analysis of Milk Long-Chain Fatty Acid Composition During Diet-Induced Milk Fat Depression. Journal of Dairy Science 91, 749-759

51. Corl, B. A., Baumgard, L. H., Griinari, J. M., Delmonte, P., Morehouse, K. M., Yurawecz, M. P., and Bauman, D. E. (2002) Trans-7,Cis-9 Cla Is Synthesized Endogenously by Delta9-Desaturase in Dairy Cows. Lipids 37, 681-688

52. Perfield, J. W., II, Bernal-Santos, G., Overton, T. R., and Bauman, D. E. (2002) Effects of Dietary Supplementation of Rumen-Protected Conjugated Linoleic Acid in Dairy Cows During Established Lactation. Journal of Dairy Science 85, 2609-2617

53. Moallem, U., Lehrer, H., Zachut, M., Livshitz, L., and Yacoby, S. (2010) Production Performance and Pattern of Milk Fat Depression of High-Yielding Dairy Cows Supplemented with Encapsulated Conjugated Linoleic Acid. Animal : an international journal of animal bioscience 4, 641-652

54. Oliveira, D. E., Gama, M. A., Fernandes, D., Tedeschi, L. O., and Bauman, D. E. (2012) An Unprotected Conjugated Linoleic Acid Supplement Decreases Milk Production and Secretion of Milk Components in Grazing Dairy Ewes. Journal of Dairy Science 95 , 1437-1446

55. Baldin, M., Gama, M. A., Dresch, R., Harvatine, K. J., and Oliveira, D. E. (2013) A Rumen Unprotected Conjugated Linoleic Acid Supplement Inhibits Milk Fat Synthesis and Improves Energy Balance in Lactating Goats. Journal of Animal Science 91, 33053314

56. de Veth, M. J., Griinari, J. M., Pfeiffer, A. M., and Bauman, D. E. (2004) Effect of Cla on Milk Fat Synthesis in Dairy Cows: Comparison of Inhibition by Methyl Esters and Free Fatty Acids, and Relationships among Studies. Lipids 39, 365-372

57. Peterson, D. G., Baumgard, L. H., and Bauman, D. E. (2002) Short Communication: Milk Fat Response to Low Doses of Tran-10, Cis-12 Conjugated Linoleic Acid (Cla). Journal of Dairy Science 85, 1764-1766

58. Baumgard, L. H., Sangster, J. K., and Bauman, D. E. (2001) Milk Fat Synthesis in Dairy Cows Is Progressively Reduced by Increasing Supplemental Amounts of Trans-10, Cis12 Conjugated Linoleic Acid (Cla). The Journal of Nutrition 131, 1764-1769

59. Hutchinson, I. A., Hennessy, A. A., Dewhurst, R. J., Evans, A. C., Lonergan, P., and Butler, S. T. (2012) The Effect of Strategic Supplementation with Trans-10,Cis-12 Conjugated Linoleic Acid on the Milk Production, Estrous Cycle Characteristics, and Reproductive Performance of Lactating Dairy Cattle. Journal of Dairy Science 95, 24422451

60. de Veth, M. J., Castaneda-Gutierrez, E., Dwyer, D. A., Pfeiffer, A. M., Putnam, D. E., and Bauman, D. E. (2006) Response to Conjugated Linoleic Acid in Dairy Cows Differing in Energy and Protein Status. Journal of Dairy Science 89, 4620-4631

61. Pappritz, J., Meyer, U., Kramer, R., Weber, E. M., Jahreis, G., Rehage, J., Flachowsky, G., and Danicke, S. (2011) Effects of Long-Term Supplementation of Dairy Cow Diets 
with Rumen-Protected Conjugated Linoleic Acids (Cla) on Performance, Metabolic Parameters and Fatty Acid Profile in Milk Fat. Archives of animal nutrition 65, 89-107

62. Baumgard, L. H., Corl, B. A., Dwyer, D. A., and Bauman, D. E. (2002) Effects of Conjugated Linoleic Acids (Cla) on Tissue Response to Homeostatic Signals and Plasma Variables Associated with Lipid Metabolism in Lactating Dairy Cows. Journal of Animal Science 80, 1285-1293

63. Bernal-Santos, G., Perfield, J. W., II, Barbano, D. M., Bauman, D. E., and Overton, T. R. (2003) Production Responses of Dairy Cows to Dietary Supplementation with Conjugated Linoleic Acid (Cla) During the Transition Period and Early Lactation. Journal of Dairy Science 86, 3218-3228

64. Hotger, K., Hammon, H. M., Weber, C., Gors, S., Troscher, A., Bruckmaier, R. M., and Metges, C. C. (2013) Supplementation of Conjugated Linoleic Acid in Dairy Cows Reduces Endogenous Glucose Production During Early Lactation. Journal of Dairy Science 96, 2258-2270

65. Kramer, R., Wolf, S., Petri, T., von Soosten, D., Danicke, S., Weber, E. M., Zimmer, R., Rehage, J., and Jahreis, G. (2013) A Commonly Used Rumen-Protected Conjugated Linoleic Acid Supplement Marginally Affects Fatty Acid Distribution of Body Tissues and Gene Expression of Mammary Gland in Heifers During Early Lactation. Lipids in health and disease 12, 96

66. Rivero, M. J., and Anrique, R. (2015) Milk Fat Depression Syndrome and the Particular Case of Grazing Cows: A Review. Acta Agriculturae Scandinavica, Section A - Animal Science 65, 42-54

67. Loor, J. J., Ferlay, A., Ollier, A., Ueda, K., Doreau, M., and Chilliard, Y. (2005) HighConcentrate Diets and Polyunsaturated Oils Alter Trans and Conjugated Isomers in Bovine Rumen, Blood, and Milk. Journal of Dairy Science 88, 3986-3999

68. Glasser, F., Ferlay, A., Doreau, M., Loor, J. J., and Chilliard, Y. (2010) T10,C12-18:2Induced Milk Fat Depression Is Less Pronounced in Cows Fed High-Concentrate Diets. Lipids 45, 877-887

69. Angulo, J., Mahecha, L., Nuernberg, K., Nuernberg, G., Dannenberger, D., Olivera, M., Boutinaud, M., Leroux, C., Albrecht, E., and Bernard, L. (2012) Effects of Polyunsaturated Fatty Acids from Plant Oils and Algae on Milk Fat Yield and Composition Are Associated with Mammary Lipogenic and Srebf1 Gene Expression. Animal : an international journal of animal bioscience 6, 1961-1972

70. Vyas, D., Teter, B. B., and Erdman, R. A. (2012) Milk Fat Responses to Dietary Supplementation of Short- and Medium-Chain Fatty Acids in Lactating Dairy Cows. Journal of Dairy Science 95, 5194-5202

71. Vyas, D., Moallem, U., Teter, B. B., Fardin-Kia, A. R., and Erdman, R. A. (2013) Milk Fat Responses to Butterfat Infusion During Conjugated Linoleic Acid-Induced Milk Fat Depression in Lactating Dairy Cows. Journal of Dairy Science 96, 2387-2399

72. Hollmann, M., and Beede, D. K. (2012) Comparison of Effects of Dietary Coconut Oil and Animal Fat Blend on Lactational Performance of Holstein Cows Fed a High-Starch Diet. Journal of Dairy Science 95, 1484-1499

73. Reveneau, C., Ribeiro, C. V., Eastridge, M. L., and Firkins, J. L. (2012) Interaction of Unsaturated Fat or Coconut Oil with Monensin in Lactating Dairy Cows Fed 12 Times Daily. Ii. Fatty Acid Flow to the Omasum and Milk Fatty Acid Profile. Journal of Dairy Science 95, 2061-2069

74. Rico, D. E., Ying, Y., and Harvatine, K. J. (2014) Comparison of Enriched Palmitic Acid and Calcium Salts of Palm Fatty Acids Distillate Fat Supplements on Milk Production and Metabolic Profiles of High-Producing Dairy Cows. Journal of Dairy Science 97, 5637-5644 
75. Boerman, J. P., and Lock, A. L. (2014) Effect of Unsaturated Fatty Acids and Triglycerides from Soybeans on Milk Fat Synthesis and Biohydrogenation Intermediates in Dairy Cattle. Journal of Dairy Science

76. Havlin, J. M., Robinson, P. H., and Karges, K. (2014) Impacts of Dietary Fat Level and Saturation When Feeding Distillers Grains to High Producing Dairy Cows. Journal of animal physiology and animal nutrition

77. Ramirez-Ramirez, H. A., Castillo Lopez, E., Jenkins, C. J., Aluthge, N. D., Anderson, C., Fernando, S. C., Harvatine, K. J., and Kononoff, P. J. (2016) Reduced-Fat Dried Distillers Grains with Solubles Reduces the Risk for Milk Fat Depression and Supports Milk Production and Ruminal Fermentation in Dairy Cows. Journal of Dairy Science 99, 1912-1928

78. Rico, D. E., and Harvatine, K. J. (2013) Induction of and Recovery from Milk Fat Depression Occurs Progressively in Dairy Cows Switched between Diets That Differ in Fiber and Oil Concentration. Journal of Dairy Science 96, 6621-6630

79. Rico, D. E., Ying, Y., Clarke, A. R., and Harvatine, K. J. (2014) The Effect of Rumen Digesta Inoculation on the Time Course of Recovery from Classical Diet-Induced Milk Fat Depression in Dairy Cows. Journal of Dairy Science 97, 3752-3760

80. Rico, D. E., Holloway, A. W., and Harvatine, K. J. (2014) Effect of Monensin on Recovery from Diet-Induced Milk Fat Depression. Journal of Dairy Science 97, 23762386

81. Jenkins, T. C., Fellner, V., and McGuffey, R. K. (2003) Monensin by Fat Interactions on Trans Fatty Acids in Cultures of Mixed Ruminal Microorganisms Grown in Continuous Fermentors Fed Corn or Barley. Journal of Dairy Science 86, 324-330

82. He, M., Perfield, K. L., Green, H. B., and Armentano, L. E. (2012) Effect of Dietary Fat Blend Enriched in Oleic or Linoleic Acid and Monensin Supplementation on Dairy Cattle Performance, Milk Fatty Acid Profiles, and Milk Fat Depression. Journal of Dairy Science 95, 1447-1461

83. Pottier, J., Focant, M., Debier, C., De Buysser, G., Goffe, C., Mignolet, E., Froidmont, E., and Larondelle, Y. (2006) Effect of Dietary Vitamin E on Rumen Biohydrogenation Pathways and Milk Fat Depression in Dairy Cows Fed High-Fat Diets. Journal of Dairy Science 89, 685-692

84. Zened, A., Troegeler-Meynadier, A., Najar, T., and Enjalbert, F. (2012) Effects of Oil and Natural or Synthetic Vitamin E on Ruminal and Milk Fatty Acid Profiles in Cows Receiving a High-Starch Diet. Journal of Dairy Science 95, 5916-5926

85. Weiss, W. P. (2012) Use of a Corn Milling Product in Diets for Dairy Cows to Alleviate Milk Fat Depression. Journal of Dairy Science 95, 2081-2090

86. Boerman, J. P., Preseault, C. L., and Lock, A. L. (2014) Effect of Dietary Antioxidant and Increasing Corn Oil Inclusion on Milk Fat Yield and Fatty Acid Composition in Dairy Cattle. Journal of Dairy Science

87. Bionaz, M., and Loor, J. J. (2008) Gene Networks Driving Bovine Milk Fat Synthesis During the Lactation Cycle. BMC genomics 9, 366

88. Smith, S., Witkowski, A., and Joshi, A. K. (2003) Structural and Functional Organization of the Animal Fatty Acid Synthase. Progress in lipid research 42, 289-317

89. Barber, M. C., Clegg, R. A., Travers, M. T., and Vernon, R. G. (1997) Lipid Metabolism in the Lactating Mammary Gland. Biochimica et biophysica acta 1347, 101-126

90. Mikkelsen, J., and Knudsen, J. (1987) Acyl-Coa-Binding Protein from Cow. Binding Characteristics and Cellular and Tissue Distribution. The Biochemical journal 248, 709714

91. Bionaz, M., and Loor, J. J. (2008) Acs11, Agpat6, Fabp3, Lpin1, and Slc27a6 Are the Most Abundant Isoforms in Bovine Mammary Tissue and Their Expression Is Affected by Stage of Lactation. The Journal of Nutrition 138, 1019-1024 
92. Corl, B. A., Baumgard, L. H., Dwyer, D. A., Griinari, J. M., Phillips, B. S., and Bauman, D. E. (2001) The Role of Delta(9)-Desaturase in the Production of Cis-9, Trans-11 Cla. The Journal of nutritional biochemistry 12, 622-630

93. Forsberg, N. E., Baldwin, R. L., and Smith, N. E. (1985) Roles of Glucose and Its Interactions with Acetate in Maintenance and Biosynthesis in Bovine Mammary Tissue. Journal of Dairy Science 68, 2544-2549

94. Zhao, F. Q. (2014) Biology of Glucose Transport in the Mammary Gland. J Mammary Gland Biol Neoplasia 19, 3-17

95. Keenan, T., and Mather, I. (2006) Intracellular Origin of Milk Fat Globules and the Nature of the Milk Fat Globule Membrane. in Advanced Dairy Chemistry Volume 2 Lipids, Springer. pp 137-171

96. Shirley, J. E., Emery, R. S., Convey, E. M., and Oxender, W. D. (1973) Enzymic Changes in Bovine Adipose and Mammary Tissue, Serum and Mammary Tissue Hormonal Changes with Initiation of Lactation. Journal of Dairy Science 56, 569-574

97. Sørensen, B. M., Chris Kazala, E., Murdoch, G. K., Keating, A. F., Cruz-Hernandez, C., Wegner, J., Kennelly, J. J., Okine, E. K., and Weselake, R. J. (2008) Effect of Cla and Other C18 Unsaturated Fatty Acids on Dgat in Bovine Milk Fat Biosynthetic Systems. Lipids 43, 903-912

98. Li, N., Zhao, F., Wei, C., Liang, M., Zhang, N., Wang, C., Li, Q. Z., and Gao, X. J. (2014) Function of Srebp1 in the Milk Fat Synthesis of Dairy Cow Mammary Epithelial Cells. International journal of molecular sciences 15, 16998-17013

99. Ma, L., and Corl, B. A. (2012) Transcriptional Regulation of Lipid Synthesis in Bovine Mammary Epithelial Cells by Sterol Regulatory Element Binding Protein-1. Journal of Dairy Science 95, 3743-3755

100. Brown, M. S., and Goldstein, J. L. (1997) The Srebp Pathway: Regulation of Cholesterol Metabolism by Proteolysis of a Membrane-Bound Transcription Factor. Cell 89, 331-340

101. Kim, J. B., Spotts, G. D., Halvorsen, Y. D., Shih, H. M., Ellenberger, T., Towle, H. C., and Spiegelman, B. M. (1995) Dual DNA Binding Specificity of Add1/Srebp1 Controlled by a Single Amino Acid in the Basic Helix-Loop-Helix Domain. Molecular and cellular biology 15, 2582-2588

102. Shimano, H. (2001) Sterol Regulatory Element-Binding Proteins (Srebps): Transcriptional Regulators of Lipid Synthetic Genes. Progress in lipid research 40, 439452

103. Horton, J. D., Shah, N. A., Warrington, J. A., Anderson, N. N., Park, S. W., Brown, M. S., and Goldstein, J. L. (2003) Combined Analysis of Oligonucleotide Microarray Data from Transgenic and Knockout Mice Identifies Direct Srebp Target Genes. Proceedings of the National Academy of Sciences of the United States of America 100, 12027-12032

104. Seo, Y. K., Chong, H. K., Infante, A. M., Im, S. S., Xie, X., and Osborne, T. F. (2009) Genome-Wide Analysis of Srebp-1 Binding in Mouse Liver Chromatin Reveals a Preference for Promoter Proximal Binding to a New Motif. Proceedings of the National Academy of Sciences of the United States of America 106, 13765-13769

105. Pissios, P., Kan, H. Y., Nagaoka, S., and Zannis, V. I. (1999) Srebp-1 Binds to Multiple Sites and Transactivates the Human Apoa-Ii Promoter in Vitro : Srebp-1 Mutants Defective in DNA Binding or Transcriptional Activation Repress Apoa-Ii Promoter Activity. Arteriosclerosis, thrombosis, and vascular biology 19, 1456-1469

106. Magana, M. M., and Osborne, T. F. (1996) Two Tandem Binding Sites for Sterol Regulatory Element Binding Proteins Are Required for Sterol Regulation of Fatty-Acid Synthase Promoter. The Journal of Biological Chemistry 271, 32689-32694

107. Edwards, P. A., Tabor, D., Kast, H. R., and Venkateswaran, A. (2000) Regulation of Gene Expression by Srebp and Scap. Biochimica et biophysica acta 1529, 103-113 
108. Ibeagha-Awemu, E. M., Li, R., Ammah, A. A., Dudemaine, P. L., Bissonnette, N., Benchaar, C., and Zhao, X. (2016) Transcriptome Adaptation of the Bovine Mammary Gland to Diets Rich in Unsaturated Fatty Acids Shows Greater Impact of Linseed Oil over Safflower Oil on Gene Expression and Metabolic Pathways. BMC genomics 17, 104

109. Sakai, J., Nohturfft, A., Cheng, D., Ho, Y. K., Brown, M. S., and Goldstein, J. L. (1997) Identification of Complexes between the Cooh-Terminal Domains of Sterol Regulatory Element-Binding Proteins (Srebps) and Srebp Cleavage-Activating Protein. The Journal of Biological Chemistry 272, 20213-20221

110. Sakai, J., Duncan, E. A., Rawson, R. B., Hua, X., Brown, M. S., and Goldstein, J. L. (1996) Sterol-Regulated Release of Srebp-2 from Cell Membranes Requires Two Sequential Cleavages, One within a Transmembrane Segment. Cell 85, 1037-1046

111. Horton, J. D., Bashmakov, Y., Shimomura, I., and Shimano, H. (1998) Regulation of Sterol Regulatory Element Binding Proteins in Livers of Fasted and Refed Mice. Proceedings of the National Academy of Sciences of the United States of America 95, 5987-5992

112. Nohturfft, A., Yabe, D., Goldstein, J. L., Brown, M. S., and Espenshade, P. J. (2000) Regulated Step in Cholesterol Feedback Localized to Budding of Scap from Er Membranes. Cell 102, 315-323

113. Korn, B. S., Shimomura, I., Bashmakov, Y., Hammer, R. E., Horton, J. D., Goldstein, J. L., and Brown, M. S. (1998) Blunted Feedback Suppression of Srebp Processing by Dietary Cholesterol in Transgenic Mice Expressing Sterol-Resistant Scap(D443n). The Journal of clinical investigation 102, 2050-2060

114. Brown, A. J., Sun, L., Feramisco, J. D., Brown, M. S., and Goldstein, J. L. (2002) Cholesterol Addition to Er Membranes Alters Conformation of Scap, the Srebp Escort Protein That Regulates Cholesterol Metabolism. Molecular cell 10, 237-245

115. Engelking, L. J., Liang, G., Hammer, R. E., Takaishi, K., Kuriyama, H., Evers, B. M., Li, W. P., Horton, J. D., Goldstein, J. L., and Brown, M. S. (2005) Schoenheimer Effect Explained--Feedback Regulation of Cholesterol Synthesis in Mice Mediated by Insig Proteins. The Journal of clinical investigation 115, 2489-2498

116. Kast-Woelbern, H. R., Dana, S. L., Cesario, R. M., Sun, L., de Grandpre, L. Y., Brooks, M. E., Osburn, D. L., Reifel-Miller, A., Klausing, K., and Leibowitz, M. D. (2004) Rosiglitazone Induction of Insig-1 in White Adipose Tissue Reveals a Novel Interplay of Peroxisome Proliferator-Activated Receptor Gamma and Sterol Regulatory ElementBinding Protein in the Regulation of Adipogenesis. The Journal of Biological Chemistry 279, 23908-23915

117. Takaishi, K., Duplomb, L., Wang, M. Y., Li, J., and Unger, R. H. (2004) Hepatic Insig-1 or -2 Overexpression Reduces Lipogenesis in Obese Zucker Diabetic Fatty Rats and in Fasted/Refed Normal Rats. Proceedings of the National Academy of Sciences of the United States of America 101, 7106-7111

118. Yabe, D., Brown, M. S., and Goldstein, J. L. (2002) Insig-2, a Second Endoplasmic Reticulum Protein That Binds Scap and Blocks Export of Sterol Regulatory ElementBinding Proteins. Proceedings of the National Academy of Sciences of the United States of America 99, 12753-12758

119. Yabe, D., Komuro, R., Liang, G., Goldstein, J. L., and Brown, M. S. (2003) LiverSpecific Mrna for Insig-2 Down-Regulated by Insulin: Implications for Fatty Acid Synthesis. Proceedings of the National Academy of Sciences of the United States of America 100, 3155-3160

120. Gong, Y., Lee, J. N., Lee, P. C., Goldstein, J. L., Brown, M. S., and Ye, J. (2006) SterolRegulated Ubiquitination and Degradation of Insig-1 Creates a Convergent Mechanism for Feedback Control of Cholesterol Synthesis and Uptake. Cell metabolism 3, 15-24 
121. Lee, J. N., Song, B., DeBose-Boyd, R. A., and Ye, J. (2006) Sterol-Regulated Degradation of Insig-1 Mediated by the Membrane-Bound Ubiquitin Ligase Gp78. The Journal of Biological Chemistry 281, 39308-39315

122. Lee, J. N., Gong, Y., Zhang, X., and Ye, J. (2006) Proteasomal Degradation of Ubiquitinated Insig Proteins Is Determined by Serine Residues Flanking Ubiquitinated Lysines. Proceedings of the National Academy of Sciences of the United States of America 103, 4958-4963

123. Porstmann, T., Santos, C. R., Griffiths, B., Cully, M., Wu, M., Leevers, S., Griffiths, J. R., Chung, Y. L., and Schulze, A. (2008) Srebp Activity Is Regulated by Mtorc1 and Contributes to Akt-Dependent Cell Growth. Cell metabolism 8, 224-236

124. Yellaturu, C. R., Deng, X., Park, E. A., Raghow, R., and Elam, M. B. (2009) Insulin Enhances the Biogenesis of Nuclear Sterol Regulatory Element-Binding Protein (Srebp)1c by Posttranscriptional Down-Regulation of Insig-2a and Its Dissociation from Srebp Cleavage-Activating Protein (Scap).Srebp-1c Complex. The Journal of Biological Chemistry 284, 31726-31734

125. Yellaturu, C. R., Deng, X., Cagen, L. M., Wilcox, H. G., Mansbach, C. M., 2nd, Siddiqi, S. A., Park, E. A., Raghow, R., and Elam, M. B. (2009) Insulin Enhances PostTranslational Processing of Nascent Srebp-1c by Promoting Its Phosphorylation and Association with Copii Vesicles. The Journal of Biological Chemistry 284, 7518-7532

126. Dong, Q., Giorgianni, F., Beranova-Giorgianni, S., Deng, X., O'Meally, R. N., Bridges, D., Park, E. A., Cole, R. N., Elam, M. B., and Raghow, R. (2015) Glycogen Synthase Kinase-3-Mediated Phosphorylation of Serine 73 Targets Sterol Response Element Binding Protein-1c (Srebp-1c) for Proteasomal Degradation. Bioscience reports 36

127. Lu, M., and Shyy, J. Y. (2006) Sterol Regulatory Element-Binding Protein 1 Is Negatively Modulated by Pka Phosphorylation. American journal of physiology. Cell physiology 290, C1477-1486

128. Li, X., Li, X., Chen, H., Lei, L., Liu, J., Guan, Y., Liu, Z., Zhang, L., Yang, W., Zhao, C., Fu, S., Li, P., Liu, G., and Wang, Z. (2013) Non-Esterified Fatty Acids Activate the Amp-Activated Protein Kinase Signaling Pathway to Regulate Lipid Metabolism in Bovine Hepatocytes. Cell biochemistry and biophysics 67, 1157-1169

129. McFadden, J. W., and Corl, B. A. (2009) Activation of Amp-Activated Protein Kinase (Ampk) Inhibits Fatty Acid Synthesis in Bovine Mammary Epithelial Cells. Biochemical and biophysical research communications 390, 388-393

130. Amemiya-Kudo, M., Shimano, H., Yoshikawa, T., Yahagi, N., Hasty, A. H., Okazaki, H., Tamura, Y., Shionoiri, F., Iizuka, Y., Ohashi, K., Osuga, J., Harada, K., Gotoda, T., Sato, R., Kimura, S., Ishibashi, S., and Yamada, N. (2000) Promoter Analysis of the Mouse Sterol Regulatory Element-Binding Protein-1c Gene. The Journal of Biological Chemistry 275, 31078-31085

131. Repa, J. J., Liang, G., Ou, J., Bashmakov, Y., Lobaccaro, J. M., Shimomura, I., Shan, B., Brown, M. S., Goldstein, J. L., and Mangelsdorf, D. J. (2000) Regulation of Mouse Sterol Regulatory Element-Binding Protein-1c Gene (Srebp-1c) by Oxysterol Receptors, Lxralpha and Lxrbeta. Genes \& development 14, 2819-2830

132. Liang, G., Yang, J., Horton, J. D., Hammer, R. E., Goldstein, J. L., and Brown, M. S. (2002) Diminished Hepatic Response to Fasting/Refeeding and Liver X Receptor Agonists in Mice with Selective Deficiency of Sterol Regulatory Element-Binding Protein-1c. The Journal of Biological Chemistry 277, 9520-9528

133. Ou, J., Tu, H., Shan, B., Luk, A., DeBose-Boyd, R. A., Bashmakov, Y., Goldstein, J. L., and Brown, M. S. (2001) Unsaturated Fatty Acids Inhibit Transcription of the Sterol Regulatory Element-Binding Protein-1c (Srebp-1c) Gene by Antagonizing LigandDependent Activation of the Lxr. Proceedings of the National Academy of Sciences of the United States of America 98, 6027-6032 
134. Xu, J., Teran-Garcia, M., Park, J. H., Nakamura, M. T., and Clarke, S. D. (2001) Polyunsaturated Fatty Acids Suppress Hepatic Sterol Regulatory Element-Binding Protein-1 Expression by Accelerating Transcript Decay. The Journal of Biological Chemistry 276, 9800-9807

135. Lengi, A. J., and Corl, B. A. (2010) Short Communication: Identification of the Bovine Sterol Regulatory Element Binding Protein-1c Promoter and Its Activation by Liver X Receptor. Journal of Dairy Science 93, 5831-5836

136. Ma, L. (2012) Regulatory Factors of Milk Fat Synthesis in Dairy Cows. Dissertation, Virginia Tech

137. Cui, Y., Liu, Z., Sun, X., Hou, X., Qu, B., Zhao, F., Gao, X., Sun, Z., and Li, Q. (2015) Thyroid Hormone Responsive Protein Spot 14 Enhances Lipogenesis in Bovine Mammary Epithelial Cells. In vitro cellular \& developmental biology. Animal 51, 586594

138. Rudolph, M. C., Wellberg, E. A., Lewis, A. S., Terrell, K. L., Merz, A. L., Maluf, N. K., Serkova, N. J., and Anderson, S. M. (2014) Thyroid Hormone Responsive Protein Spot14 Enhances Catalysis of Fatty Acid Synthase in Lactating Mammary Epithelium. Journal of lipid research 55, 1052-1065

139. Chen, Y., Patel, V., Bang, S., Cohen, N., Millar, J., and Kim, S. F. (2012) Maturation and Activity of Sterol Regulatory Element Binding Protein 1 Is Inhibited by Acyl-Coa Binding Domain Containing 3. PloS one 7, e49906

140. Ponugoti, B., Kim, D. H., Xiao, Z., Smith, Z., Miao, J., Zang, M., Wu, S. Y., Chiang, C. M., Veenstra, T. D., and Kemper, J. K. (2010) Sirt1 Deacetylates and Inhibits Srebp-1c Activity in Regulation of Hepatic Lipid Metabolism. The Journal of Biological Chemistry 285, 33959-33970 


\section{Chapter 3}

\section{Analysis of chromatin immunoprecipitation of SREBP1 in bovine mammary epithelial cells}

\section{Introduction}

Animal performance can be regulated by many factors including nutrition. Nutrients supplied by diet ingredients can impact milk fat production and composition (Garnsworthy et al., 2006). Dietary polyunsaturated fatty acids (PUFA), especially t10, c12-conjugated linoleic acid (CLA) can induce milk fat depression (MFD) up to $50 \%$ (Bauman et al., 2011). Much of this influence is exerted at cellular levels. Decreasing milk fat synthesis depends on decreased activity of mammary epithelial cells. Multiple control points can influence cellular activity and one mechanism is gene transcription. Much of the regulation of lipid synthesis is mediated by transcription factor interaction with gene promoters. Sterol regulatory element binding protein 1 (SREBP1) is regarded as the key global regulator of lipid synthesis coordinating the suppression of mammary lipogenic gene expression during MFD (Baumgard et al., 2002b, Peterson et al., 2003). SREBP1 belongs to the basic helix-loop-helix leucine zipper (bHLHLZ) family of DNA binding transcription factors. Different from other bHLHLZ family members, SREBP1 precursor is synthesized and anchored in the endoplasmic reticulum membrane through two membrane spanning domains, that are cleaved to release their $\mathrm{NH}_{2}$-domain to migrate to the nucleus and bind to the sterol regulatory elements (SRE) in the promoters of SREBP1 target genes (Brown and Goldstein, 1997). A well-conserved arginine residue in the basic domain of other bHLHLZ transcription factors was 
substituted by a tyrosine in SREBPs, which allow SREBPs not only bind to the classic palindromic E-boxes (CANNTG), but also recognize non non-palindromic SREs (Kim et al., 1995). Substitution of this atypical tyrosine to arginine restricted the binding to Eboxes only (Kim et al., 1995). This duo-binding specificity enables SREBPs to regulate a broad spectrum of gene transcription.

The original SRE sequence (ATCACCCCAC) was found in the promoter of low density lipoprotein (LDL) receptor (Briggs et al., 1993). A novel motif (ACTACANNTCCC) characterized in mouse liver, is present in $76 \%$ of the total SREBP1-binding peaks (Seo et al., 2009). The SRE sequence can vary among SREBP1 target genes according to the current studies using a promoter-reporter gene system, that indicated some difficulty in assigning a consensus SRE sequence (Edwards et al., 2000).

SREBP1 activates gene transcription involved in fatty acid synthesis (Tontonoz et al., 1993). Overexpression and knockdown of SREBP1-induced change in lipogenic gene expression confirmed the role of SREBP1 in fat synthesis in bovine mammary epithelial cells (Ma and Corl, 2012, Li et al., 2014). Using a promoter luciferase reporter system in combination with site-directed mutagenesis identified more than one SRE in the proximal promoters of fatty acid synthase (FASN) (Latasa et al., 2003), acetyl-CoA carboxylase-2 (ACC2) (Oh et al., 2003) and hexokinase II (HKII) (Gosmain et al., 2004), indicating direct binding of SREBP1 to its target genes to regulate lipid homeostasis. Optimal transcriptional activation requires other transcription factors to bind to the adjacent location of the SREs (usually 15 base pairs around SREs). At least three cofactor binding sites are found in SREBP1-target gene promoters: nuclear factor-Y (NF-Y) (Magana et al., 2000), specificity protein 1 (Sp1) (Edwards et al., 2000) and cAMP-response element 
binding protein (CREB) (Dooley et al., 1999). A thorough study of SREBP1 binding site profile in bovine mammary gland has not been reported yet. The functions and interactions between SRE and its cofactors in bovine has not been studied. In dairy cows, fatty acids are synthesized exclusively in adipose tissue and the mammary gland (Palmquist, 2006a). Dairy cows utilize acetate and hydroxyl-butyrate as precursors for de novo fatty acid synthesis and the mammary gland is insensitive to insulin regulation, suggesting a central role of SREBP1 in fatty acid metabolism and possibly a different regulatory response from non-ruminants.

From this study, I confirmed the direct binding of mammary SREBP1 to the promoter regions of its target genes using chromatin immunoprecipitation (ChIP). Second, a preliminary characterization of genes regulated by SREBP1 in bovine mammary tissue was completed using developed ChIP methods coupled with deep sequencing (ChIP-Seq).

\section{Methods and materials}

\section{Reagents}

Fetal bovine serum was from Atlanta Biologicals. Cell culture media and other cell culture reagents were purchased from Sigma (St. Louis, MO). Taq PCR Master mix kit was purchased from Qiagen (Valencia, CA). GoTaq QPCR master mix was purchased from Promega (Madison, WI). ChIP-IT express magnetic chromatin immunoprecipitation kit and sonication shearing kit were purchased from Active Motif (Carlsbad, CA).

\section{Preparation of samples for CHIP assay}

The first set of samples were prepared from cultured bovine mammary epithelial cells to validate the customized SREBP1 ChIP-grade antibody (GenScript, Piscataway, 
NJ). Bovine mammary epithelial cells (MacT) were seeded in 150-mm culture dishes and grown to $80 \%$ confluence. Cells were harvested and prepared according to the ChIP assay kit instructions. Chromatin was cross-linked by treating with $37 \%$ formaldehyde and incubated on a shaking platform for 5 minutes at room temperature. Then the fixation reaction was stopped by adding $1.25 \mathrm{M}$ glycine with continuous rocking for 5 minutes. Cells were lysed in $1 \mathrm{~mL}$ lysis buffer supplemented with protease inhibitors and PMSF and incubated on ice for $30 \mathrm{~min}$. The cell lysates were transferred to an ice-cold dounce homogenizer and dounced on ice with 30 strokes to aid in nuclei release. The nuclei were sheared on ice with 20 pulses of $20 \mathrm{sec}$ sonication using a sonic dismembrator model 100 at setting 1 (Fisher Scientific, Waltham, MA). The chromatin was sheared to fragment length of 150-300 bp. Each sample was normalized to $25 \mu \mathrm{g}$ chromatin by Bradford assay for immunoprecipitation. The chromatin was incubated with $2 \mu \mathrm{g}$ of SREBP1 antibody or normal rabbit IgG at $4{ }^{\circ} \mathrm{C}$ for $3 \mathrm{~h}$. Then the antibody bound chromatin was precipitated with $25 \mu \mathrm{L}$ Protein G Magnetic bead slurry overnight at $4{ }^{\circ} \mathrm{C}$. The beads were washed and the chromatin was eluted using the buffer from ChIP kit. The eluted chromatin was reverse cross-linked in $5 \mathrm{M} \mathrm{NaCl}$ overnight at $65^{\circ} \mathrm{C}$. The samples were treated with Proteinase $\mathrm{K}$ for $1 \mathrm{~h}$ at room temperature. The supernatant was collected as chromatin DNA.

A second set of samples were prepared from bovine mammary tissue. The tissue samples were collected through mammary biopsy of three healthy, mid-lactating dairy cows at the Virginia Tech dairy complex and snap-frozen for further analysis. Mammary tissue ( 200 mg) was homogenized and fixed in $37 \%$ formaldehyde for $10 \mathrm{~min}$. Then samples were processed followed the ChIP processing procedures described for cultured 
cells. $50 \mu \mathrm{L}$ aliquots of each sheared chromatin sample were used to assess shearing efficiency for desired chromatin length and determine DNA concentration. The proteins were digested with a Proteinase $\mathrm{K}$ incubation for $1 \mathrm{~h}$ at $42{ }^{\circ} \mathrm{C}$. The chromatin DNA was purified with 1:1 phenol/chloroform tris-EDTA saturated buffer saturated at $\mathrm{pH} 8$, and followed by ethanol precipitation supplementing with $1 \mu \mathrm{L}$ linear acrylamide $(5 \mathrm{mg} / \mathrm{mL}$, Ambion, Austin, TX) to facilitate the enrichment of DNA. The pellets were dissolved in $25 \mu \mathrm{L}$ water.

\section{PCR and real-time PCR analysis of SREBP1-target gene promoter}

End-point PCR was performed on DNA collected by ChIP. Four sets of DNA templates were tested: Input DNA from sheared chromatin (1 to 10 dilution); positive and negative control using RNA pol II and IgG antibody supplied by Active Motif; tested DNA from SREBP1-ChIP sample. The primers for SRE in SREBP1-proximal promoter (-28/-153) were: 5'-CCCATTTCCCAAGAGCGAAC-3' for sense and 5'AAGTCAGAAGAGCGGTCG-3' for antisense. The primers used for SRE in FASNproximal promoter (-418/-630) were: 5'-GCCCATCACCCTATCACCTA-3' for sense and 5'-GGCGTACTTGGGTCACTCT-3' for antisense. The primers for SRE in SCDproximal promoter (-209/-406) were: 5'-GCATCCAGTTCTTGCTTCTT-3' for sense and 5'-CTGCTGTGCTGGGGATTT-3' for antisense. PCR conditions were: one cycle of $95{ }^{\circ} \mathrm{C}$ for $2 \mathrm{~min} ; 32$ cycles of $95{ }^{\circ} \mathrm{C}$ for $30 \mathrm{~s}, 55^{\circ} \mathrm{C}$ for $1 \mathrm{~min}$ and $72{ }^{\circ} \mathrm{C}$ for $45 \mathrm{~s}$; and one cycle of $72{ }^{\circ} \mathrm{C}$ for $1 \mathrm{~min}$. PCR products were separated in $2 \%$ agarose gel for electrophoresis and analyzed by SYBR safe staining.

Real-time PCR was performed using the Quantitect SYBR Green PCR kit (Qiagen) in an Applied Biosystems 7300 Real-time PCR machine (Foster City, CA). Two 
sets of samples were used: ChIP and IgG sample. Reactions were as follows: 1 cycle at $95^{\circ} \mathrm{C}$ for $10 \mathrm{~min}$, followed by 40 cycles at $95^{\circ} \mathrm{C}$ for $30 \mathrm{secs}, 58^{\circ} \mathrm{C}$ for $30 \mathrm{secs}$, and $72{ }^{\circ} \mathrm{C}$ for $1 \mathrm{~min}$. Each reaction was performed in duplicate wells. The efficiency of the primers was tested by producing a standard curve with 10-fold dilution of known input DNA quantities. Amplification efficiency between 90 to $110 \%$ was considered acceptable. $\mathrm{Ct}$ value vs DNA quantity (log scale) of the dilution was plotted to produce the standard curve. The fold-enrichment of SREBP1-targeted gene promoter was obtained using the slope of the standard curve and followed a two-step calculation: first solving for the DNA quantity of the ChIP and IgG samples following the equation: $\mathrm{Y}=\mathrm{M}(\log \mathrm{X})+\mathrm{B}$. Y was the $\mathrm{Ct}$ value, $\mathrm{X}$ was DNA quantity, $\mathrm{M}$ is the slope of the standard curve. $\mathrm{B}$ is the $\mathrm{Ct}$ value when $\mathrm{X}$ equal to 1 . Then, calculating the fold enrichment of the ChIP sample relative to the IgG sample.

\section{ChIP sequencing library construction and data processing}

Three SREBP1-ChIP and input DNA samples from three animals were purified, ligated to sequencing adaptors and PCR amplified in preparation for deep sequencing at the Virginia Bioinformatics Institutes (VBI). The library preparation protocol from Illumina was used to prepare samples for analysis with the Illumina Genome Analyzer. Three ChIP samples multiplexed in one lane and 3 Input samples in the second. HiSeq output was set for $1 \times 100$ single read cycle clustering and sequencing per lane. An estimated 10 million uniquely mapped tags were sufficient to identify all binding sites for SREBP1. The data generated was analyzed with assistance from the Data Analysis Core at VBI. Reads from three independent ChIP samples, with the peaks identified in each replicate having at least a $60 \%$ overlap were considered ideal. After the sequencing, the 
short tags $(<50 \mathrm{bp}$ ) were mapped to the bovine genome (Ensemble cow genome assemble UMD3.1). The tags that were unique to only one location in the genome were selected. And then all the unique tags were extended to the average sizes of the library fragments ( 150-300 bp) and binned into consecutive bins running the length of each chromosome. The binned data can be visualized using the UCSC browser (http://www.genome.ucsc.edu) (O'Geen et al., 2010). Peaks identification was performed by counting the number of overlapped reads at each nucleotide position and defining the genomic position with the highest number as the peak position within a $1 \mathrm{~kb}$ significant region (Sun et al., 2011). The peaks identified through regular peak calling procedure using Model-based Analysis of ChIP-Seq (MACS version 2.0). The following code was applied: macs2 callpeak -t ChIP.bam -c Control.bam --broad -g hs --broad-cutoff 0.1. The effective genome size $=2.70 \mathrm{e}+09$ in the algorithm. The band width which is used to scan the genome ONLY for model building was set to be 300. The regions within MFOLD range of high-confidence enrichment ratio against background to build model was set to be default $[5,50]$. the first 10 sequences from the input treatment file was used to determine the tag size.

Three sets of peaks designated to each sample were generated. Top 10 peaks based on q-value and fold-change were investigated and the nearest gene was identified. A preliminary examination of potential lipogenic genes regulated by SREBP1 was also assembled with the references in Ensemble cow genome database. To identify SREBP1 bound promoters of lipogenic genes, more than 51 genes related to lipid synthesis and their predicted nearest SRE binding site was investigated and 17 of them were confirmed present in the SREBP1-ChIP. Peaks in the promoter region $\pm 50 \mathrm{~kb}$ of the gene start point 
were taken into consideration as potential SRE binding sites. The start and the end of the peaks, the located chromosome number, the fold-change, the $-\log _{10} \mathrm{p}$-value, the $-\log _{10} \mathrm{q}-$ value and the distance to the nearest gene were reported. The fold-change was calculated by taking the average of the number of ChIP (or input) tags divided by the number of the tags in the sample background set at each position in the region (Tuteja et al., 2009). The statistical significance of the positive binding sites was measured by false discovery rate (FDR) which was the expected proportion of false positive binding sites among those that were found to be significant (Park, 2009). Q-value is a criterion of significance based on minimal FDR where peaks can be ranked based on q-value (Bailey et al., 2013).

\section{Results}

\section{ChIP-PCR validation}

The effectiveness of the customized SREBP1 antibody for ChIP use on MacT cells were validated. The PCR results in Figure 3.2 A-B showed the presence of SRE of three SREBP1-target genes in input sample, in RNApol II sample as well as SREBP1ChIP sample by using specific promoter primers, respectively. PCR results showed strong affinity of RNApol II to three SREs while SREBP1appeared less affinity but clear binding to the SREs. No apparent binding was detected in negative control IgG samples.

After the bovine SREBP1 antibody was validated, the condition of the ChIP protocol was optimized for bovine mammary tissues. The time of formaldehyde fixing was compared in order to achieve proper crosslink between proteins and DNA. Lowest sheared chromatin DNA yield was detected when incubating for 5 min as for cell culture samples. Fixing for 7.5 min the concentration of chromatin DNA started to increase and 
reach peak $(828 \mathrm{ng} / \mu \mathrm{L})$ at $10 \mathrm{~min}$ then dropped when incubated for $15 \mathrm{~min}$. The shearing efficiency was also determined by using three shearing times to maximize the change and generate chromatin fragment length of 100-200 bp. Figure 3.1 shows the gel electrophoresis of shearing for 200s, 300s and 400s with 400s shearing optimal and selected for the following experiments. Figure 3.2 C-E shows the PCR results of mammary tissue samples. Specific SREs for three SREBP1-target genes were detected in ChIP samples (SREBP1 and RNApol II) and input sample, but not in the negative control (IgG). These two experiments confirmed the presence of SRE in three lipogenic genes SREBP1, FASN and SCD.

\section{ChIP-QPCR enrichment test}

The enrichment of SRE in three lipogenic genes of ChIP was determined by QPCR. First, the primer amplification efficiency (AE) was calculated through 10-time dilution of input sample. The AE for SREBP1, FASN and SCD were 105.86, 107.14, and 97.31\%, respectively. The fold-enrichment of ChIP relative to IgG sample were 5.97, 7.77 and 3.49 for SREBP1, FASN and SCD, respectively (Figure 3.3). Though SCD failed to reach the minimal 5-fold enrichment in ChIP sample, the minimal 5-fold enrichment for SREBP1 in ChIP sample was achieved when the experiment was repeated (data not shown). Therefore, three ChIP and their respective input samples were prepared using the working procedure and proceeded for deep sequencing.

\section{ChIP-Seq data analysis}

Three pairs of ChIP and input samples from three cows were prepared for deep sequencing. Total mapped reads and peaks called are summarized in Table 3.1. The total mapped reads varied among ChIP samples from 34 million to 125 million reads, but were 
fairly consistent for the input samples. However, the total peaks called were consistent in ChIP samples but varied in input samples. The average peaks called for ChIP was about 9,500 , but for input sample, input 2 recorded only 11,788 peaks compared with the other two input recording above 27,000 peaks. There were 604, 56 and 1380 peaks identified in samples 1, 2 and 3, respectively (See Appendix 1). The q-value of the peaks ranged from 1.33 to 87.44 . None of the q-value exceed 100 . The fold-change varied from 1.47 to 23.55. Two out of three samples detected peaks with 5-fold enrichment over $50 \%$. Samples 2 only recorded less than $30 \%$ peaks with 5-fold enrichment which might be due to the smaller peak size.

A summary of 17 lipogenic genes and their nearest potential SRE binding site are shown in Table 3.2. The distance from the start of the gene ranging $\pm 50 \mathrm{k}$ bp was considered potential SRE binding sites. For example, SREBP1 recorded 1 binding site ($88 \mathrm{bp}$ ). There were no peaks near lipogenic gene GPAT. Peaks in 11 of 17 genes located beyond the 5 '-end transcription start site whereas the remaining 6 were located after the transcription starting site of the gene. The q-value of the peaks near those selected lipogenic genes varied from 1.66 to 43.79 . The highest q-value peak was near DGAT2 (43.79) and the lowest q-value peak was near ACCa (1.66). The highest fold-enrichment peak detected was near DGAT2 (18.51). There were 12 of 17 peaks detected foldenrichment over 5-fold threshold. The peaks near SREBP1, FASN and SCD1 recorded over 5-fold enrichment. 


\section{Discussion}

Chromatin immunoprecipitation is a powerful approach to investigate the interaction between transcription factors and DNA. Using specific antibody to detect transcription factor binding to the specific sites in the promoter of genes allows investigators to identify target genes regulated by the transcription factors. Mature SREBP1 regulated lipogenic enzyme gene transcription through SRE binding sites in the promoter of those lipogenic genes (Brown and Goldstein, 1997). The first ChIP experiment on MacT cells was to validate the SREBP1 antibody for ChIP as well as confirm the presence of SRE in three known SREBP1-target genes SREBP1 (Dif et al., 2006) , FASN (Latasa et al., 2003) and SCD1 (Estany et al., 2014). RNApol II was used as positive control because the active transcription binding sites should be positive to RNApol II binding while a nonspecific antibody was used as a negative control (O'Geen et al., 2010). PCR is a simple way to detect whether there was positive SRE-binding (Wagschal et al., 2007). With proper controls (positive and negative control and input) the antibody was confirmed effectively detected SREBP1-bound SRE on SREBP1, FASN and SCD promoter.

Next, the ChIP protocol was optimized for lactating bovine mammary. The fixing time for in vivo samples were slightly different from culture cell samples (Gavrilov et al., 2014). Chromatin was sheared to shorter fragment (150-300 bp) compared to the ones from cell samples in order to meet the requirement of sequencing. ChIP-PCR and ChIPQPCR are effective approaches to investigate protein-DNA interaction in bovine (Ao et al., 2015) and other species and tissues (Seo et al., 2009, Rijnkels et al., 2013), but studies on SREBP1 binding in bovine mammary tissue have not been reported yet. A minimal 
fold-enrichment of specific binding in ChIP samples relative to IgG sample needed to be met while the actual fold increase in ChIP samples varies among different target proteins. For example, enrichment of RNApol II binding can easily exceed over 100-fold increase (Sun et al., 2011). For low abundance or low affinity target protein, such as transcription factors, a minimum 5-fold increase in signal of ChIP sample over IgG samples is suggested (Haring et al., 2007). For the current experiment, two of three investigated genes had at least 5-fold enrichment but SCD did not. To be noted, the Ct value of the control $\operatorname{IgG}$ in three tested genes were over 30, indicating low nonspecific binding compared to ChIP samples. This was also consistent with the PCR result, of which no apparent band was detected in $\mathrm{IgG}$ group.

Deep sequencing following chromatin immunoprecipitation with SREBP1 antibody enabled us to characterized the global isoform specific expression of genes related to fatty acid synthesis in mammary gland. Currently, our promoter knowledge partially relies on in vitro promoter construct panels, which are limited to one or a few genes at a time (Lengi and Corl, 2010). To provide a catalog of active promoters in lactating bovine mammary tissue and identify SREBP1-bound SREs in selected lipogenic genes, a combination of ChIP-seq and bioinformatics approach was used. In this study, total mapped reads varied from 34 million to 126 million but relatively consistent total peaks called at about 9,500 peaks in ChIP samples which was far less than results from study on RNApol II in mouse liver tissues (Sun et al., 2011). For input samples, a fairly consistent number of mapped reads were obtained and relatively stable peaks were called in input 1 and 3 but surprisingly less in input 2 . No treatment was imposed in the sequencing nor control tissues used as comparison. It is difficult to determine whether the 
counts reflected the normal reads in bovine mammary tissue or abnormal reads due to sequencing errors. Peak calling was performed using MACS 2.0 by comparing ChIP sample to input sample. The peaks generated were considered the DNA fragments that were enrichment through SREBP1-ChIP. However, the size of peaks varied among samples and q-value and fold-change were relatively low.

The peaks generated through MACS were ranked based on q-value and foldchange. The top 10 peaks for each sample were selected for further characterization of their closest genes. The genes investigated displayed several interesting features. No major overlapping was detected among three samples, indicating very little consistency among the samples. Second, a considerable number of peaks were located in regions where there were no surrounding genes, indicating the potential for non-specific binding due to the low quality of sample preparation. Third, the majority of genes close to the top peaks were not directly related to lipid metabolism. These factors call into question the success of ChIP-seq assay and the accuracy of the identity of the identified genes.

Due to the low q-value and fold enrichment of the ChIP samples and variation among samples, the profile of binding sites was investigated only for selected lipogenic genes based on genes previously reported in mouse liver SREBP1-ChIP-seq data (Seo et al., 2009). Predicted SREs in the promoters of genes encoding enzymes essential for fatty acid (FA) synthesis (ACC $\alpha$, FASN), preformed FA uptake (LPL), long-chain (ACSL1) and short chain (ACSS2) intracellular FA activation, intracellular FA trafficking (FABP3), triglyceride synthesis (APGAT1, Lipin1) and transcription regulation (Insig1, SCAP and PPARG) among 12 other genes and isomers were observed. There was only one peak detected near the lipogenic genes within $50 \mathrm{~kb}$ of the transcription start sites. 
This result is inconsistent with previous reports in HEK293 cells (Dif et al., 2006) and MacT cells (Lengi and Corl, 2010). A peak that is 1085 bp upstream of FASN promoter found in sample3, is more distant than the $-150 \mathrm{bp}$ binding site found in mice FASN promoter (Latasa et al., 2003). Only 1 binding site found in the promoter of PPARG, SCAP and LPL were consistent with previous reports (Tontonoz et al., 1993, Friedman, 2006, Seo et al., 2009). Furthermore, there was 1 binding site found in Insig1, indicating potential direct regulation of Insig1 by SREBP1. Over 50\% of peaks were located within $\pm 1,000 \mathrm{bp}$ of the transcription start site of the investigated genes, $88 \%$ of which were located within $\pm 10 \mathrm{k}$ bp. It is difficult to make a clear cutoff for positive peak detection due to the low q-value for expected peaks.

In summary, the current study validated a bovine SREBP1 antibody suitable for ChIP experiments and confirmed the presence of SRE in three known SREBP1 target genes SREBP1, FASN and SCD via PCR and QPCR analysis. Furthermore, a ChIP-seq investigation was performed on three independent bovine mammary tissue samples and investigated global binding SREBP1 in the genome. Due to the likely low affinity of SREBP1 antibody and inconsistency for sequencing, only SRE binding sites in 17 selected lipogenic genes were investigated. Further study should utilize more controls such as multiple tissue biopsy and control IgG to determine the effectiveness of procedures. For detection of SREBP1-binding, proper treatments (such as normal milk fat yield vs. milk fat depression) could be the better approach to detect the relative enrichment of potential target genes due to the low affinity and low abundance of transcription factors compared to other global regulators, such as RNApol II. 


\section{References}

1. Garnsworthy, P. C., Masson, L. L., Lock, A. L., and Mottram, T. T. (2006) Variation of Milk Citrate with Stage of Lactation and De Novo Fatty Acid Synthesis in Dairy Cows. Journal of Dairy Science 89, 1604-1612

2. Bauman, D. E., Harvatine, K. J., and Lock, A. L. (2011) Nutrigenomics, Rumen-Derived Bioactive Fatty Acids, and the Regulation of Milk Fat Synthesis. Annual review of nutrition 31, 299-319

3. Peterson, D. G., Matitashvili, E. A., and Bauman, D. E. (2003) Diet-Induced Milk Fat Depression in Dairy Cows Results in Increased Trans-10, Cis-12 Cla in Milk Fat and Coordinate Suppression of Mrna Abundance for Mammary Enzymes Involved in Milk Fat Synthesis. The Journal of Nutrition 133, 3098-3102

4. Baumgard, L. H., Matitashvili, E., Corl, B. A., Dwyer, D. A., and Bauman, D. E. (2002) Trans-10, Cis-12 Conjugated Linoleic Acid Decreases Lipogenic Rates and Expression of Genes Involved in Milk Lipid Synthesis in Dairy Cows. Journal of Dairy Science 85, 2155-2163

5. Brown, M. S., and Goldstein, J. L. (1997) The Srebp Pathway: Regulation of Cholesterol Metabolism by Proteolysis of a Membrane-Bound Transcription Factor. Cell 89, 331-340

6. Kim, J. B., Spotts, G. D., Halvorsen, Y. D., Shih, H. M., Ellenberger, T., Towle, H. C., and Spiegelman, B. M. (1995) Dual DNA Binding Specificity of Add1/Srebp1 Controlled by a Single Amino Acid in the Basic Helix-Loop-Helix Domain. Molecular and cellular biology 15, 2582-2588

7. $\quad$ Briggs, M. R., Yokoyama, C., Wang, X., Brown, M. S., and Goldstein, J. L. (1993) Nuclear Protein That Binds Sterol Regulatory Element of Low Density Lipoprotein Receptor Promoter. I. Identification of the Protein and Delineation of Its Target Nucleotide Sequence. The Journal of Biological Chemistry 268, 14490-14496

8. Seo, Y. K., Chong, H. K., Infante, A. M., Im, S. S., Xie, X., and Osborne, T. F. (2009) Genome-Wide Analysis of Srebp-1 Binding in Mouse Liver Chromatin Reveals a Preference for Promoter Proximal Binding to a New Motif. Proceedings of the National Academy of Sciences of the United States of America 106, 13765-13769

9. Edwards, P. A., Tabor, D., Kast, H. R., and Venkateswaran, A. (2000) Regulation of Gene Expression by Srebp and Scap. Biochimica et biophysica acta 1529, 103-113

10. Tontonoz, P., Kim, J. B., Graves, R. A., and Spiegelman, B. M. (1993) Add1: A Novel Helix-Loop-Helix Transcription Factor Associated with Adipocyte Determination and Differentiation. Molecular and cellular biology 13, 4753-4759

11. Li, N., Zhao, F., Wei, C., Liang, M., Zhang, N., Wang, C., Li, Q. Z., and Gao, X. J. (2014) Function of Srebp1 in the Milk Fat Synthesis of Dairy Cow Mammary Epithelial Cells. International journal of molecular sciences 15, 16998-17013

12. Ma, L., and Corl, B. A. (2012) Transcriptional Regulation of Lipid Synthesis in Bovine Mammary Epithelial Cells by Sterol Regulatory Element Binding Protein-1. Journal of Dairy Science 95, 3743-3755

13. Latasa, M. J., Griffin, M. J., Moon, Y. S., Kang, C., and Sul, H. S. (2003) Occupancy and Function of the -150 Sterol Regulatory Element and -65 E-Box in Nutritional Regulation of the Fatty Acid Synthase Gene in Living Animals. Molecular and cellular biology 23, 5896-5907

14. Oh, S. Y., Park, S. K., Kim, J. W., Ahn, Y. H., Park, S. W., and Kim, K. S. (2003) Acetyl-Coa Carboxylase Beta Gene Is Regulated by Sterol Regulatory Element-Binding Protein-1 in Liver. The Journal of Biological Chemistry 278, 28410-28417 
15. Gosmain, Y., Lefai, E., Ryser, S., Roques, M., and Vidal, H. (2004) Sterol Regulatory Element-Binding Protein-1 Mediates the Effect of Insulin on Hexokinase Ii Gene Expression in Human Muscle Cells. Diabetes 53, 321-329

16. Magana, M. M., Koo, S. H., Towle, H. C., and Osborne, T. F. (2000) Different Sterol Regulatory Element-Binding Protein-1 Isoforms Utilize Distinct Co-Regulatory Factors to Activate the Promoter for Fatty Acid Synthase. The Journal of Biological Chemistry 275, 4726-4733

17. Dooley, K. A., Bennett, M. K., and Osborne, T. F. (1999) A Critical Role for Camp Response Element-Binding Protein (Creb) as a Co-Activator in Sterol-Regulated Transcription of 3-Hydroxy-3-Methylglutaryl Coenzyme a Synthase Promoter. The Journal of Biological Chemistry 274, 5285-5291

18. Palmquist, D. (2006) Milk Fat: Origin of Fatty Acids and Influence of Nutritional Factors Thereon. in Advanced Dairy Chemistry Volume 2 Lipids, Springer. pp 43-92

19. O'Geen, H., Frietze, S., and Farnham, P. (2010) Using Chip-Seq Technology to Identify Targets of Zinc Finger Transcription Factors. Engineered Zinc Finger Proteins: ...

20. Sun, H., Wu, J., Wickramasinghe, P., Pal, S., Gupta, R., Bhattacharyya, A., AgostoPerez, F. J., Showe, L. C., Huang, T. H., and Davuluri, R. V. (2011) Genome-Wide Mapping of Rna Pol-Ii Promoter Usage in Mouse Tissues by Chip-Seq. Nucleic acids research 39, 190-201

21. Tuteja, G., White, P., Schug, J., and Kaestner, K. H. (2009) Extracting Transcription Factor Targets from Chip-Seq Data. Nucleic acids research 37, e113

22. Park, P. J. (2009) Chip-Seq: Advantages and Challenges of a Maturing Technology. Nat Rev Genet 10, 669-680

23. Dif, N., Euthine, V., Gonnet, E., Laville, M., Vidal, H., and Lefai, E. (2006) Insulin Activates Human Sterol-Regulatory-Element-Binding Protein-1c (Srebp-1c) Promoter through Sre Motifs. The Biochemical journal 400, 179-188

24. Estany, J., Ros-Freixedes, R., Tor, M., and Pena, R. N. (2014) A Functional Variant in the Stearoyl-Coa Desaturase Gene Promoter Enhances Fatty Acid Desaturation in Pork. PloS one 9, e86177

25. Ao, J., Wei, C., Si, Y., Luo, C., Lv, W., Lin, Y., Cui, Y., and Gao, X. (2015) Tudor-Sn Regulates Milk Synthesis and Proliferation of Bovine Mammary Epithelial Cells. International journal of molecular sciences 16, 29936-29947

26. Rijnkels, M., Freeman-Zadrowski, C., Hernandez, J., Potluri, V., Wang, L., Li, W., and Lemay, D. G. (2013) Epigenetic Modifications Unlock the Milk Protein Gene Loci During Mouse Mammary Gland Development and Differentiation. PloS one 8, e53270

27. Haring, M., Offermann, S., Danker, T., Horst, I., Peterhansel, C., and Stam, M. (2007) Chromatin Immunoprecipitation: Optimization, Quantitative Analysis and Data Normalization. Plant methods 3, 11

28. Lengi, A. J., and Corl, B. A. (2010) Short Communication: Identification of the Bovine Sterol Regulatory Element Binding Protein-1c Promoter and Its Activation by Liver X Receptor. Journal of Dairy Science 93, 5831-5836

29. Schäfer-Somi, S. (2003) Cytokines During Early Pregnancy of Mammals: A Review. Animal reproduction science

30. Welsh, M., Mares, J., Karlsson, T., Lavergne, C., Bréant, B., and ... (1994) Shb Is a Ubiquitously Expressed Src Homology 2 Protein. Oncogene

31. König, J., Hartel, M., Nies, A., and ... (2005) Expression and Localization of Human Multidrug Resistance Protein (Abcc) Family Members in Pancreatic Carcinoma, Wiley Online Library

32. Zhang, Y., Zhou, L., and Miller, C. (1998) A Splicing Variant of a Death Domain Protein That Is Regulated by a Mitogen-Activated Kinase Is a Substrate for C-Jun N-Terminal Kinase in the Human Central Nervous .... Proceedings of the National ... 
33. SAUIC, M., CLAYTON, T., FURTMFILLER, R., and ... (2008) Pwz-029, a Compound with Moderate Inverse Agonist Functional Selectivity at Gabaa Receptors Containing A5 Subunits, Improves Passive, but Not Active, Avoidance .... Brain research

34. Minegishi, Y., Coustan-Smith, E., Wang, Y., and ... (1998) Mutations in the Human $\Lambda 5 / 14.1$ Gene Result in B Cell Deficiency and Agammaglobulinemia. The Journal of ...

35. Brockington, M., Blake, D., Prandini, P., Brown, S., and ... (2001) Mutations in the Fukutin-Related Protein Gene (Fkrp) Cause a Form of Congenital Muscular Dystrophy with Secondary Laminin A2 Deficiency and Abnormal ..., Elsevier

36. Lee, S. K., Kim, S. B., Kim, J. S., Moon, C. H., Han, M. S., Lee, B. J., Chung, D. K., Min, Y. J., Park, J. H., Choi, D. H., Cho, H. R., Park, S. K., and Park, J. W. (2005) Butyrate Response Factor 1 Enhances Cisplatin Sensitivity in Human Head and Neck Squamous Cell Carcinoma Cell Lines. International journal of cancer. Journal international du cancer 117, 32-40

37. Niemann, A., Ruegg, M., Padula, V. L., and ... (2005) Ganglioside-Induced Differentiation Associated Protein 1 Is a Regulator of the Mitochondrial Network New Implications for Charcot-Marie-Tooth Disease. The Journal of cell ...

38. Sanchez-Sanchez, R., Morales-Lazaro, S. L., Baizabal, J. M., Sunkara, M., Morris, A. J., and Escalante-Alcalde, D. (2012) Lack of Lipid Phosphate Phosphatase-3 in Embryonic Stem Cells Compromises Neuronal Differentiation and Neurite Outgrowth. Dev Dyn 241, 953-964

39. Munford, R., and Hunter, J. (1992) Acyloxyacyl Hydrolase, a Leukocyte Enzyme That Deacylates Bacterial Lipopolysaccharides, Has Phospholipase, Lysophospholipase, Diacylglycerollipase, and .... Journal of Biological Chemistry

40. Peterfy, M. (2012) Lipase Maturation Factor 1: A Lipase Chaperone Involved in Lipid Metabolism. Biochimica et biophysica acta 1821, 790-794

41. Friedman, J. (2006) New Transcription Factors and Their Role in Diabetes and Therapy, 


\section{Figures}

\section{Figure 3.1 Gel Analysis of sonication shearing}

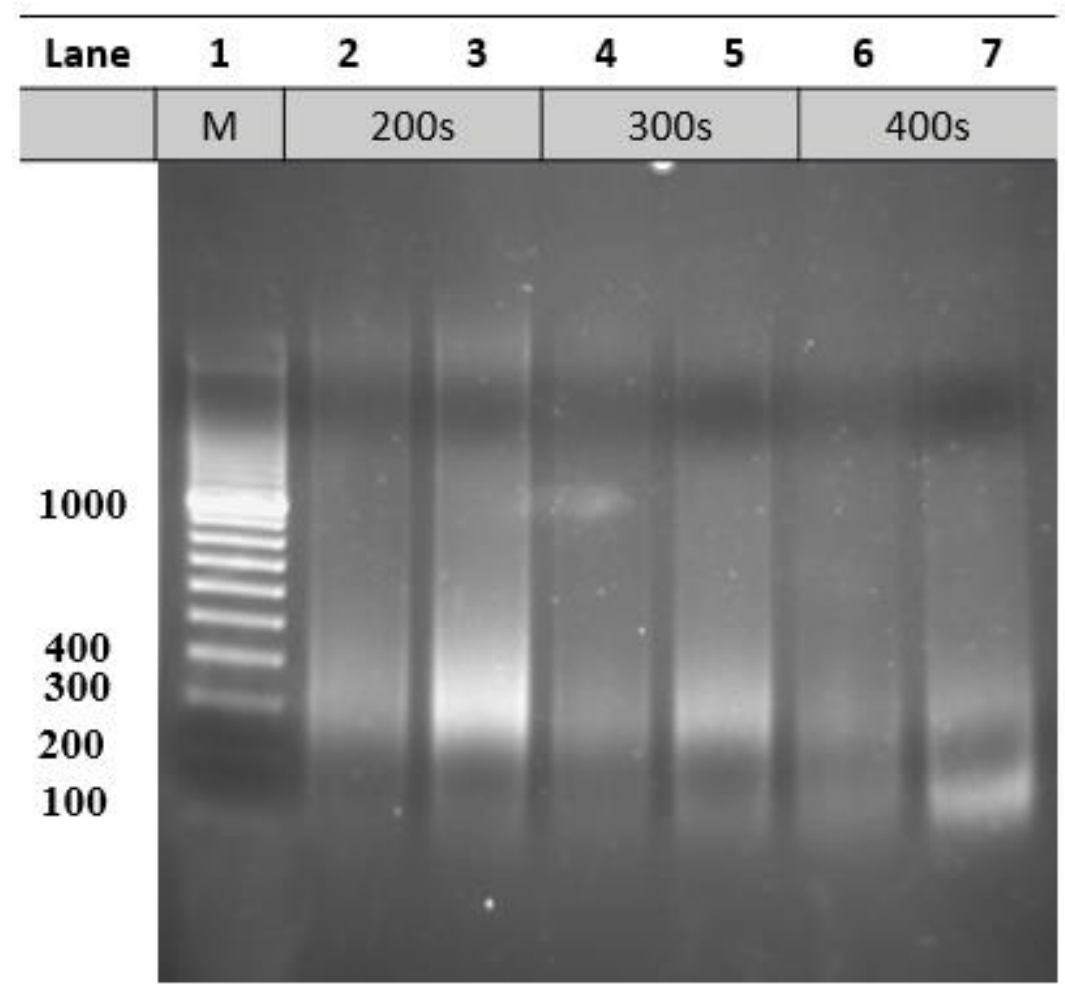

Bovine mammary tissues ( $200 \mathrm{mg}$ ) were fixed for 10 minutes in $37 \%$ formaldehyde. Then samples were homogenized and lysed on ice for 30 minutes. The homogenates were dounced in a glass Dounce homogenizer (small clearance) on ice for another 30 strokes. The homogenate was centrifuged as described above, and the pelleted nuclei were suspended in shearing buffer. Three samples were sheared with 10,15 or 20 pulses. The sheared chromatin samples were reversecrosslinked, treated with Proteinase $\mathrm{K}$ and RNase A, then phenol/chloroform extracted and precipitated in $100 \%$ ethanol. The pellets were dissolved in water and separated on a $1 \%$ agarose gel by electrophoresis. Lane 1: 100 to 5000 bp ladder; Lane 2-3: MG sheared for 200s and loaded with different amount (2 and $10 \mu \mathrm{L}$ ); Lane 4-5: MG sheared for 300s and loaded with different amount (2 and $10 \mu \mathrm{L}$ ); Lane 6-7: MG sheared for 400s and loaded with different amount (2and $10 \mu \mathrm{L})$. 
Figure 3.2 PCR validation of known targets of ChIP samples

A

\begin{tabular}{ccccccc}
\hline Lane & $\mathbf{1}$ & $\mathbf{2}$ & $\mathbf{3}$ & $\mathbf{4}$ & $\mathbf{5}$ \\
\hline Sample & $\mathrm{M}$ & IgG & $\begin{array}{c}\text { RNA } \\
\text { pol II }\end{array}$ & $\begin{array}{c}\text { SREB } \\
\text { P1 }\end{array}$ & Input \\
\hline & $*$ & & & & \\
\hline
\end{tabular}

B

FAS: 212 bp

\begin{tabular}{cccccccccccc}
\cline { 2 - 8 } & Lane & $\mathbf{1}$ & $\mathbf{2}$ & $\mathbf{3}$ & $\mathbf{4}$ & $\mathbf{5}$ & $\mathbf{6}$ & $\mathbf{7}$ & $\mathbf{8}$ & $\mathbf{9}$ \\
\hline Sample & M & IgG & $\begin{array}{l}\text { RNA } \\
\text { pol II }\end{array}$ & $\begin{array}{l}\text { SRE } \\
\text { BP1 }\end{array}$ & Input & IgG & $\begin{array}{l}\text { RNA } \\
\text { pol II }\end{array}$ & SRE & BP1 & Input \\
& & & & & & & & & & & \\
SRE: $126 \mathrm{bp} \longrightarrow$ SCD:197 bp
\end{tabular}

$\mathrm{C}$

\begin{tabular}{cccccc}
\hline Lane & $\mathbf{1}$ & $\mathbf{2}$ & $\mathbf{3}$ & $\mathbf{4}$ & $\mathbf{5}$ \\
\hline Sample & M & IgG & $\begin{array}{c}\text { RNA } \\
\text { pol II }\end{array}$ & $\begin{array}{c}\text { SREB } \\
\text { P1 }\end{array}$ & Input \\
\hline & $*$ & & & & \\
\hline
\end{tabular}

D

\begin{tabular}{|c|c|c|c|c|c|}
\hline Lane & 1 & 2 & 3 & 4 & 5 \\
\hline Sample & M & IgG & $\begin{array}{l}\text { RNA } \\
\text { pol II }\end{array}$ & $\begin{array}{c}\text { SREB } \\
\text { P1 }\end{array}$ & Input \\
\hline
\end{tabular}




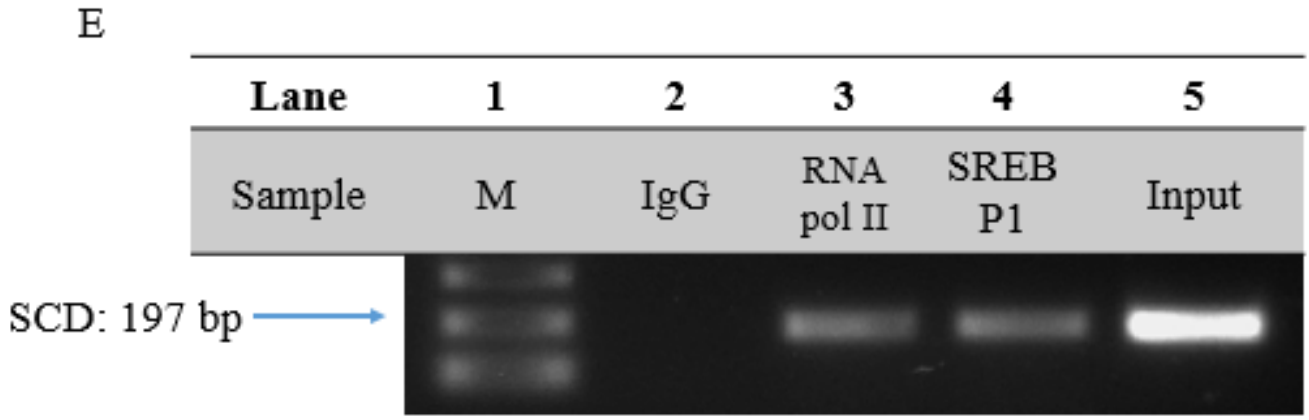

Chromatin DNA cross-linked with SREBP1 from MacT cells and bovine mammary tissues was precipitated with anti-SREBP1 or non-specific (IgG) antibodies as described in materials and methods. The PCR products were generated by amplification of sterol responsive elements (SRE) in the promoters of known target of SREBP1. Amplicons were resolved in 2\% agarose gels. The figures are representatives of three independent experiments. A-C: MacT cells samples; D-E: mammary tissues sample. M: marker; IgG: negative control, non-specific antibody; RNA pol II: positive control, RNA polymerase II; SRE: sterol regulatory element binding protein SRE;

FASN: fatty acid synthase SRE; SCD: stearoyl-CoA desaturase SRE. 


\section{Figure 3.3 QPCR validation of fold-enrichment of SREBP1 binding}

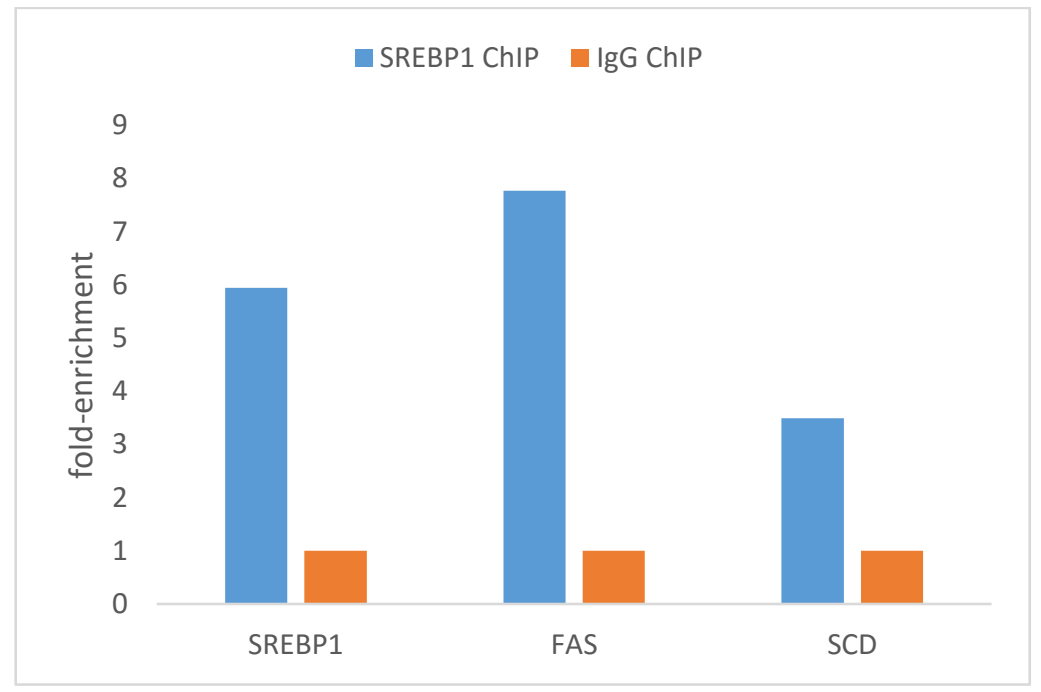

Chromatin DNA cross-linked with SREBP1 from bovine mammary tissues were precipitated with specific (SREBP1) or non-specific (IgG) antibodies as described in materials and methods. Realtime PCR and primers specific to the sterol responsive elements (SRE) in the promoter of three known SREBP1 target genes were used to determine the fold-enrichment of ChIP vs. IgG samples. Representative results in this experiment were shown. SREBP1: sterol regulatory element binding protein SRE; FASN: fatty acid synthase SRE; SCD: stearoyl-CoA desaturase SRE. 
Table

Table 3.1 Summary of ChIP-Seq data

\begin{tabular}{ccc}
\hline Sample & $\begin{array}{c}\text { Total Peaks } \\
\text { called }\end{array}$ & $\begin{array}{c}\text { Total Mapped } \\
\text { read }\end{array}$ \\
\hline CHIP1 & 10135 & 125963693 \\
CHIP2 & 8698 & 72441114 \\
CHIP3 & 9694 & 34431052 \\
\hline INPUT1 & 278093 & 157235283 \\
\hline INPUT2 & 11788 & 147707373 \\
\hline INPUT3 & 276519 & 161902094 \\
\hline
\end{tabular}

Table 3.2 List of nearest potential SRE binding site in selected lipogenic gene promoters

\section{ChIP}

\begin{tabular}{|c|c|c|c|c|c|c|c|c|}
\hline Ch & Start & End & $\begin{array}{l}\text { Fold- } \\
\text { change }\end{array}$ & $\begin{array}{c}-\log _{10} \\
\text { pvalue }\end{array}$ & $\begin{array}{c}-\log _{10} \\
\text { qvalue }\end{array}$ & Distance & Gene & $\begin{array}{c}\text { Reference } \\
\text { ID }\end{array}$ \\
\hline 2 & $\begin{array}{c}12272 \\
1775\end{array}$ & $\begin{array}{c}12272 \\
2001\end{array}$ & 4.00 & 6.90 & 2.86 & -249 & FABP3 & $\frac{\mathrm{NM}_{3.2} 17431}{}$ \\
\hline
\end{tabular}

\begin{tabular}{|c|c|c|c|c|c|c|c|c|}
\hline 4 & $\begin{array}{c}11790 \\
6527\end{array}$ & $\begin{array}{c}11790 \\
6885\end{array}$ & 8.22 & 14.94 & 9.86 & -379 & Insig1 & $\begin{array}{c}\text { NM_00107 } \\
7909.1\end{array}$ \\
\hline 8 & $\begin{array}{c}67477 \\
977\end{array}$ & $\begin{array}{c}67478 \\
248\end{array}$ & 6.04 & 11.68 & 6.96 & -2017 & LPL & $\begin{array}{c}\text { NM_00107 } \\
5120.1\end{array}$ \\
\hline 8 & $\begin{array}{c}96376 \\
516\end{array}$ & $\begin{array}{c}96376 \\
717\end{array}$ & 4.48 & 7.80 & 3.61 & -2207 & ACBA1 & $\begin{array}{c}\text { NM_00102 } \\
4693.1\end{array}$ \\
\hline 11 & $\begin{array}{c}10414 \\
7107\end{array}$ & $\begin{array}{c}10414 \\
7254\end{array}$ & 7.22 & 11.70 & 6.98 & +651 & AGPAT2 & $\begin{array}{c}\text { NM_00108 } \\
0264\end{array}$ \\
\hline 11 & $\begin{array}{c}86131 \\
000\end{array}$ & $\begin{array}{c}86131 \\
167\end{array}$ & 7.00 & 11.01 & 6.35 & +2462 & Lipin1 & $\begin{array}{c}\text { NM_00120 } \\
6156.1\end{array}$ \\
\hline
\end{tabular}




\begin{tabular}{|c|c|c|c|c|c|c|c|c|}
\hline 13 & $\begin{array}{c}64793 \\
142\end{array}$ & $\begin{array}{c}64793 \\
216\end{array}$ & 3.84 & 6.85 & 2.82 & -25 & ACSS2 & $\begin{array}{c}\text { NM_00110 } \\
5339.1\end{array}$ \\
\hline 16 & $\begin{array}{c}55917 \\
212\end{array}$ & $\begin{array}{c}55918 \\
246\end{array}$ & 18.51 & 50.37 & 43.79 & $-22,511$ & DGAT2 & $\begin{array}{c}\text { NM_20579 } \\
3\end{array}$ \\
\hline 19 & $\begin{array}{c}14006 \\
300\end{array}$ & $\begin{array}{c}14006 \\
561\end{array}$ & 3.39 & 5.47 & 1.66 & -1085 & FASN & $\begin{array}{c}\text { NM_00101 } \\
2669.1\end{array}$ \\
\hline 19 & $\begin{array}{c}35234 \\
613\end{array}$ & $\begin{array}{c}35234 \\
620\end{array}$ & 13.03 & 24.90 & 19.17 & +43423 & $\mathrm{ACC} \alpha$ & $\begin{array}{c}N_{4.2} 17422 \\
4.2\end{array}$ \\
\hline 19 & $\begin{array}{c}51383 \\
551\end{array}$ & $\begin{array}{c}51383 \\
837\end{array}$ & 7.44 & 13.22 & 8.33 & -88 & SREBP1 & $\begin{array}{c}\text { NM_00111 } \\
3302.1\end{array}$ \\
\hline 21 & $\begin{array}{c}21493 \\
185\end{array}$ & $\begin{array}{c}21493 \\
467\end{array}$ & 5.88 & 12.16 & 7.39 & -25295 & PLIN1 & $\begin{array}{c}\text { NM_00108 } \\
3699.1\end{array}$ \\
\hline 22 & $\begin{array}{c}52765 \\
247\end{array}$ & $\begin{array}{c}52765 \\
495\end{array}$ & 5.09 & 8.90 & 4.53 & -2516 & PPARG & $\begin{array}{c}\mathrm{NM} \_18102 \\
4.2\end{array}$ \\
\hline 22 & $\begin{array}{c}57486 \\
634\end{array}$ & $\begin{array}{c}57486 \\
785\end{array}$ & 6.40 & 9.72 & 5.27 & -354 & SCAP & $\begin{array}{c}\text { NM_00110 } \\
1889.1\end{array}$ \\
\hline 24 & $\begin{array}{c}49908 \\
843\end{array}$ & $\begin{array}{c}49908 \\
989\end{array}$ & 6.56 & 9.73 & 5.27 & +3582 & ACAA2 & $\begin{array}{c}\text { NM_00103 } \\
5342.2\end{array}$ \\
\hline 26 & $\begin{array}{c}21149 \\
595\end{array}$ & $\begin{array}{c}21149 \\
741\end{array}$ & 5.37 & 7.35 & 3.23 & $+1,277$ & SCD & $\begin{array}{c}\text { NM_17395 } \\
9.4\end{array}$ \\
\hline 27 & $\begin{array}{c}14289 \\
455\end{array}$ & $\begin{array}{c}14289 \\
625\end{array}$ & 3.61 & 6.15 & 2.25 & $+1,122$ & ACSL1 & $\begin{array}{c}\text { NM_00107 } \\
6085.1\end{array}$ \\
\hline
\end{tabular}

The closest SRE binding site is listed for 17 selected lipogenic genes. Peaks were detected for regular peak calling and pooled to screen for potential SRE binding sites within 50k distance from lipogenic gene transcription start site. Ch: chromosome No.; Start: peak start site; End: peak end site; Fold-change: the value represents $\log _{2}$ fold-change from the sequencing threshold; p-value: the value represents - $\log _{10} \mathrm{p}$-value from the sequencing threshold; q-value: the value represents - $\log _{10}$ q-value from the sequencing threshold; summit: relative summit position to peak start; distance: the distance from the peak start site to the transcription start site of the respective gene, "-" indicates peaks upstream to the transcription start site while "+" indicates downstream of transcription start site; Gene: lipogenic gene; Reference ID: NCBI reference ID. 


\section{Chapter 4}

\section{Trans10, cis12-CLA regulates SREBP1 activation through proteasomal degradation of Insig1}

\section{Introduction}

Trans 10, cis12-conjugated linoleic acid (t10, c12-CLA) induced milk fat depression (MFD) in dairy cows has been demonstrated through abomasal infusion (Baumgard et al., 2000) or dietary supplementation of t10, c12-CLA (Bernal-Santos et al., 2003) and high concentrate/low forage diet studies (Peterson et al., 2003). The reduction of milk fat yield is due to the decreased expression of genes involved in milk fat synthesis, i.e. acetyl CoA carboxylase (ACC), fatty acid synthetase (FASN) and $\Delta 9$ desaturase (SCD) (Baumgard et al., 2002b). Sterol regulatory element binding protein-1 (SREBP1) is the key transcription factor that mediates the transcription regulation of lipogenic enzymes (Ma and Corl, 2012, Li et al., 2014). T10, c12-CLA-induced MFD could be due to the SREBP1 coordinated down-regulation of lipogenic gene. The role of t10, c12-CLA in regulating SREBP1 activation is of interest in this study.

SREBP1 is synthesized as a $125 \mathrm{kDa}$ precursor protein (pSREBP1) and resides in the endoplasmic reticulum (ER) in a complex with SREBP cleavage activating protein (SCAP) (Sakai et al., 1997). The activation of SREBP1 requires SCAP-mediated transport to the Golgi apparatus (GA) and cleavage to a $65 \mathrm{kDa}$ mature form (mSREBP1) which migrates to the nucleus and promotes transcription of genes it regulates, including SREBP1 (Horton et al., 1998, Eberle et al., 2004). Insulin induced gene-1 (Insig1) is an ER protein which anchors the SCAP-SREBP1 complex, preventing 
SREBP1 activation (Yang et al., 2002). The interaction of Insig1 with the SCAPSREBP1 complex is regulated through a two-step process that includes ubiquitination and removal of Insig1 from the ER membrane. When the sterol level drops, ER-residing ubiquitin ligase gp78 ubiquitinates Insig1 in preparation for proteasomal degradation (Gong et al., 2006, Lee et al., 2006b). Then, UBX domain-containing protein 8 (UBXd8) and valosin-containing protein (VCP) complex remove ubiquitinated Insig1 out of ER membrane. In the absence of Insig1, SCAP escorts SREBP1 to GA for proteolytic activation (Lee et al., 2006a).

Unsaturated fatty acids are known to block the maturation of SREBP1 in cultured cells (Hannah et al., 2001), and this is analogous to the inhibition of SREBP1 activation observed with MFD and the reduction in transcription of SREBP1 target genes. To be noted, oleate (C18:1), linoleate (C18:2) and arachidonate (C20:4) were effective for the inhibition. In the absence of fatty acids, sterols did not cause a sustained decrease of nuclear SREBP1 (Hannah et al., 2001). An essential step in the release of SCAP-SREBP1 from the ER is the removal of Insig1 from SCAP-SREBP1 complex for degradation mediated by the Ubxd8-VCP complex. Unsaturated fatty acids alter the structure of Ubxd8 and block the removal of Insig1 from the ER by causing dissociation of the Ubxd8-VCP complex from Insig1 (Lee et al., 2008). I hypothesized that t10, c12-CLA mediated inhibition of SREBP1 activation through blocking the Ubxd8-VCP complex from removing Insig1 for proteasomal degradation in bovine mammary epithelial cells and thus inhibits lipogenic gene transcription.

\section{Materials and methods}

\section{Cell culture}


A bovine mammary epithelial cell line MacT cells was used in this experiment (Huynh et al., 1991). Cells were cultured in DMEM/F12 medium supplemented with $10 \%$ fetal bovine serum (Atlanta Biologicals, Lawrenceville, GA) and $100 \mathrm{U}$ penicillin, $0.01 \mathrm{mg}$ streptomycin, and $0.25 \mu \mathrm{g} / \mathrm{mL}$ amphotericin B (1× antibiotic/antimycotic solution; Sigma). Cells were routinely maintained at $37{ }^{\circ} \mathrm{C}$ in $5 \% \mathrm{CO}_{2}$.

\section{Fatty acid treatments}

A $100 \mathrm{mM}$ stock solution of each fatty acid was prepared by diluting the fatty acid completely in $\mathrm{NaOH}$ in equal molar ratio above $68^{\circ} \mathrm{C}$, then complexed to fatty acid free-BSA (>99\%, sigma) in a 2.5 to 1 ratio (5 mM fatty acid to $2 \mathrm{mM}$ BSA). Fatty acidBSA complexes were filtered through a $0.22 \mu \mathrm{m}$ filter before addition to cells. Fatty acid was adjusted to designated concentrations with BSA and added to cells at equal volume (for control, only BSA was added). All solutions were prepared fresh and use on the same day.

\section{Expression vector construction and transfection}

Expression vector for C-terminal FLAG-tagged bovine Insig1 protein was constructed by RT-PCR amplifying a 951-base pair (bp) product of bovine Insig1 (NM_001077909). The amplifying primers were as following: F: 5'-

\section{ACTCCTCCGCGTCCCTCCT-3'; R: 5'-CCCAAACCTTGCCACTCTTC-3'. The} resulting amplicon was cloned into the pCR4-TOPO vector (Invitrogen, Carlsbad, CA) and then subcloned into the pFLAG-CMV5b expression vector (Invitrogen) using the flanking EcoRI restriction sites in the pCR4-TOPO vector and the EcoRI site in the expression vector. Site-directed mutagenesis were performed using the QuikChange Lightning Site-Directed Mutagenessi kit (Stratagene, San Diego, CA) to destroy the stop 
codons to create an in-frame fusion protein containing a C-terminal FLAG-tag. The stop codon was changed to glycine ( $\mathrm{t} 917 \mathrm{~g})$ using the primers as following: $\mathrm{F}$ : 5'GTGCGCCTGAGGATTCCATCACTGTGTGGCTTT-3'; R: 5'AAAGCCACACAGTGATGGAATCCTCAGGCGCAC-3'. 84 nucleotides following the stop codon intervening the expression of FLAG tag was chopped out using BamHI restriction site. Successful cloning, mutagenesis and correct orientation were confirmed by sequencing at each step.

Another expression vector coding for an N-terminal myc-tagged bovine Ubxd8 protein was constructed by RT-PCR amplifying a 1653 bp product encompassing the coding region of bovine Ubxd8 (XM_005209156) with the primers as following: F: 5'CGGGTCAGAAGCGTAGAGG-3'; R: 5'-CTGGGTTGGAGGTGAAGAGT-3', which was cloned into the pCR4-TOPO vector. The coding region of Ubxd8 was then subcloned into the pCMV-Tag3A expression vctor using PCR primers containing BamHI and HindIII restriction sites and cloning into the in the BamHI and HindIII restriction sites in the Tag3a expression vector, to create an in-frame fusion protein containing an $\mathrm{N}$ terminal myc-tag. Successful cloning and correct orientation were confirmed by sequencing.

For transient transfection of FLAG-Insig1, cells were seeded in 6-well plates at 3 $\times 10^{5}$ cells /well for $24 \mathrm{~h}$ to reach $80 \%$ confluency. Fresh medium was replaced $1 \mathrm{~h}$ before transfection. Cells were transfected with $2 \mu \mathrm{g}$ FLAG-Insig1 plasmids using jetPEI transfection reagent (PolyPlus Transfection, New York, NY). After $24 \mathrm{~h}$, the cells were treated with indicated fatty acids at designated concentrations and time for further study. 
For immunoprecipitation assay, cells were seeded in $60 \mathrm{~mm}$ plates at $3 \times 10^{6}$ cells /plate. After reaching $80 \%$ confluency, cells were co-transfected with $5 \mu$ g FLAG-Insig1 and $5 \mu \mathrm{g}$ Myc-Ubxd8, or with $5 \mu \mathrm{g}$ FLAG-Insig1/Myc-Ubxd8 with the respect empty vector as single transfection controls. After $24 \mathrm{~h}$, cells were treated with $75 \mu \mathrm{mmol} / \mathrm{L} \mathrm{t} 10$, c12-CLA or palmitic acid for another $6 \mathrm{~h}$. Cells were lysed and prepared for immunoprecipitation.

\section{Insig1 decay assay}

The cells were transfected with $2 \mu \mathrm{g}$ FLAG-Insig1 plasmids for $24 \mathrm{~h}$, and then cultured with $75 \mu \mathrm{M}$ t10, c12-CLA for $6 \mathrm{~h}$ prior to administration of $60 \mu \mathrm{g} / \mathrm{mL}$ cycloheximide to prevent further protein synthesis. Cells were harvested $0,1.5,3$ and 4.5 $\mathrm{h}$ after cycloheximide addition and lysed for immunoblot analysis of Insig1 to measure the decay. In addition to that, another set of cells were cultured with $75 \mu \mathrm{M}$ t10, c12-CLA and in the presence or absence of MG132 for $6 \mathrm{~h}$ and harvested for immunoblot analysis. MG132 is an inhibitor of proteasomal degradation and served as a positive control.

\section{Immunoprecipitation (IP)}

Whole cell lysates were prepared with cold lysis buffer $(50 \mathrm{mM}$ Hepes- $\mathrm{HCl}, \mathrm{pH}$ at 7.4, $150 \mathrm{mM} \mathrm{NaCl}, 1.5 \mathrm{M} \mathrm{MgCl}_{2}, 1 \%$ Triton X-100 and protease inhibitors) and passed through a 23g needle several times before centrifugation. Protein concentrations were determined using the Bradford Assay (Bio-Rad, Hercules, CA). After the proteins were normalized to the same level ( $800 \mu \mathrm{g}$ per treatment), $2 \mu \mathrm{g}$ rabbit anti-Myc antibody

(Sigma, St. Louis, MO) and $20 \mu \mathrm{L}$ protein G plus agarose beads (\#sc2002, Santa Cruz Biotechnology, Santa Cruz, CA) were added to $1 \mathrm{~mL}$ cell lysates and incubated in $4{ }^{\circ} \mathrm{C}$ 
overnight. Beads were washed with PBS four times and eluted with $2 \times$ sample buffer.

The supernatant was analyzed by immunoblotting.

\section{RT-PCR and real-time PCR (qPCR)}

Total RNA was extracted from cells using TRI Reagent (Molecular Research Center Inc., Cincinnati, OH) according to the manufacturer's instructions. RNA pellets were resuspended in RNase-free $\mathrm{H}_{2} \mathrm{O}$ and concentrations were quantified at $260 \mathrm{~nm}$ using a NanoDrop 1000 spectrophotometer (Thermo Fisher Scientific Inc., Wilmington, DE). 2 $\mu \mathrm{g}$ RNA per reaction were reversed transcribed to its cDNA using the Omniscript RT kit (Qiagen, Valencia, CA) according to the manufacturer's instructions and Oligo-dT (Eurofins MWG/Operon, Huntsvile, AL) as the primer. Real-time PCR was performed using the Quantitect SYBR Green PCR kit (Qiagen) in an Applied Biosystems 7300 Real-time PCR machine (Foster City, CA). Reactions were as follows: 1 cycle at $95^{\circ} \mathrm{C}$ for $10 \mathrm{~min}$, followed by 40 cycles at $95^{\circ} \mathrm{C}$ for $30 \mathrm{secs}, 58^{\circ} \mathrm{C}$ for $30 \mathrm{secs}$, and $72^{\circ} \mathrm{C}$ for 1 min. Each reaction was performed in duplicate wells. Relative quantification of gene transcripts was determined using three pairs of endogenous controls, beta-2microglobulin (B2M), eukaryotic translation initiation factor 3 subunit $\mathrm{K}$ (EIF3K) and ribosomal protein S15 (RPS15). Primer amplification efficiency was tested with dilutions of primers, which generated a standard curve and the slope was used to calculated the efficiency. The range from $95{ }^{\circ} \mathrm{C}$ to $105{ }^{\circ} \mathrm{C}$ was considered proper. fold change was calculated using $2^{-\Delta \Delta} \mathrm{Ct}$ method (Livak and Schmittgen, 2001) with control treatment as the calibrator. Gene-specific primers for the transcripts used in the study are shown in Table 1.

\section{Protein extraction and Immunoblotting}


Whole cell lysates were prepared with cold lysis buffer (50 mM Tris, $\mathrm{pH} 7.4$, 0.5\% Triton X-100, $0.3 \mathrm{M} \mathrm{NaCl}, 2 \mathrm{mM}$ EDTA, $\mathrm{pH}$ 8.0, and protease inhibitors). Protein concentrations were determined using the Bradford Assay (Bio-Rad, Hercules, CA). Samples were diluted to equal amounts of proteins and heated at $95{ }^{\circ} \mathrm{C}$ for 5 min after adding $2 \times$ Laemmli sample buffer (Sigma Chemical Co., St. Louis, MO). Proteins were separated by SDS-PAGE using 7.5 to $12 \%$ PAGEr Gold PlusPreCast SDSpolyacrylamide gels (Lonza, Rockland, ME), and transferred to Western blotting (WB) PVDF membrane (Bio-Rad, Hercules, CA). Membranes were then blocked in 5\% nonfat milk TBS-T blocking buffer (0.05 M Tris pH 7.4, 0.2 M NaCl, 0.1\% Tween, and 5\% dried non-fat milk) on a rocker for $1 \mathrm{~h}$ at room temperature. Membranes were probed with the indicated primary antibodies, anti-FLAG (1 to 4000, \#F3165, Sigma, St. Louis MO), anti-SREBP1(1 to 4000, customized antibody from GenScript, Piscataway, NJ) and anti- $\beta$-Actin (1 to 10,000, \#A2228, Sigma) was used as loading control in blocking buffer at $4{ }^{\circ} \mathrm{C}$ overnight, then incubated with secondary antibody anti-goat IgG1 (1 to 10000 , \#sc2354, Santa Cruz Biotechnology, Santa Cruz, CA) for $1 \mathrm{~h}$ at room temperature, and added detection reagents to the blot using ECL-plus Chemiluminescence Subtract (Amersham Biosciences, Pittsburgh, PA) according to the manufacturer's instructions and incubate for $5 \mathrm{~min}$. Chemiluminescene was measured using a Chemicdoc XRS digital imaging system and densitometry was performed using Quantity One software (Bio-Rad, Hercules, CA).

\section{Statistical Analysis}

All data were analyzed using the MIXED procedure (SAS 9.4, SAS institute Inc., Cary NC). The model included the treatment as fixed effect and the experiment replicate 
as random effect. For cycloheximide experiment, the treatment effect at each time point was tested using slice statement. Post-test comparison were carried out using Tukey's test for pairwise comparisons. Contrasts were used to separate the treatment means of different fatty acid groups: 1) t10, c12-CLA vs other fatty acids; 2) t10, c12-CLA vs c9, t11-CLA; 3) unsaturated fatty acids vs saturated acid. Differences were considered significant when $p<0.05$ and tendency at $p<0.10$. Results were graphed using GraphPad Prism 7 (GraphPad software, San Diego, CA). Each experiment was repeated at least three times.

\section{Results}

\section{Increasing t10, c12-CLA reduced SREBP1 and lipogenic gene expression}

The effect of t10, c12-CLA on SREBP1 and transcription of its target genes was investigated in MacT. Cells were treated with increasing concentrations of t10, c12-CLA and measured SREBP1 protein expression in a relatively short term incubation of $6 \mathrm{~h}$. Both pSREBP1 and mSREBP1 responded to CLA treatment in a dose dependent pattern. As CLA concentration increased, the expression of both proteins decreased (Figure 4.1a). The protein expression of pSREBP1 remained unchanged until CLA concentration increased to $60 \mu \mathrm{M}$, while mSREBP1 dropped dramatically by $48 \%$ at CLA concentration of $20 \mu \mathrm{M}$. Both proteins continued to decrease to less than $20 \%$ as CLA increased (Figure 4.1b). Furthermore, CLA also downregulated mRNA of SREBP1 and its target genes after $24 \mathrm{~h}$ CLA incubation (Figure 4.2). The reduction of mRNA of SREBP1, FASN and SCD1 reached significance at $40 \mu \mathrm{M}$ CLA and continued to decrease in a dose-dependent pattern (Figure 4.2a-c). mRNA of Insig1increased unexpectedly at lower CLA concentration $(20 \mu \mathrm{M})$. As CLA increased, Insig1 started to 
decline and reached significance at $60 \mu \mathrm{M}$ CLA (Figure 4.2d). Insig2 failed to respond to CLA treatment, thus withdrew from the following study. Taken together, increasing CLA had a inhibitory effect on SREBP1 protein activation and its target genes involved in lipogenesis.

\section{t10, c12-CLA increased Insig1 protein expression}

Insig1 is the key regulator of SREBP1 activation in the ER membrane, and whether CLA blocked SREBP1 activation through Insig1 was of interest. A FLAGtagged-Insig1 plasmid was constructed to facilitate the measurement due to the deficiency of a valid bovine antibody to detect endogenous Insig1. MacT cells were transfected with FLAG-Insig1 and treated with t10, c12-CLA for 6 h. CLA increased FLAG-Insig1 protein expression in a dose-dependent pattern and reached significance above $40 \mu \mathrm{M}$ (Figure 4.3). This result was inconsistent with its mRNA expression, which was downregulated by increasing t10, c12-CLA. Further investigation showed that Insig1 protein was not only increased by t10, c12-CLA but other fatty acid treatments (Figure 4.4). Another CLA, c9, t11-CLA, unsaturated fatty acids linoleic acid (c9, c12 18:2) and oleic acid (c9 18:1) also increased FLAG-Insig1 expression, though to a lesser extent compared to t10, c12-CLA treatment, significantly higher than no fatty acid control. Saturated fatty acid (palmitic acid in this study) reduced FLAG-Insig1 expression compared with control $(p<0.05)$. Taken together, unsaturated fatty acid, especially t10, c12-CLA, increased Insig1 protein expression, but palmitic acid reduced Insig1 protein expression.

\section{t10, c12-CLA reduced Insig1 degradation}


To determine if the reduction of FLAG-Insig1 protein expression was due to increased protein synthesis or decreased protein degradation, cycloheximide (CHX), a protein synthesis inhibitor, and MG132, a proteasomal inhibitor, along with t10, c12CLA were applied to measure FLAG-Insig1 expression. Without new Insig1 protein being synthesized, CLA treatment significantly slowed FLAG-Insig1 decay rate after CHX addition (Figure 4.5a-b). At $1.5 \mathrm{~h}$ and $3 \mathrm{~h}$ time points, there were about $85 \%$ and

$67 \%$ of proteins accumulation in the CLA treatment group compared with $59 \%$ and $44 \%$ in CHX-only group. The CLA effect diminished after 4.5h of CHX incubation. On the other hand, cells treated with MG132 for 6h effectively blocked FLAG-Insig1 degradation. Cells treated with t10, c12-CLA also produced the same effect but an even higher protein expression of FLAG-Insig1 (Figure 4.5b). To be noted, cells treated with combination of MG132 and t10, c12-CLA for the same period of time, failed to produce an additive effect by further increasing in FLAG-Insig1. Taken together, t10, c12-CLA increased Insig 1 protein expression by blocking protein degradation rather than stimulating protein synthesis.

\section{CLA reduced interaction between Insig1 and Ubxd8}

The mechanism of CLA interfering Insig1 degradation is also of interest. Another expression vector coding for Myc-tagged-Ubxd8, along with FLAG-Insig1, were cotransfected with MacT cells for $24 \mathrm{~h}$. The cells were treated with either $75 \mu \mathrm{M} \mathrm{t10,} \mathrm{c12-}$ CLA or $75 \mu \mathrm{M}$ palmitic acid for another $6 \mathrm{~h}$ before IP with anti-myc antibody. The association of Myc-Ubxd8 and Flag-Insig1 was assessed by precipitation of myc. Less FLAG-Insig1 was detected in CLA treatment group compared with control (Figure 4.6), 
indicating reduced interaction of the Insig1-Ubxd8. Palmitic acid (PA) treatment resulted in more FLAG-insig1 production compared with control and CLA.

\section{Discussion}

The negative effect (50\% reduction) of supplementing t10, c12-CLA in dairy cows appeared to be a specific to mammary gland response (Kramer et al., 2013). For example, whole-body homeostatic signals and plasma variables associated with lipid metabolism and energy homeostasis seem to be unaffected (Baumgard et al., 2002a). Li et al. (Li et al., 2014) found SREBP1 has a central role in regulating milk fat synthesis and is a key gene involved in milk fat synthesis. Thus, it is of interest to investigate the mechanism whereby CLA regulating SREBP1 and SREBP1-targeted lipogenic genes in mammary gland.

From the present study, t10, c12-CLA decreased pSREBP1, mSREBP1 and mRNA expression in a dose-dependent pattern in MacT cells. Hannah et al. (Hannah et al., 2001) reported a similar pattern in HEK293 cells using arachidonate, while Peterson et al. (Peterson et al., 2004) treated MacT cells with $75 \mu \mathrm{M} \mathrm{t10,} \mathrm{c12-CLA} \mathrm{for} \mathrm{48h} \mathrm{but}$ only detected mSREBP1 reduction. Wang et al. (Wang et al., 2014) showed that, increased t10, c12-CLA concentration to $75 \mu \mathrm{M}$ and $150 \mu \mathrm{M}$, triglyceride accumulation in primary bovine epithelial cells decreased 58 and $87 \%$ accordingly, which was in agreement with the SREBP1 expression measurement in the present study. The protein expression of pSREBP1 and mSREBP1 decreased $42 \%$ and $62 \%$ when CLA concentration increased up to $100 \mu \mathrm{M}$. On the other hand, CLA also down-regulated SREBP1-target genes FASN, SCD1 and SREBP1 (Horton et al., 2003, Bionaz and Loor, 2008b). The mRNA of lipogenic genes FASN, SCD1, SREBP1, and Insig1 decreased in 
response to t10, c12-CLA treatment except Insig2. Moreover, the lowest significant level $(60 \mu \mathrm{M})$ were higher than that $(40 \mu \mathrm{M})$ found in bovine adipose tissue explant culture (Choi et al., 2014). Abomasal infusion of $3.5 \mathrm{~g} / \mathrm{d} \mathrm{t10,} \mathrm{c12-CLA} \mathrm{was} \mathrm{sufficient} \mathrm{to} \mathrm{induce}$ milk fat depression by $25 \%$ (Baumgard et al., 2001), while supplementing $6 \mathrm{~g} / \mathrm{d}$ rumenprotected t10, c12-CLA failed to alter the lipogenic gene expression (Kramer et al., 2013). Taken together, supplementing t10, c12-CLA effectively inhibited SREBP1 and its target lipogenic gene expression in vitro, but more work is needed to define the dosage and means of supplementing in vivo.

The molecular mechanism of CLA-induced SREBP1 inhibition is not well characterized in dairy cows. Insig1 acts as a ER anchor protein and responds to increase of sterol level, binding to SCAP (Yang et al., 2002) thus preventing SCAP-SREBP1 complex from migrating to GA for SREBP1 proteolytic processing (Radhakrishnan et al., 2007). Lee et al. (Lee et al., 2008) also showed that unsaturated fatty acids inhibited Insig1 degradation. The study further confirmed, when supplemented at higher levels (75 $\mu \mathrm{M})$ that, t10, c12-CLA, among other unsaturated fatty acids increased Insig1 protein. Especially, t10, c12-CLA increased Insig1 protein expression in a dose-dependent pattern, which was in line with the reciprocal change previously observed in CLAinduced SREBP1 inhibition. However, the decrease in Insig1 protein with different unsaturated fatty acid was inconsistent with the findings in milk fat depression, where t10, c12-CLA is the isomer-specific CLA to cause the reduction (Bauman et al., 2011). The discrepancy between in vitro and in vivo setting might account for the inconsistence, rather than other factors preventing other unsaturated fatty acids from inhibiting milk fat synthesis. In deficiency of sterol (fasting), Insig1 was degraded, and SREBP1 was 
liberated to process into its mature form to activate its target gene expression, including Insig1. Newly synthesized Insig1 protein provided a feedback inhibition on further SREBP1 activation (Engelking et al., 2004, McFarlane et al., 2014). In current study, lower level of t10, c12-CLA ( $20 \mu \mathrm{M})$ still significantly increased Insig1 mRNA while Insig1 protein started to decline, which was in line with previous finding (Gong et al., 2006). Insig2, a liver-specific and insulin selectively regulated Insig transcript (Yabe et al., 2003), though expressed in bovine mammary gland (Bionaz and Loor, 2008b), failed to respond to increased t10, c12-CLA treatment in MacT cells. On the other hand, in contrast to the rapid turnover of Insig1, Insig2 had a much longer half-life and exhibited a long term regulation on cholesterol metabolism (Lee et al., 2006a), this might explain the insensitivity of Insig2 mRNA expression to CLA in current testing.

Insig1 is an ER protein subject to ER-associated degradation (Ikeda et al., 2009). Insig1 was ubiquitinated by an ER-associated E3 ubiquitin ligase, gp78, but the process can be halted by repletion of sterol (Lee et al., 2006b). CLA-induced increase of Insig1 is due to the inhibition of Insig1 degradation rather than increasing Insig1 protein synthesis. The disappearance of FLAG-Insig1 protein was slower upon CHX treatment. It can be explained by the MG132-like proteosomal degradation inhibition attributed to the addition of t10, c12-CLA. Ubiquitinated Insig1 interacted with Ubxd8 and VCP was recruited to extract the Insig1-Ubxd8 complex from ER membrane and translocated to cytosol for proteosomal degradation, while the interaction between Insig1 and Ubxd8 can be disrupted by polyunsaturated fatty acids (PUFAs) (Lee et al., 2008). The interaction between Ubxd8 and Insig1 was tested by immunoprecipitation. FLAG-Insig1 was 
precipitated along with Ubxd8 in vehicle or PA treatment, while CLA treatment reduced the precipitated FLAG-Insig1, supporting the hypothesis.

SCAP-SREBP1 complex is carried by coat protein complex II (COP-II) vesicles for export from the ER to the Golgi for proteolytic processing to release mSREBP1 (Sun et al., 2007). The COP-II binding site in SCAP was triggered to bind to Insig1 instead by sterols (Sun et al., 2005). The pSREBP1 in GA was processed by site-1 protease (S1P) and site-2 protease (S2P), which were activated by low sterols level, and the N-terminal fragment was released into nucleus (Pai et al., 1998). Recently, a novel PUFA-sensitive SREBP1 cleavage system was recognized through the suppression of nuclear mutant SREBP1 which is not responsive to sterols (Nakakuki et al., 2014). Besides, a S2P recognition sequence in SREBP1 was involved in this novel processing, which indicated PUFAs might be associated with the Golgi SREBP1 cleavage in addition to the known SCAP/Insig1 regulatory pathway.

Taken together, this study investigated the inhibitory effect of t10, c12-CLA on SREBP1 activation and SREBP1-targeted lipogenic gene transcription in MacT cells. The inhibition on SREBP1 activation was through the regulation of Insig1 caused by PUFAs. To be specific, t10, c12-CLA reduced Insig1 proteosomal degradation by disrupting the interaction between Insig1 and Ubxd8. The present study of the molecular mechanism of t10, c12-CLA-inhibited SREBP1 activation would aid understanding of the regulation of SREBP1-regulated lipogenesis in bovine mammary gland.

\section{References}

1. Baumgard, L. H., Corl, B. A., Dwyer, D. A., Saebo, A., and Bauman, D. E. (2000) Identification of the Conjugated Linoleic Acid Isomer That Inhibits Milk Fat Synthesis. 
American journal of physiology. Regulatory, integrative and comparative physiology 278, R179-184

2. Bernal-Santos, G., Perfield, J. W., II, Barbano, D. M., Bauman, D. E., and Overton, T. R. (2003) Production Responses of Dairy Cows to Dietary Supplementation with Conjugated Linoleic Acid (Cla) During the Transition Period and Early Lactation. Journal of Dairy Science 86, 3218-3228

3. Peterson, D. G., Matitashvili, E. A., and Bauman, D. E. (2003) Diet-Induced Milk Fat Depression in Dairy Cows Results in Increased Trans-10, Cis-12 Cla in Milk Fat and Coordinate Suppression of Mrna Abundance for Mammary Enzymes Involved in Milk Fat Synthesis. The Journal of Nutrition 133, 3098-3102

4. Baumgard, L. H., Matitashvili, E., Corl, B. A., Dwyer, D. A., and Bauman, D. E. (2002) Trans-10, Cis-12 Conjugated Linoleic Acid Decreases Lipogenic Rates and Expression of Genes Involved in Milk Lipid Synthesis in Dairy Cows. Journal of Dairy Science 85, 2155-2163

5. Ma, L., and Corl, B. A. (2012) Transcriptional Regulation of Lipid Synthesis in Bovine Mammary Epithelial Cells by Sterol Regulatory Element Binding Protein-1. Journal of Dairy Science 95, 3743-3755

6. Li, N., Zhao, F., Wei, C., Liang, M., Zhang, N., Wang, C., Li, Q. Z., and Gao, X. J. (2014) Function of Srebp1 in the Milk Fat Synthesis of Dairy Cow Mammary Epithelial Cells. International journal of molecular sciences 15, 16998-17013

7. Sakai, J., Nohturfft, A., Cheng, D., Ho, Y. K., Brown, M. S., and Goldstein, J. L. (1997) Identification of Complexes between the Cooh-Terminal Domains of Sterol Regulatory Element-Binding Proteins (Srebps) and Srebp Cleavage-Activating Protein. The Journal of Biological Chemistry 272, 20213-20221

8. $\quad$ Eberle, D., Hegarty, B., Bossard, P., Ferre, P., and Foufelle, F. (2004) Srebp Transcription Factors: Master Regulators of Lipid Homeostasis. Biochimie 86, 839-848

9. Horton, J. D., Bashmakov, Y., Shimomura, I., and Shimano, H. (1998) Regulation of Sterol Regulatory Element Binding Proteins in Livers of Fasted and Refed Mice. Proceedings of the National Academy of Sciences of the United States of America 95, 5987-5992

10. Yang, T., Espenshade, P. J., Wright, M. E., Yabe, D., Gong, Y., Aebersold, R., Goldstein, J. L., and Brown, M. S. (2002) Crucial Step in Cholesterol Homeostasis: Sterols Promote Binding of Scap to Insig-1, a Membrane Protein That Facilitates Retention of Srebps in Er. Cell 110, 489-500

11. Gong, Y., Lee, J. N., Lee, P. C., Goldstein, J. L., Brown, M. S., and Ye, J. (2006) SterolRegulated Ubiquitination and Degradation of Insig-1 Creates a Convergent Mechanism for Feedback Control of Cholesterol Synthesis and Uptake. Cell metabolism 3, 15-24

12. Lee, J. N., Song, B., DeBose-Boyd, R. A., and Ye, J. (2006) Sterol-Regulated Degradation of Insig-1 Mediated by the Membrane-Bound Ubiquitin Ligase Gp78. The Journal of Biological Chemistry 281, 39308-39315

13. Lee, J. N., Gong, Y., Zhang, X., and Ye, J. (2006) Proteasomal Degradation of Ubiquitinated Insig Proteins Is Determined by Serine Residues Flanking Ubiquitinated Lysines. Proceedings of the National Academy of Sciences of the United States of America 103, 4958-4963

14. Hannah, V. C., Ou, J., Luong, A., Goldstein, J. L., and Brown, M. S. (2001) Unsaturated Fatty Acids Down-Regulate Srebp Isoforms 1a and 1c by Two Mechanisms in Hek-293 Cells. The Journal of Biological Chemistry 276, 4365-4372

15. Lee, J. N., Zhang, X., Feramisco, J. D., Gong, Y., and Ye, J. (2008) Unsaturated Fatty Acids Inhibit Proteasomal Degradation of Insig-1 at a Postubiquitination Step. The Journal of Biological Chemistry 283, 33772-33783 
16. Huynh, H. T., Robitaille, G., and Turner, J. D. (1991) Establishment of Bovine Mammary Epithelial Cells (Mac-T): An in Vitro Model for Bovine Lactation. Exp Cell Res 197, 191-199

17. Livak, K. J., and Schmittgen, T. D. (2001) Analysis of Relative Gene Expression Data Using Real-Time Quantitative Pcr and the 2(-Delta Delta C(T)) Method. Methods 25, 402-408

18. Kramer, R., Wolf, S., Petri, T., von Soosten, D., Danicke, S., Weber, E. M., Zimmer, R., Rehage, J., and Jahreis, G. (2013) A Commonly Used Rumen-Protected Conjugated Linoleic Acid Supplement Marginally Affects Fatty Acid Distribution of Body Tissues and Gene Expression of Mammary Gland in Heifers During Early Lactation. Lipids in health and disease 12, 96

19. Bauman, D. E., and Griinari, J. M. (2003) Nutritional Regulation of Milk Fat Synthesis. Annual review of nutrition 23, 203-227

20. Baumgard, L. H., Corl, B. A., Dwyer, D. A., and Bauman, D. E. (2002) Effects of Conjugated Linoleic Acids (Cla) on Tissue Response to Homeostatic Signals and Plasma Variables Associated with Lipid Metabolism in Lactating Dairy Cows. Journal of Animal Science 80, 1285-1293

21. Peterson, D. G., Matitashvili, E. A., and Bauman, D. E. (2004) The Inhibitory Effect of Trans-10, Cis-12 Cla on Lipid Synthesis in Bovine Mammary Epithelial Cells Involves Reduced Proteolytic Activation of the Transcription Factor Srebp-1. The Journal of Nutrition 134, 2523-2527

22. Wang, H., Liu, H., Liu, J., Zhao, K., Wang, C., and Yang, W. (2014) High-Level Exogenous Trans10, Cis12 Conjugated Linoleic Acid Plays an Anti-Lipogenesis Role in Bovine Mammary Epithelial Cells. Animal science journal 85, 744-750

23. Horton, J. D., Shah, N. A., Warrington, J. A., Anderson, N. N., Park, S. W., Brown, M. S., and Goldstein, J. L. (2003) Combined Analysis of Oligonucleotide Microarray Data from Transgenic and Knockout Mice Identifies Direct Srebp Target Genes. Proceedings of the National Academy of Sciences of the United States of America 100, 12027-12032

24. Bionaz, M., and Loor, J. J. (2008) Gene Networks Driving Bovine Milk Fat Synthesis During the Lactation Cycle. BMC genomics 9, 366

25. Choi, S. H., Silvey, D. T., Johnson, B. J., Doumit, M. E., Chung, K. Y., Sawyer, J. E., Go, G. W., and Smith, S. B. (2014) Conjugated Linoleic Acid (T-10, C-12) Reduces Fatty Acid Synthesis De Novo, but Not Expression of Genes for Lipid Metabolism in Bovine Adipose Tissue Ex Vivo. Lipids 49, 15-24

26. Baumgard, L. H., Sangster, J. K., and Bauman, D. E. (2001) Milk Fat Synthesis in Dairy Cows Is Progressively Reduced by Increasing Supplemental Amounts of Trans-10, Cis-

12 Conjugated Linoleic Acid (Cla). The Journal of Nutrition 131, 1764-1769

27. Radhakrishnan, A., Ikeda, Y., Kwon, H. J., Brown, M. S., and Goldstein, J. L. (2007) Sterol-Regulated Transport of Srebps from Endoplasmic Reticulum to Golgi: Oxysterols Block Transport by Binding to Insig. Proceedings of the National Academy of Sciences of the United States of America 104, 6511-6518

28. Bauman, D. E., Harvatine, K. J., and Lock, A. L. (2011) Nutrigenomics, Rumen-Derived Bioactive Fatty Acids, and the Regulation of Milk Fat Synthesis. Annual review of nutrition 31, 299-319

29. Engelking, L. J., Kuriyama, H., Hammer, R. E., Horton, J. D., Brown, M. S., Goldstein, J. L., and Liang, G. (2004) Overexpression of Insig-1 in the Livers of Transgenic Mice Inhibits Srebp Processing and Reduces Insulin-Stimulated Lipogenesis. The Journal of clinical investigation 113, 1168-1175

30. McFarlane, M. R., Liang, G., and Engelking, L. J. (2014) Insig Proteins Mediate Feedback Inhibition of Cholesterol Synthesis in the Intestine. The Journal of Biological Chemistry 289, 2148-2156 
31. Yabe, D., Komuro, R., Liang, G., Goldstein, J. L., and Brown, M. S. (2003) LiverSpecific Mrna for Insig-2 Down-Regulated by Insulin: Implications for Fatty Acid Synthesis. Proceedings of the National Academy of Sciences of the United States of America 100, 3155-3160

32. Ikeda, Y., Demartino, G. N., Brown, M. S., Lee, J. N., Goldstein, J. L., and Ye, J. (2009) Regulated Endoplasmic Reticulum-Associated Degradation of a Polytopic Protein: P97 Recruits Proteasomes to Insig-1 before Extraction from Membranes. The Journal of Biological Chemistry 284, 34889-34900

33. Sun, L. P., Seemann, J., Goldstein, J. L., and Brown, M. S. (2007) Sterol-Regulated Transport of Srebps from Endoplasmic Reticulum to Golgi: Insig Renders Sorting Signal in Scap Inaccessible to Copii Proteins. Proceedings of the National Academy of Sciences of the United States of America 104, 6519-6526

34. Sun, L. P., Li, L., Goldstein, J. L., and Brown, M. S. (2005) Insig Required for SterolMediated Inhibition of Scap/Srebp Binding to Copii Proteins in Vitro. The Journal of Biological Chemistry 280, 26483-26490

35. Pai, J. T., Guryev, O., Brown, M. S., and Goldstein, J. L. (1998) Differential Stimulation of Cholesterol and Unsaturated Fatty Acid Biosynthesis in Cells Expressing Individual Nuclear Sterol Regulatory Element-Binding Proteins. The Journal of Biological Chemistry 273, 26138-26148

36. Nakakuki, M., Kawano, H., Notsu, T., Imada, K., Mizuguchi, K., and Shimano, H. (2014) A Novel Processing System of Sterol Regulatory Element-Binding Protein-1c Regulated by Polyunsaturated Fatty Acid. Journal of biochemistry 
Table

Table 4.1 Primer sequences for transcripts used in real-time quantitative PCR

\begin{tabular}{|c|c|c|c|}
\hline Transcript & Accession number & Primers (5' to 3') & \\
\hline SREBP1 & NM_001113302 & $\begin{array}{l}\text { Forward } \\
\text { Reverse }\end{array}$ & $\begin{array}{l}\text { atgccatcgagaaacgctac } \\
\text { gtccgcagactcaggttctc }\end{array}$ \\
\hline SCD1 & NM_173959 & $\begin{array}{l}\text { Forward } \\
\text { Reverse }\end{array}$ & $\begin{array}{l}\text { ccctttcettgagctgtctg } \\
\text { atgctgactctctcccctga }\end{array}$ \\
\hline FASN & NM_001012669 & $\begin{array}{l}\text { Forward } \\
\text { Reverse }\end{array}$ & $\begin{array}{l}\text { ctgcaactcaacgggaactt } \\
\text { aggctggtcatgttctccag }\end{array}$ \\
\hline Insig1 & NM_001077909 & $\begin{array}{l}\text { Forward } \\
\text { Reverse }\end{array}$ & $\begin{array}{l}\text { gtcatcgccaccatcttctc } \\
\text { agtggaacctctcggtgtgtt }\end{array}$ \\
\hline Insig2 & XM_003581843 & $\begin{array}{l}\text { Forward } \\
\text { Reverse }\end{array}$ & $\begin{array}{l}\text { tccagtgtgatgcggtgtgta } \\
\text { agtgtgaccgacgtgatagtt }\end{array}$ \\
\hline EIF3k & NM_001034489 & $\begin{array}{l}\text { Forward } \\
\text { Reverse }\end{array}$ & $\begin{array}{l}\text { gcgatgtttgagcagatgag } \\
\text { gcattttctttggcetgtgt }\end{array}$ \\
\hline $\mathrm{B} 2 \mathrm{M}$ & NM_173893 & $\begin{array}{l}\text { Forward } \\
\text { Reverse }\end{array}$ & $\begin{array}{l}\text { tgctgaagaatcgggagaag } \\
\text { ccttgctgttgggagtgaa }\end{array}$ \\
\hline RPS15 & XM585783 & $\begin{array}{l}\text { Forward } \\
\text { Reverse }\end{array}$ & $\begin{array}{l}\text { ctctgtgcattcgggttttc } \\
\text { gggctctctgggttcctct }\end{array}$ \\
\hline
\end{tabular}




\section{Figure}

Figure 4.1 t10, c12-CLA reduced SREBP1 protein expression.

$\mathbf{a}$

\begin{tabular}{|c|c|c|c|c|c|c|}
\hline $\mathrm{CLA}(\mu \mathrm{M})$ & 0 & 20 & 40 & 60 & 80 & 100 \\
\hline pSREBP1 & & & & 5 & $=$ & 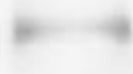 \\
\hline mSREBP1 & & & $2=$ & i & hise & 8.9 \\
\hline
\end{tabular}

b

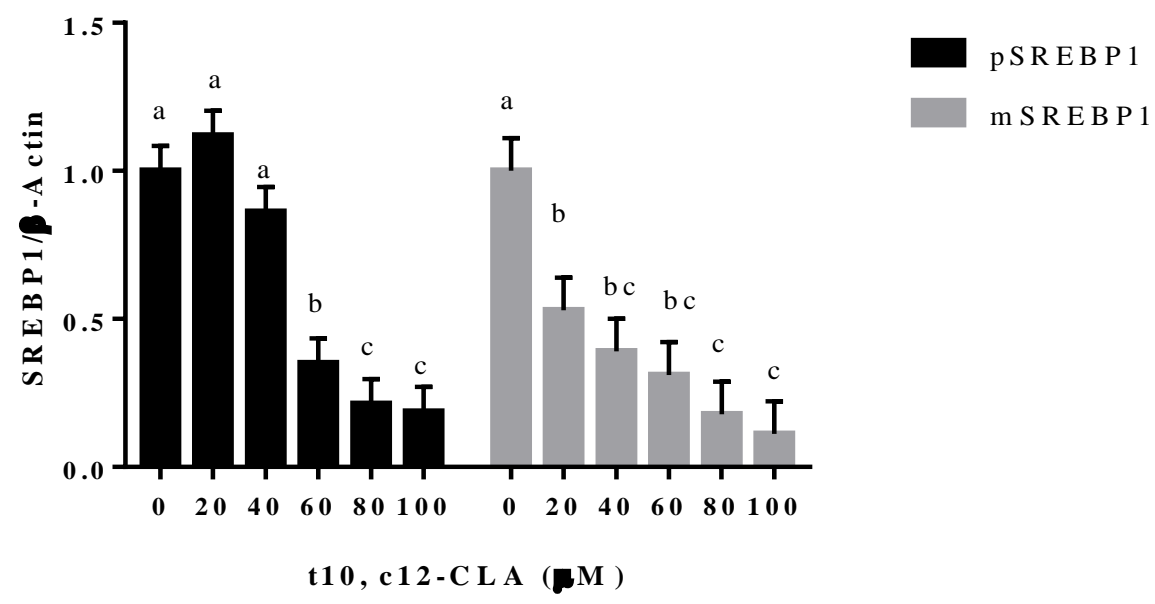

Cells were seeded in 6-well plates at $3 \times 10^{5}$ cells /well. On the next day, after reaching $80 \%$ confluency, cells were treated with increasing concentrations of t10, c12-CLA for $6 \mathrm{~h}$. Total protein lysates were extracted and $60 \mu \mathrm{g}$ protein were analyzed by immunoblotting. a.

Representative immunoblots of pSREBP1 (125 kDa) and mSREBP1 (65 kDa). b. Data represent mean pSREBP1 and mSREBP1 protein abundance normalized to $\beta$-actin $\pm \mathrm{SEM}, \mathrm{n}=3$. Mean $( \pm$ SEM) was compared using Tukey's test and difference was considered significant when $p<$ 0.05 . 
Figure 4.2 t10, c12-CLA reduced lipogenic gene expression.
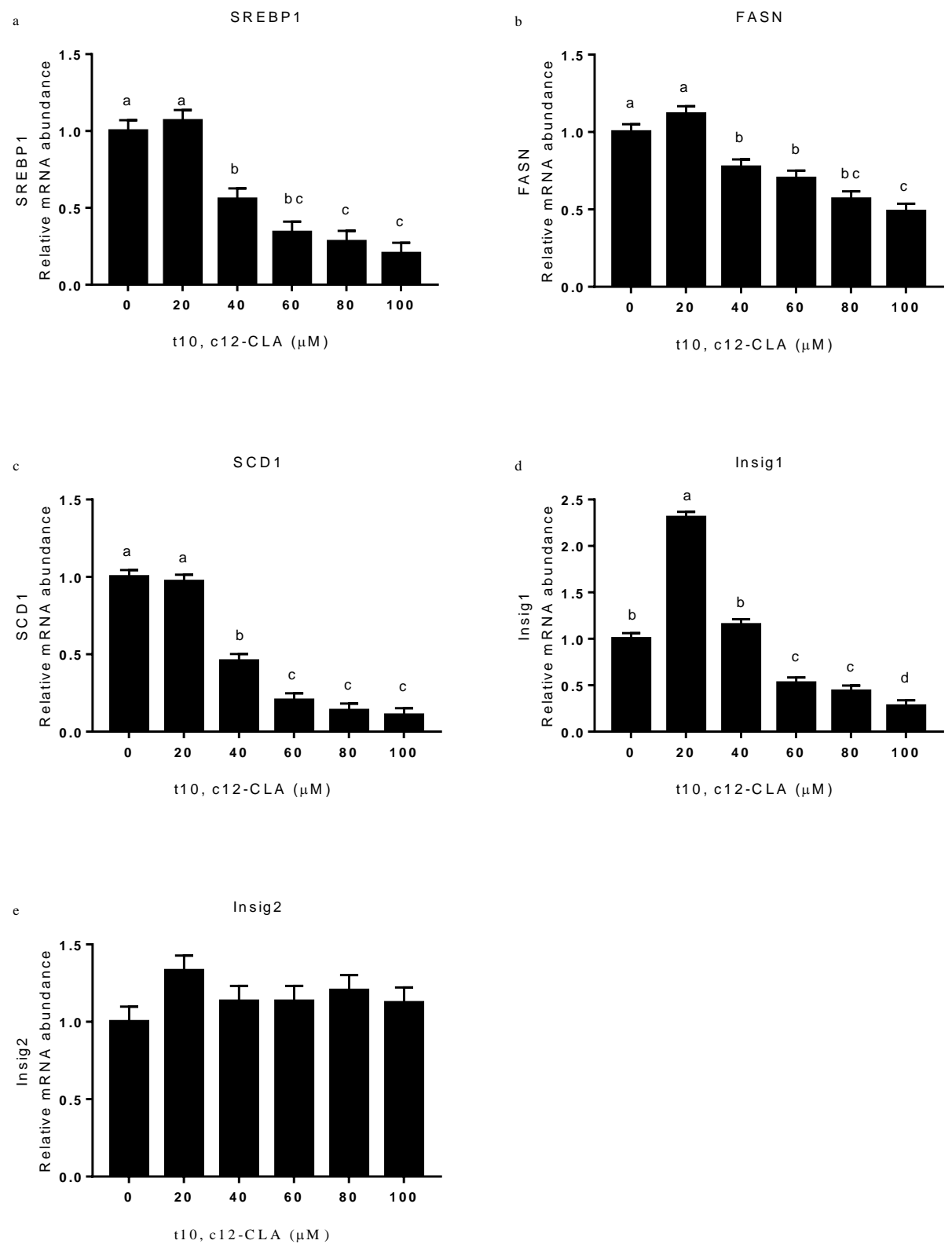

Cells were seeded in 6-well plates at $3 \times 10^{5}$ cells /well. On the next day, after reaching $80 \%$ confluency, cells were treated with increasing concentrations of t10, c12-CLA for $24 \mathrm{~h}$. All mRNAs were measured by qPCR and normalized to 3 endogenous control genes B2M, RPS15 and EIF3K. Mean $( \pm$ SEM) was compared using Tukey’s test and difference was considered significant when $p<0.05$. a: SREBP1; b: FASN; c: SCD1; d: Insig1; e: Insig2. 
Figure 4.3 t10, c12-CLA increased Insig1 protein expression.

$\mathbf{a}$

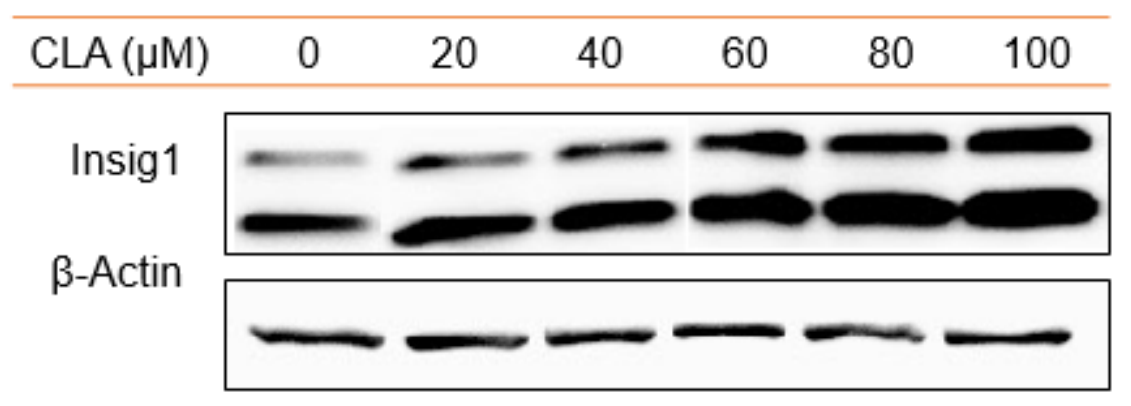

$\mathrm{b}$

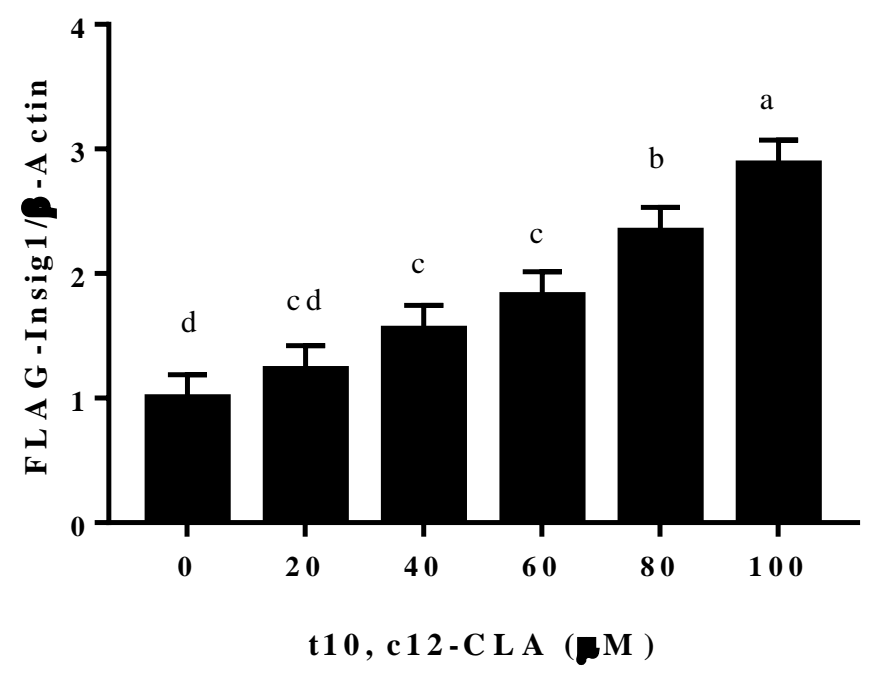

Cells were seeded in 6-well plates at $3 \times 10^{5}$ cells /well. On the next day, after reaching $80 \%$ confluency, cells were transfected with $2 \mu \mathrm{g}$ pCMV-FLAG-Insig1 for $24 \mathrm{~h}$. Then cells were incubated with increasing concentrations of t10, c12-CLA for $6 \mathrm{~h}$. Total protein lysates were extracted and $60 \mu \mathrm{g}$ proteins were analyzed by immunoblotting. a. Representative immunoblots of FLAG-Insig1 (25 and $28 \mathrm{kDa}$ ). b. Data represent mean FLAG-Insig1 protein abundance normalized to $\beta$-actin \pm SEM, $n=3$. Mean ( \pm SEM) was compared using Tukey's test and difference was considered significant when $p<0.05$. 
Figure 4.4 Unsaturated fatty acids increased Insig1 protein expression.

$\mathbf{a}$

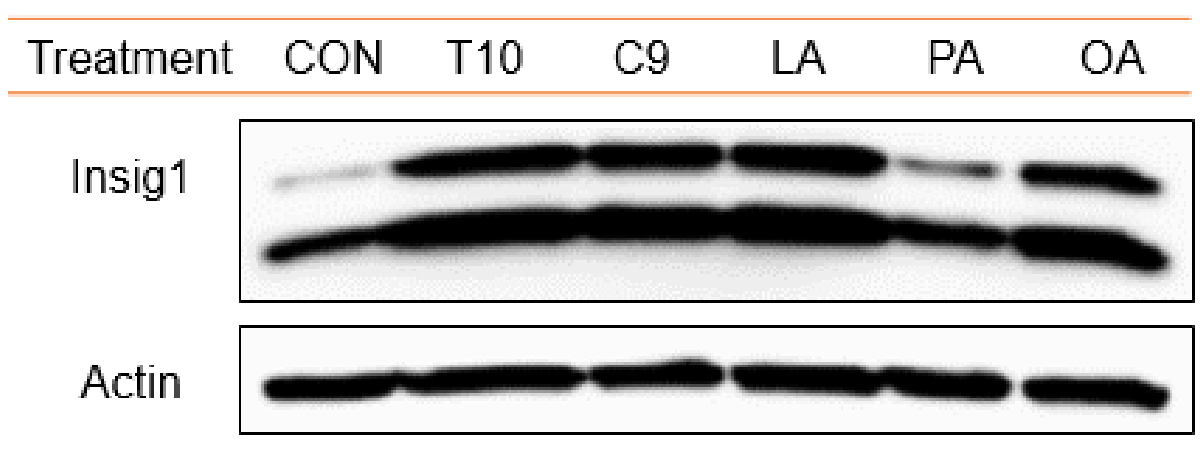

b

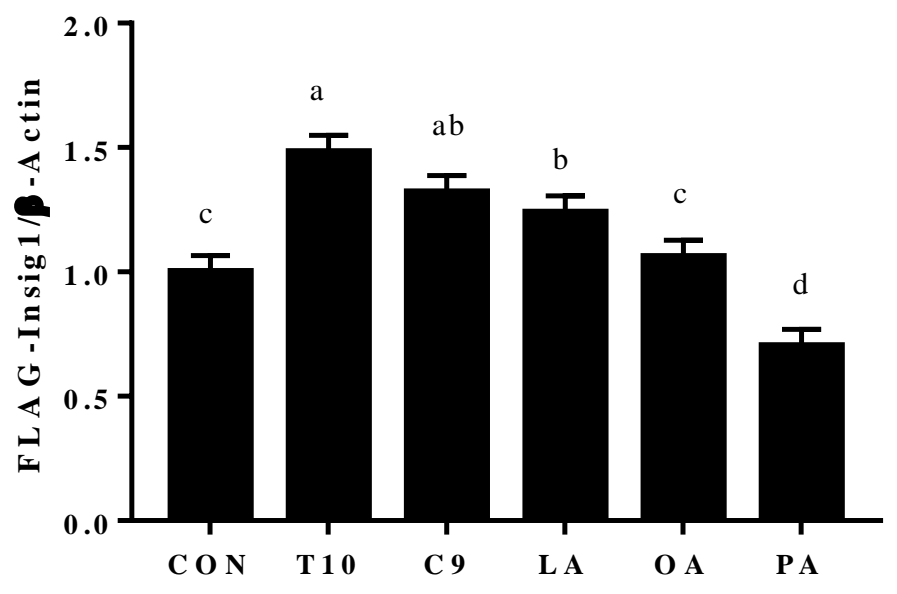

Cells were seeded in 6 -well plates at $3 \times 10^{5}$ cells /well. On the next day, after reaching $80 \%$ confluency, cells were transfected with $2 \mu \mathrm{g}$ pCMV-FLAG-Insig1 for $24 \mathrm{~h}$. Then cells were incubated with $75 \mu \mathrm{M}$ of the indicated fatty acids for $6 \mathrm{~h}$. Total protein lysates were extracted, and $60 \mu \mathrm{g}$ proteins were analyzed by immunoblotting. a. Representative immunoblots of FLAGInsig1 (25 and $28 \mathrm{kDa})$. b. Data represent mean FLAG-Insig1 protein abundance normalized to $\beta$ actin \pm SEM, n=3. Mean $( \pm$ SEM) was compared using Tukey’s test and were considered significant when $p<0.05$. CON: BSA, T10: t10, c12-CLA, C9: c9, t11-CLA, LA: linoleic acid, OA: oleic acid, PA: palmitic acid. 
Figure 4.5 t10, c12-CLA reduced Insig1 degradation.

$\mathbf{a}$

\begin{tabular}{|c|c|c|c|c|c|c|c|c|}
\hline Lane & 1 & 2 & 3 & 4 & 5 & 6 & 7 & 8 \\
\hline $\mathrm{t} 10, \mathrm{c} 12-\mathrm{CLA}$ & \multicolumn{4}{|c|}{+} & \multicolumn{4}{|c|}{-} \\
\hline $\mathrm{CHX}(\mathrm{h})$ & 0 & 1.5 & 3 & 4.5 & 0 & 1.5 & 3 & 4.5 \\
\hline Insig1 & & & - & - & - & - & - & - \\
\hline$\beta$-Actin & & & & & & & & \\
\hline
\end{tabular}

b

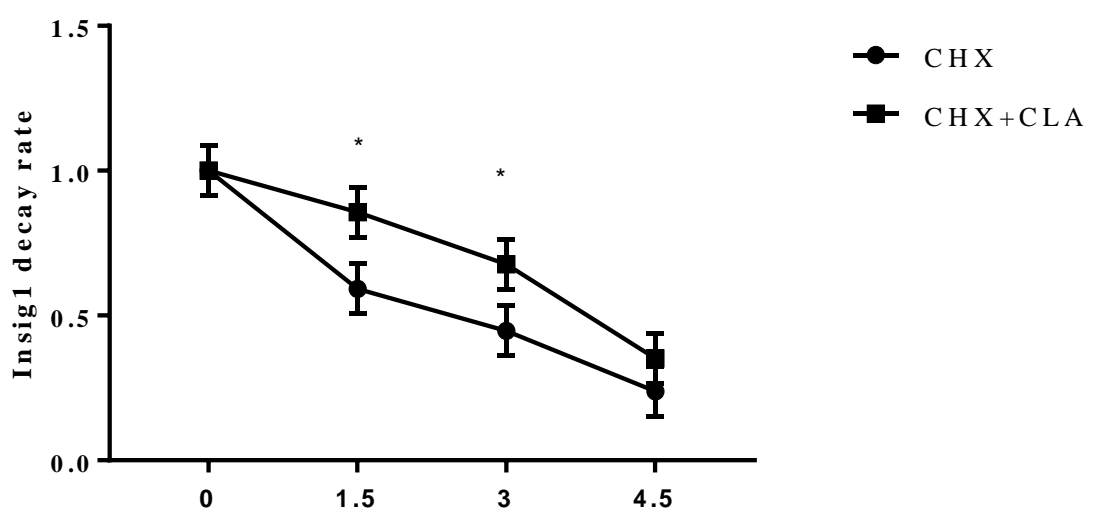

Time (h)

c

\begin{tabular}{cccccc}
\hline Lane & 1 & 2 & 3 & 4 \\
\hline MG132 & - & + & - & + \\
t10, c12-CLA & - & - & + & + \\
\hline Insig1 & - & - & & & \\
\cline { 2 - 4 } & & & & & \\
\cline { 2 - 4 } & & & & \\
\cline { 2 - 4 } & & & & & \\
\cline { 2 - 4 }
\end{tabular}


d

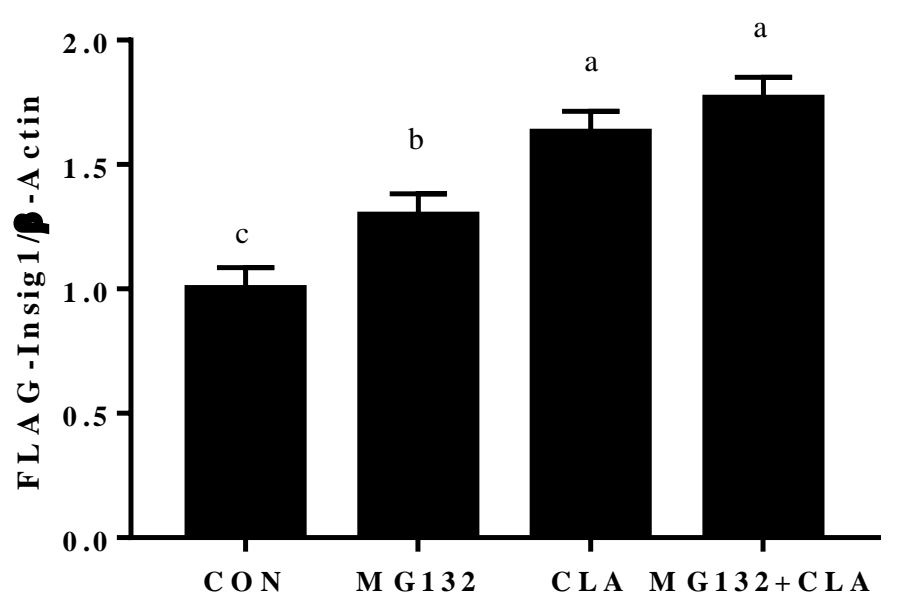

Cells were seeded in 6-well plates at $3 \times 10^{5}$ cells /well. On the next day, after reaching $80 \%$ confluency, cells were transfected with $2 \mu \mathrm{g}$ pCMV-FLAG-Insig1 for $24 \mathrm{~h}$. a. Cells were incubated with $75 \mu \mathrm{M}$ CLA for $6 \mathrm{~h}$. Then cells were treated with or without cycloheximide $(\mathbf{C H X}, 60 \mu \mathrm{g} / \mathrm{mL}$ ) for another $4.5 \mathrm{~h}$. Cells were harvested at indicated time points after CHX addition. b. Cells were treated with either $10 \mu \mathrm{M}$ MG132 or $75 \mu \mathrm{M}$ t10, c12-CLA (CLA) or both for $6 \mathrm{~h}$. Total protein lysates were extracted, and the levels of indicated proteins were analyzed by immunoblotting. c. Representative immunoblots of FLAG-Insig1 (25 and 28 kDa). d. Data represent mean FLAG-Insig1 protein abundance normalized to $\beta$-actin \pm SEM, $n=3$. Means were compared using Tukey's test and were considered significant when $p<0.05$. 
Figure 4.6 CLA reduced interaction between Insig1 and Ubxd8.

\begin{tabular}{ccccccc}
\hline Lane & $\mathbf{1}$ & $\mathbf{2}$ & $\mathbf{3}$ & $\mathbf{4}$ & $\mathbf{5}$ & $\mathbf{6}$ \\
\hline FLAG-Insig1 & + & + & - & + & + & + \\
Myc-Ubxd8 & + & - & + & + & + & + \\
CLA & - & - & - & + & - & - \\
PA & - & - & - & - & + & - \\
IgG & - & - & - & - & - & + \\
\hline
\end{tabular}

IB:

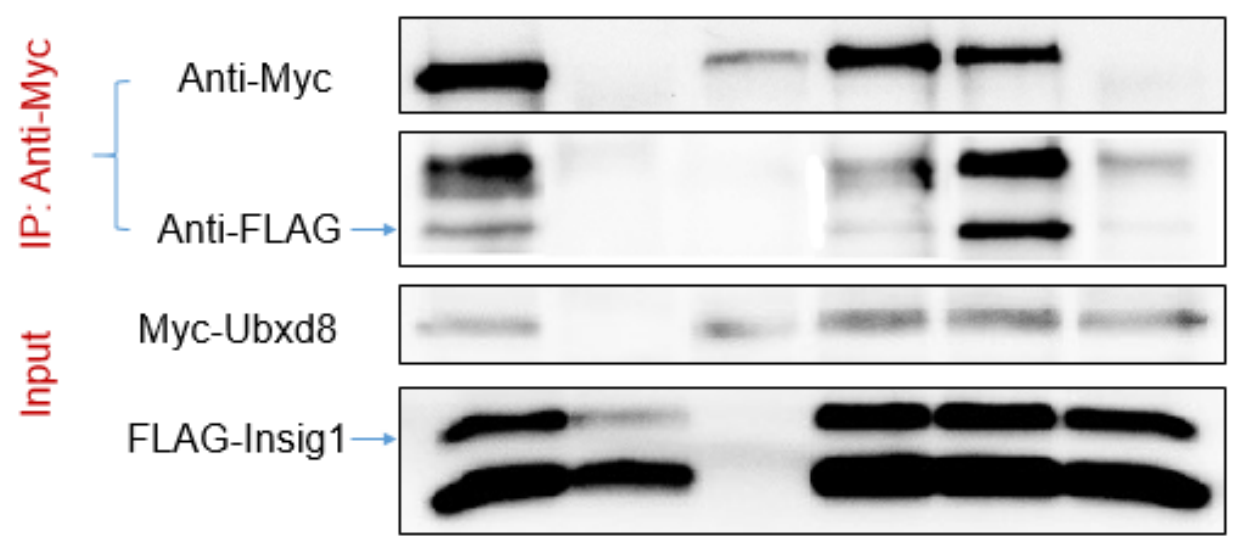

Cells were seeded in $60 \mathrm{~mm}$ dishes at $3 \times 10^{6}$ cells /well. On the next day, after reaching $80 \%$ confluency, cells were transfected with either $5 \mu \mathrm{g}$ of Myc-Ubxd8 or $5 \mu \mathrm{g}$ of FLAG-Insig1 or both for $24 \mathrm{~h}$. Then cells were treated with either $75 \mu \mathrm{M} \mathrm{t10,} \mathrm{c12-CLA} \mathrm{or} 75 \mu \mathrm{M}$ palmitic acid for $6 \mathrm{~h}$. Total protein lysates were extracted $30 \mu \mathrm{g}$ protein was used as input. $900 \mu \mathrm{g}$ protein was precipitated with rabbit anti-FLAG antibody or rabbit control IgG. The pellets were washed and analyzed by immunoblotting with either mouse anti-FLAG or mouse anti-Myc antibodies. $30 \mu \mathrm{g}$ total protein lysates were used as input sample. BSA: co-transfection with FLAG-Insig1 and Myc-Ubxd8, no fatty acid included. Insig1: single transfection control, only transfected with FLAG-Insig1. Ubxd8: single transfection control, only transfected with Myc-Ubxd8. CLA: cotransfection with FLAG-Insig1 and Myc-Ubxd8, t10, c12-CLA treated. PA: co-transfection with FLAG-Insig1 and Myc-Ubxd8, palmitic acid treated. IgG: antibody control, co-transfection with FLAG-Insig1 and Myc-Ubxd8. 


\section{Chapter 5}

\section{Regulation of SREBP1 activation through mTOR signaling, AMPK and glucose availability in bovine mammary epithelial cells}

\section{Introduction}

Mammalian target of rapamycin ( $\mathbf{m T O R}$ ) complex activity is one of the key signaling pathways that responds to insulin-mediated regulation in mammary gland of cows (Bionaz, 2012). Insulin induced-mTOR signaling regulated milk protein synthesis in Mac-T cells (Appuhamy et al., 2011). Activation of mTOR increased lipogenic gene expression in mouse hepatocytes (Porstmann et al., 2008) and lipid accumulation in mouse liver (Laplante and Sabatini, 2009). Inhibited or defected mTOR signaling protected mice from developing diet- or age-induced hepatic steatosis by down-regulating SREBP1 and decreasing de novo lipogenesis (Yecies et al., 2011, Yuan et al., 2012).

The mechanism of SREBP1 activation regulated by mTOR signaling was proposed in human obesity and cancer research. The cAMP response element-binding protein (CREB) transcription coactivator 2 (CRTC2), was phosphorylated by mTOR and removed suppression of SREBP1 activation transport to the Golgi apparatus (GA) (Han et al., 2015b). mTOR complex 1 (mTORC1) regulates the localization of Lipin1, a phosphatidic acid phosphatase, thus promoted nuclear entry of SREBP1 (Peterson et al., 2011). mTOR complex 2 (mTORC2) modulated the phosphorylation of glycogen synthase kinase 3 (GSK3), prevented the GSK3-dependent proteasomal degradation of SREBP1 (Li et al., 2015).

AMP-activated protein kinase (AMPK), as an energy sensor activated by declining intracellular energy level, is another potential regulator of lipid metabolism. 
Activated AMPK inhibited de novo fatty acid synthesis in MacT cells (McFadden and Corl, 2009). NEFA-induced AMPK activation inhibited the protein expression of SREBP1 and decreased the mRNA level of lipogenic genes in bovine hepatocytes ( $\mathrm{Li}$ et al., 2013). AMPK directly phosphorylated SREBP1 on Ser372 and suppressed SREBP1 activation in hepatocytes (Li et al., 2011). Jiang et al. (Jiang et al., 2012) reported that t10, c12-CLA activated AMPK activity in adipocytes, which is of interest in this study to test whether AMPK plays a role in CLA-induced SREBP1 inhibition in mammary epithelial cells.

Cheng et al. (Cheng et al., 2015) has shown that culturing cells in minimal glucose concentration was sufficient to stabilize SREBP cleavage-activating protein (SCAP) through N-glycosylation to facilitate the SCAP-SREBP1 complex trafficking to GA. Increasing glucose improved energy, and thus regulates AMPK activity (Kimura et al., 2003), removed the suppression on mTORC1, and elevated SREBP1 activation (Danai et al., 2013). In mammary gland, glucose could be essential to lipid metabolism via regulation of SREBP1.

The objective of this study is to examine three potential regulators of SREBP1 activation and regulatory signaling pathways in bovine mammary epithelial cells. I hypothesized that 1) insulin-induced mTOR signaling stimulates lipogenesis via activation of SREBP1; 2) t10, c12-CLA inhibited SREBP1 through AMPK phosphorylation; and 3) glucose stabilizes SCAP and facilitates SREBP1 activation.

\section{Materials and methods}

\section{Reagents}


Bovine insulin, glucose, bovine serum albumin (BSA, >99\% fatty acids free), DMSO, Antibiotic-Antimycotic Solution (100x), phosphatase inhibitor cocktail (PIC, 100x) and sodium orthovanadate were purchased from Sigma (St. Louis, MO). DMEM with high glucose and DMEM Without glucose, L-glutamine, phenol red, sodium pyruvate and sodium bicarbonate were purchased from Sigma. Fetal bovine serum was from Atlanta Biologicals (Lawrenceville, GA). Trans10, cis12-CLA and linoleic acid were purchased from Nu-Chek-Prep (Elysian, MN). mTOR inhibitors rapamycin and Torin1, GSK3 inhibitor CHIR99021 and AMPK inhibitor dorsomorphin were purchased from LC Laboratories (Woburn, MA). DharmaFECT reagent \#2, siRNA specific against bovine SREBP1, non-targeting siRNA were from Dharmacon (Thermo Fisher Scientific, Waltham, MA). NE-PER Nuclear and Cytoplasmic extraction kit was from Thermo (Rockford, IL). Primary antibodies to p-AMPK $\alpha$ (Thr172, \#2535), AMPK $\alpha$ (\#2603), Lipin1 (\#14906), LaminB1 (\#14906), MEK1/2(\#13435), p-mTOR (Ser2448, \#5536), mTOR (\#2983) and CRTC2 (\#3826) were from Cell Signaling (Beverly, MA). $\beta$-Actin (\#A2228) was from Sigma (St. Louis, MO). p-CRTC2 (Ser171, \#51565) and SCAP (\#109474) were from GeneTex (Irvine, CA). Customized antibody against SREBP1 from GenScript (Piscataway, NJ). Secondary antibodies rabbit anti-goat $\operatorname{IgG}_{1}-\mathrm{HRP}$ (1: 10000, \#2768), mouse anti-goat $\operatorname{IgG}_{1}-\mathrm{HRP}(1: 10000, \# 2354)$ and rabbit anti-goat $\operatorname{IgG}_{2 \alpha}$ (1: 10000, \#2061) were from Santa Cruz Biotechnology (Santa Cruz, CA).

\section{Cell culture and Treatments}

Experiments were performed using low passage number (less than 10 passages) bovine mammary epithelial cell line MacT. Cells were cultured in Dulbecco's modified Eagle's medium/Nutrient F-12 Ham (DMEM/F12) containing 10\% fetal bovine serum, 
$100 \mathrm{U}$ penicillin, $0.01 \mathrm{mg}$ streptomycin, and $0.25 \mu \mathrm{g} / \mathrm{mL}$ amphotericin $\mathrm{B}(1 \times$ antibiotic/antimycotic solution). Cells were routinely maintained at $37^{\circ} \mathrm{C}$ in $5 \% \mathrm{CO}_{2}$.

For mTOR kinase experiments, cells were seeded in 6-well plates at a density of 3 $\times 10^{5} /$ well. After reaching $80 \%$ confluency, cells were serum-starved for $24 \mathrm{~h}$. For protein detection, cells were treated with indicated chemicals for $6 \mathrm{~h}$. An initial chemical concentration and treatment time were screened from literature values and the lowest effective concentration and time were chosen and used at the following concentration: $100 \mathrm{ng} / \mathrm{mL}$ insulin, $100 \mathrm{nM}$ rapamycin, $250 \mathrm{nM}$ Torin1, $10 \mu \mathrm{M}$ CHIR99021. For mRNA measurement, cells were treated with indicated reagents for $24 \mathrm{~h}$.

For nuclear and cytoplasmic protein extraction, cells were seeded in $100 \mathrm{~mm}$ plates at $3 \times 10^{6}$ cells /plate. After reaching $80 \%$ confluency, cells were serum-starved for $24 \mathrm{~h}$. Cells were treated with $100 \mathrm{ng} / \mathrm{mL}$ insulin or $100 \mathrm{ng} / \mathrm{mL}$ insulin and $250 \mathrm{nM}$ Torin 1 for another $6 \mathrm{~h}$.

For fatty acid treatments, either linoleic acid or t10, c12-CLA, were dissolved in $100 \mathrm{mM} \mathrm{NaOH}$, diluted in fatty acid free-BSA DMEM/F12 medium at 2.5 to 1 ratio (5 $\mathrm{mM}$ fatty acid to $2 \mathrm{mM}$ BSA). $75 \mu \mathrm{M} \mathrm{t10,} \mathrm{c12-CLA,} 10 \mu \mathrm{M}$ AMPK inhibitor dorsomorphin was determined from literature and used in this experiment.

For glucose treatment, glucose was prepared at stock solution $(2.5 \mathrm{M})$ in $\mathrm{dH}_{2} \mathrm{O}$. Serum free, glucose free culture medium was prepared from no-glucose DMEM medium supplementing with L-glutamin, sodium bicarbonate. The next morning after seeding, cells will switch to treatment medium for $1 \mathrm{~h}$, then add designated concentrations of glucose $(0,1,5,25 \mathrm{mM})$, and continue to incubate for another $12 \mathrm{~h}$.

\section{Gene Knockdown by siRNA}


siRNAs were delivered to cells by DharmaFECT reagent \#2 (Dharmacon) at 100 nM according to the manufacturer's protocol. Treatment included two specific siRNAs against SREBP1 (siRNA: 5'-ccacaacgccaucgagaaauu-3' and 5'-gcaccgaggccaaguugaauu3'), siRNA with a random sequence as negative control (NEG) and transfection reagent alone as untransfected control $(\mathbf{C})$. Transfection reagent was removed after $24 \mathrm{~h}$ and replenished with culture medium without serum. Cells were incubated for $24 \mathrm{~h}$ then proceeded to treatment.

\section{Protein preparation and Western blot analysis}

Whole cell lysates were prepared with cold lysis buffer (50 mM Tris, $\mathrm{pH} 7.4$, 0.5\% Triton X-100, 0.3 M NaCl, 2 mM EDTA, pH 8.0, and PIC). For phosphorylated proteins, vanadate was added to the buffer as phosphatase inhibitor in addition to PIC. Cytosolic and nuclear proteins were extracted and separated using the NE-PER Nuclear and Cytoplasmic Extraction Reagents kit (Thermo, Rockford, IL) according to the manufacturer's instructions. Protein concentrations were determined using the Bradford Assay (Bio-Rad, Hercules, CA). Samples were diluted to equal amounts of proteins (60 $\mu \mathrm{g}$ ) and heated at $95{ }^{\circ} \mathrm{C}$ for 5 min after adding $2 \times$ Laemmli sample buffer (Sigma Chemical Co., St. Louis, MO). LaminB1 and MEK1/2 were used as loading controls for the nuclear and the cytoplasmic fractions, respectively. And $\beta$-Actin was used as loading control for whole cell lysates. Proteins were separated by SDS-PAGE using 7.5 and $12 \%$ PAGEr Gold PlusPreCast SDS-polyacrylamide gels (Lonza, Rockland, ME), and transferred to Western blot PVDF membrane (Bio-Rad, Hercules, CA). Membranes were then blocked in 5\% nonfat milk TBS-T blocking buffer (0.05 M Tris pH 7.4, $0.2 \mathrm{M} \mathrm{NaCl}$, $0.1 \%$ Tween, and $5 \%$ dried non-fat milk) on a rocker for $1 \mathrm{~h}$ at room temperature. 
Membranes were probed with the indicated primary antibodies, then detected with secondary antibodies, and developed using ECL-plus chemiluminescence subtract (Amersham Biosciences, Pittsburgh, PA) according to the manufacturer's instructions. Chemiluminescene was measured using a Chemicdoc XRS digital imaging system and densitometry was performed using Quantity One software (Bio-Rad, Hercules, CA).

\section{RT-PCR and real-time PCR (qPCR)}

Total RNA was extracted from cells using TRI Reagent (Molecular Research Center Inc., Cincinnati, $\mathrm{OH})$ according to the manufacturer's instructions. RNA pellets were resuspended in RNase-free $\mathrm{H}_{2} \mathrm{O}$ and concentrations were quantified at $260 \mathrm{~nm}$ using a NanoDrop 1000 spectrophotometer (Thermo Fisher Scientific Inc., Wilmington, DE). 2 $\mu \mathrm{g}$ RNA per reaction were reversed transcribed to its cDNA using the Omniscript RT kit (Qiagen, Valencia, CA) according to the manufacturer's instructions and Oligo-dT (Eurofins MWG/Operon, Huntsvile, AL) as the primer. Real-time PCR was performed using the Quantitect SYBR Green PCR kit (Qiagen) in an Applied Biosystems 7300 Real-time PCR machine (Foster City, CA). Reactions were as follows: 1 cycle at $95{ }^{\circ} \mathrm{C}$ for $10 \mathrm{~min}$, followed by 40 cycles at $95^{\circ} \mathrm{C}$ for $30 \mathrm{secs}, 58^{\circ} \mathrm{C}$ for $30 \mathrm{secs}$, and $72{ }^{\circ} \mathrm{C}$ for 1 min. Each reaction was performed in duplicate wells.

Five genes encoding lipogenic enzymes in lipogenesis (Ma and Corl, 2012) were selected and the effect of mTOR activity on their mRNA abundance by qPCR was examined. These genes included fatty acid synthase (FASN), fatty acid binding protein 3 (FABP3), stearoyl-CoA desaturase 1 (SCD1), glycerol-3-phosphate acyltransferase (GPAT) and SREBP1. Relative quantification of these gene transcripts was determined using the geometric mean of three pairs of endogenous controls, beta-2-microglobulin 
(B2M), eukaryotic translation initiation factor 3 subunit K (EIF3K) and ribosomal protein S15 (RPS15). Primer amplification efficiency was tested with dilutions of primers, which generated a standard curve and the slope was used to calculate the efficiency. The range from 95 to $105 \%$ was considered acceptable. Fold change was calculated using $2^{-\Delta \Delta} \mathrm{Ct}$ method (Livak and Schmittgen, 2001) with control treatment as the calibrator. Gene-specific primers for the transcripts used in the study are shown in Table 1.

\section{Statistical Analysis}

All data were analyzed using the MIXED procedure (SAS 9.4, SAS institute Inc., Cary NC). The model included the treatment as a fixed effect and experiment replicate as a random effect. Post-test comparison were carried out using Tukey's test for pairwise comparisons. Differences were considered significant when $p<0.05$. Results were graphed using GraphPad Prism 7 (GraphPad software, San Diego, CA). Each experiment was repeated at least three times.

\section{Results}

\section{mTOR kinase affects SREBP1 levels in MacT}

The effect of mTOR kinase activity on SREBP1 levels was determined. Insulin was applied to activate mTOR (Appuhamy et al., 2012), and rapamycin and Torin1 were used to inhibit mTOR activity (Peterson et al., 2011). To further confirm the extent of inhibition of mTOR, insulin was added to the cells after 30 min of rapamycin or Torin 1 incubation. Insulin significantly increased mTOR phosphorylation by over $90 \%$, while rapamycin and Torin 1 effectively suppressed mTOR phosphorylation compared to the phosphorylation of mTOR. There was no significant difference in the inhibitory effect of 
mTOR between rapamycin or Torin 1 as well as the inhibitor groups and control (Figure 1 a-b). Next, activated mTOR stimulated expression of precursor SREBP1 (pSREBP1) and matured SREBP1 (mSREBP1) by 51 and 67\%, respectively (Figure 5.1 a, c). The stimulatory effect diminished when rapamycin or Torin1 was added in the medium, while no significant difference between rapamycin/Torin1 containing group and control was detected (Figure 5.1 a, c).

\section{mTOR kinase affects lipogenic gene expression in MacT}

Insulin increased mRNA abundance of SREBP1, FASN and SCD1 by 55\%, $90 \%$ and $69 \%$, respectively after $24 \mathrm{~h}$ incubation (Figure 5.2 a, b, d). Addition of mTOR inhibitors, especially Torin1, removed the stimulatory effect of insulin and reduced the expression of these gene to be not different from control group. Insulin increased FABP3, to our surprise, by over 10-fold, which indicated mTOR signaling effectively promoted preformed long chain fatty acid transport (Figure 5.2 c). However, insulin failed to elicit a response of mRNA expression of GPAT which remained unchanged with either treatment $(p=0.09)$. To be noted, the mRNA expression of these genes responded differently to the two mTOR inhibitors. Rapamycin failed to inhibit SREBP1 and FASN mRNA expression while Torin1 effectively down-regulated the expression of these transcripts compared with insulin group (Figure 5.2 a-b).

\section{mTOR kinase affects lipogenic gene transcription via SREBP1}

SREBP1 is known to be the master transcription factor of lipogenic genes (Bionaz and Loor, 2008b). Whether mTOR kinase regulated lipogenic gene transcription via SREBP1 or in a parallel manner analogous to SREBP1 was determined. Knockdown of SREBP1 by siRNA was established. pSREBP1 and mSREBP1 were reduced by $75 \%$ and 
59\%, respectively (Figure 5.3 a-b). The presence of insulin increased both oprotein and mRNA level of SREBP1 as well as the phosphorylation of mTOR in untransfected cells or cells transfected with nonsense siRNA (Figure 5.3 a-b). Knockdown of SREBP1 downregulated the mRNA levels of SREBP1 (87\%), FASN (41\%), SCD1 (33\%) and FABP3 (29\%) but not GPAT (Figure $3 \mathbf{c - g}$ ). For those decreased genes, insulin treatment failed to rescue the lipogenic gene expression except FABP3, which increased about 2fold compared to control.

mTOR kinase affects cytoplasmic CRTC2 phosphorylation, Lipin1 cellular redistribution and GSK3-dependent proteasomal degradation

Insulin-induced mTOR increased cytoplasmic ratio of p-CRTC2/t-CRTC2 by 42\% compared to that of the Torin1-treated groups (Figure 5.5a, c). Nuclear CRTC2 phosphorylation was unaffected even though mTOR was activated, but p-CRTC2 had a higher expression level in both group (Figure 5.5a). Insulin increased cytoplasmic Lipin1 significantly by $70 \%$, while it tended to increase nuclear level of Lipin 1 compared to that of Torin1 group $(p=0.0936)($ Figure 5.5a-b).

Insulin increased mTOR phosphorylation as Figure 1 shows, while Torin1 abolished the insulin effect. CHIR99021, a GSK3 inhibitor, had no effect on mTOR phosphorylation (Figure 5.4a). Torin 1 decreased pSREBP1 and mSREBP1 expression by $20 \%$ and 30\%, respectively, compared with insulin group (Figure 5.4 a-b). Adding CHIR99021 to block GSK activity restored pSREBP1 and mSREBP1 expression significantly more than the insulin group $(p=0.03)$ and to a level comparable to insulin group (Figure 5.4 b). Adding CHIR99021 to insulin treatment further increased 
pSREBP1 and mSREBP1 by 55\% and 35\%, respectively, compared to insulin group (Figure 5.4).

\section{Glucose activated SREBP1 through SCAP}

Glucose increased SCAP expression in a dose-dependent pattern and reached significance at $5 \mathrm{mM}$ with a $35 \%$ increase for $12 \mathrm{~h}$ incubation compared to no glucose group (Figure 5.6 a-b). Further extending incubation without glucose devastated the viability of cells (data not shown). Glucose incubation also increased SCAP expression in a time-dependent pattern when MacT cells were incubated with $5 \mathrm{mM}$ glucose from 0 to $24 \mathrm{~h}$ (data not shown). Along with increased SCAP protein expression, glucose availability also affected SREBP1 protein expression. pSREBP1 and mSREBP1 increased accordingly as glucose concentration increased. To be noted, glucose was sufficient to increase mSREBP1 by $223 \%$ as low as $1 \mathrm{mM}$ glucose; further increasing glucose concentration maintained the over 2-fold mSREBP1 expression in treatment group compared to control (Figure 5.6a-b).

\section{t10, c12-CLA increases AMPK activity}

t10, c12-CLA (CLA) increased AMPK phosphorylation by 94\%, while linoleic acid (LA) also increased AMPK phosphorylation to a lesser extent but still significantly higher than control (Figure 5.7a-b). CLA decreased pSREBP1 by 50\% as LA decreased it to a comparable $44 \%$ (Figure 5.7c). To be noted, the AMPK phosphorylation was abated with dorsomorphin addition, an AMPK inhibitor, to only about $31 \%$ increase, but still significantly higher that control $(p=0.022)$. When dorsomorphin was added, it partially rescued the reduction of pSREBP1 to only decrease about $22 \%$, but still significantly lower than control $(p=0.0028)$ (Figure 5.7c). 


\section{Discussion}

Milk fat synthesis consumes over one third of energy intake in dairy cows during early lactation (Bauman et al., 2008). This is the maternal nature of mammals to provide energy for their neonate even in severe negative energy balance. The reasons to spare energy and prioritize for mammary fatty acid synthesis and output are not well characterized. Insulin plays a role in coordinating energy partitioning and maintaining normal mammary functions (Bauman and Griinari, 2003, Osorio et al., 2016). During mid-lactation, when cows return to positive energy balance, insulin's effect might direct adipose tissue use of mammary fatty acid precursors and cause milk fat depression (MFD). However, elevated circulating insulin failed to elicit MFD (McGuire et al., 1995, Griinari et al., 1997, Baumgard et al., 2000, Corl et al., 2006). One possibility is the insulin induced local cellular signaling exerts a counter-effect reserving the capability of mammary nutrient uptake for fatty acid synthesis.

From this study, change of mTOR signaling regulated lipogenesis via SREBP1. First of all, insulin activated mTOR phosphorylation in MacT cells and the dosage (100 $\mathrm{ng} / \mathrm{mL}$ ) to achieve the optimal activation of mTOR was consistent with a previous study (Appuhamy et al., 2011). However, the pathways that high insulin concentration-induced mTOR signaling was not resolved in the current experiment. It is possible that insulin bound to insulin like growth factor -1 receptor (IGF-1R) thus activated Akt (van Heemst, 2010) while mTOR was the downstream target of Akt (Yecies et al., 2011). Rapamycin (Chiang and Abraham, 2005, Sobolewska et al., 2009, Rosner et al., 2010) and Torin1 (Francipane and Lagasse, 2013, Atkin et al., 2014) effectively inhibited mTOR phosphorylation and is consistent with other reports. However, no further reduction in 
mTOR phosphorylation in inhibitor containing groups compared to control (Figure 5.1ab). The mTOR phosphorylation might be low at the start of the experiment due to the cell synchronization and no serum present across treatments throughout the study (Yonezawa et al., 2006, Appuhamy et al., 2012, Suzuki et al., 2015). The reason for using two mTOR inhibitors was the discrepancy of rapamycin induced mTOR inhibition on lipogenic gene expression and different cell types (Thoreen and Sabatini, 2009, Peterson et al., 2011).

Secondly, increased SREBP1 expression due to activated mTOR was consistent with previous reports (Porstmann et al., 2008, Yecies et al., 2011). The effect of mTOR on lipogenic gene expression was demonstrated. Activated mTOR increased the mRNA expression of SREBP1 as well as the selected lipogenic genes, while mTOR inhibition reduced lipogenic gene expression. These finding confirmed that the role of mTOR in lipogenesis in bovine mammary gland (Osorio et al., 2016). These results were in agreement with reports in primary hepatocyte and adipocyte culture (Peterson et al., 2011, Yecies et al., 2011) but in disagreement with a report in bovine mammary explant culture (Shao et al., 2013). They reported insulin had a time-dependent response on lipogenic gene expression, but the treatment length and dosage were different from ours.

Lastly, whether mTOR induced lipogenesis was through SREBP1 or a parallel stimulatory effect along with SREBP1 was evaluated. siRNA-directed SREBP1 knockdown decreased SREBP1 protein and mRNA expression as well as other lipogenic genes, which is consistent with a previous report (Ma and Corl, 2012). Addition of insulin activated mTOR phosphorylation, but failed to rescue the reduction in lipogenic gene expression, indicating that mTOR signaling activated lipogenesis through SREBP1. 
Three potential regulatory pathways of mTOR signaling on SREBP1 activation were tested in the current study. Firstly, mTOR regulated SREBP1 transport through CRTC2, a central regulator of gluconeogenesis (Wang et al., 2009), which acts as a suppressor in lipogenesis (Han et al., 2015b). Dephosphorylated CRTC2 was associated with one of the COP-II subunits Sec31 (Bi et al., 2007). Activated mTOR phosphorylated CRTC2 and disrupted the interaction between CRTC2 and Sec31, which interacted with Sec23, another COP-II subunit, allowing COP-II dependent SREBP1 to transport to GA for proteolytic processing. The results showed that insulin-induced mTOR increased phosphorylation of cytoplasmic CRTC2, indicating less CRTC would interfere SREBP1 transport. However, nuclear CRTC2 was not regulated by mTOR, which was consistent with a previous report (Han et al., 2015b). Considering the serum starvation during the study, it might explain why nuclear CRCT2 was highly phosphorylated in both groups.

Secondly, mTOR regulated nuclear entry of SREBP1 via phosphorylation of Lipin1 (Peterson et al., 2011). Dephosphorylated Lipin1 resides in outer membrane of nucleus. Lipin1 alters the structure of Lamin A, one of the nuclear matrix proteins, and prevents mature SREBP1 access to DNA (Peterson et al., 2011). On the other hand, Lipin1 served as a component of nuclear receptor PPAR $\alpha /$ PGC1- $\alpha$ complex, promoted mitochondrial fatty acid oxidation(Finck et al., 2006). mTOR phosphorylates Lipin1 and relocates it to cytosol where it serves as a phosphate phosphatase to promote triglyceride synthesis. Increased cytoplasmic Lipin1 expression was observed with insulin treatment. Increased cytoplasmic Lipin1 promoted lipid accumulation in hepatocytes ( $\mathrm{Hu}$ et al., 2012). However, no significant decrease of nuclear Lipin1 was observed, which was contradictory to my hypothesis. Given that Lipin1 is also a SREBP1 target gene 
(Ishimoto et al., 2009, Ma and Corl, 2012), it may be that relatively short treatment period used in this experiment was not be adequate to elicit a response of nuclear Lipin1 expression.

Lastly, mTOR inhibits GSK3-dependent proteasomal degradation of SREBP1 (Li et al., 2015). GSK3 phosphorylated serine 73 of pSREBP1, lowered its affinity for SCAP, thus exposed it to the ubiquitin ligase complex of F-box and WD domain containing protein $7\left(\mathrm{SCF}^{\mathrm{fbw} 7}\right)$ which leads to proteasomal degradation (Sundqvist et al., 2005, Dong et al., 2015). Nutrition starvation (Dong et al., 2015) or mTORC2 inhibition (Li et al., 2015) will induce activation of GSK3, and thus promotes SREBP1 degradation. Torin1 inhibited mTORC2 (Smrz et al., 2011) and thus led to SREBP1 degradation, as observed in current study. Addition of the GSK3 inhibitor CHIR99021 effectively reversed this process, indicating mTORC2 regulates SREBP1 degradation. Treated in combination with insulin, CHIR99021, as expected, had an additive effect on protein expression and activation of SREBP1.Taken together, the data supported the role of insulin-induced mTOR signaling on SREBP1 activation by facilitating transport to the GA, access to nucleus and inhibition of protein degradation, thus stimulated mammary lipogenesis.

Our data showed that t10, c12-CLA increased AMPK phosphorylation, which was consistent with the findings in adipocytes (Jiang et al., 2009). In current study, linoleic acid treatment, which served as a fatty acid control, also activated AMPK to a lesser extent, contradictory to previous report in 3T3-L1 adipocytes (Jiang et al., 2012). Li et al (Li et al., 2013) reported that NEFA supplement, which contained a portion of linoleic acid, increased AMPK phosphorylation in bovine hepatocytes. Activated AMPK phosphorylated pSREBP1 and blocked its further activation in hepatocytes (Li et al., 
2011). CLA-induced pSREBP1 reduction was attenuated by dorsomorphin-induced AMPK inhibition. More evidence of AMPK regulation was found in mammary epithelial cells. McFadden and Corl (McFadden and Corl, 2009) also found that AMPK caused decreased in de novo fatty acid synthesis by increasing acetyl-CoA carboxylase- $\alpha$ (ACC) phosphorylation but a compensatory increase of SREBP1 mRNA expression. Burgos et al. (Burgos et al., 2013) reported AMPK repressed mTORC1 signaling under energy deficiency. Appuhamy et al. (Appuhamy et al., 2014) argued that, essential amino acids (EAAs), as energy substrates to activate mTOR phosphorylation, might overshadow the negative effect from AMPK. Future studies are warranted to reveal the mechanism of CLA inducing AMPK phosphorylation and its essential role in energy balance to regulate lipid metabolism in bovine mammary gland.

Supplementing t10, c12-CLA reduced endogenous glucose production in dairy cows (Hotger et al., 2013). Activation of AMPK might account for the reduction, and increased glucose uptake and decreased lipogenic gene transcription (Zhang et al., 2011). Extra glucose might partition toward fatty acid synthesis by up-regulating lipogenic gene expression (Liu et al., 2013). Cheng et al. (Cheng et al., 2015) identified SCAP acted as a glucose responsive protein, and was essential for SREBP1 activation and SREBP1dependent lipogenesis. Even when glucose level was low, as long as one of the three Nglycosylated sites on SCAP was activated, it was sufficient to maintain SCAP expression (Cheng et al., 2015). These findings indicated glucose affected lipid metabolism through regulation of SREBP1. Glucose effectively increased SREBP1 activation. Even though the increase of SCAP did not reach significance, the activation of SREBP1 was significantly increased at glucose concentrations above $1 \mathrm{mM}$. The glucose effect on 
SCAP expression exhibited a dose-dependent and time-dependent pattern. The same pattern was seen in SREBP1 activation as well. Taken together, glucose is not only pivotal for lactose synthesis, but also regulates lipid metabolism through activation of SREBP1.

In conclusion, activation of mTOR signaling, AMPK phosphorylation and glucose availability are the potential regulators on SREBP1 activation in bovine mammary epithelial cells. Their potential regulatory pathways were summarized in

Figure 5.8, insulin-induced mTOR signaling regulates lipogenesis via SREBP1. And the stimulatory effect is based on the regulation on CRTC2, Lipin1 and GSK3-dependent proteosomal degradation. CLA inhibits SREBP1 activation through AMPK phosphorylation but further research on the mechanism of CLA-induced AMPK activation is needed. Glucose availability stabilizes SCAP through glycosylation, facilitating SREBP1 activation. These findings provide preliminary data for investigating nutrient availability, especially energy supply on SREBP1 activation.

\section{References}

1. Bionaz, M. (2012) Milk Protein Synthesis in the Lactating Mammary Gland: Insights from Transcriptomics Analyses,

2. Appuhamy, J. A., Bell, A. L., Nayananjalie, W. A., Escobar, J., and Hanigan, M. D. (2011) Essential Amino Acids Regulate Both Initiation and Elongation of Mrna Translation Independent of Insulin in Mac-T Cells and Bovine Mammary Tissue Slices. The Journal of Nutrition 141, 1209-1215

3. Porstmann, T., Santos, C. R., Griffiths, B., Cully, M., Wu, M., Leevers, S., Griffiths, J. R., Chung, Y. L., and Schulze, A. (2008) Srebp Activity Is Regulated by Mtorc1 and Contributes to Akt-Dependent Cell Growth. Cell metabolism 8, 224-236

4. Laplante, M., and Sabatini, D. M. (2009) An Emerging Role of Mtor in Lipid Biosynthesis. Current Biology 19, R1046-R1052

5. Yecies, J. L., Zhang, H. H., Menon, S., Liu, S., Yecies, D., Lipovsky, A. I., Gorgun, C., Kwiatkowski, D. J., Hotamisligil, G. S., Lee, C. H., and Manning, B. D. (2011) Akt Stimulates Hepatic Srebp1c and Lipogenesis through Parallel Mtorc1-Dependent and Independent Pathways. Cell metabolism 14, 21-32 
6. Yuan, M., Pino, E., Wu, L., Kacergis, M., and Soukas, A. A. (2012) Identification of AktIndependent Regulation of Hepatic Lipogenesis by Mammalian Target of Rapamycin (Mtor) Complex 2. The Journal of Biological Chemistry 287, 29579-29588

7. Han, J., Li, E., Chen, L., Zhang, Y., Wei, F., Liu, J., Deng, H., and Wang, Y. (2015) The Creb Coactivator Crtc2 Controls Hepatic Lipid Metabolism by Regulating Srebp1.

Nature

8. Peterson, T. R., Sengupta, S. S., Harris, T. E., Carmack, A. E., Kang, S. A., Balderas, E., Guertin, D. A., Madden, K. L., Carpenter, A. E., Finck, B. N., and Sabatini, D. M. (2011) Mtor Complex 1 Regulates Lipin 1 Localization to Control the Srebp Pathway. Cell 146, 408-420

9. Li, S., Oh, Y. T., Yue, P., Khuri, F. R., and Sun, S. Y. (2015) Inhibition of Mtor Complex 2 Induces Gsk3/Fbxw7-Dependent Degradation of Sterol Regulatory Element-Binding Protein 1 (Srebp1) and Suppresses Lipogenesis in Cancer Cells. Oncogene

10. McFadden, J. W., and Corl, B. A. (2009) Activation of Amp-Activated Protein Kinase (Ampk) Inhibits Fatty Acid Synthesis in Bovine Mammary Epithelial Cells. Biochemical and biophysical research communications 390, 388-393

11. Li, X., Li, X., Chen, H., Lei, L., Liu, J., Guan, Y., Liu, Z., Zhang, L., Yang, W., Zhao, C., Fu, S., Li, P., Liu, G., and Wang, Z. (2013) Non-Esterified Fatty Acids Activate the Amp-Activated Protein Kinase Signaling Pathway to Regulate Lipid Metabolism in Bovine Hepatocytes. Cell biochemistry and biophysics 67, 1157-1169

12. Li, Y., Xu, S., Mihaylova, M. M., Zheng, B., Hou, X., Jiang, B., Park, O., Luo, Z., Lefai, E., Shyy, J. Y., Gao, B., Wierzbicki, M., Verbeuren, T. J., Shaw, R. J., Cohen, R. A., and Zang, M. (2011) Ampk Phosphorylates and Inhibits Srebp Activity to Attenuate Hepatic Steatosis and Atherosclerosis in Diet-Induced Insulin-Resistant Mice. Cell metabolism 13, 376-388

13. Jiang, S., Wang, W., Miner, J., and Fromm, M. (2012) Cross Regulation of Sirtuin 1, Ampk, and Ppargamma in Conjugated Linoleic Acid Treated Adipocytes. PloS one 7, e48874

14. Cheng, C., Ru, P., Geng, F., Liu, J., Yoo, J. Y., Wu, X., Cheng, X., Euthine, V., Hu, P., Guo, J. Y., Lefai, E., Kaur, B., Nohturfft, A., Ma, J., Chakravarti, A., and Guo, D. (2015) Glucose-Mediated N-Glycosylation of Scap Is Essential for Srebp-1 Activation and Tumor Growth. Cancer Cell 28, 569-581

15. Kimura, N., Tokunaga, C., Dalal, S., Richardson, C., Yoshino, K., Hara, K., Kemp, B. E., Witters, L. A., Mimura, O., and Yonezawa, K. (2003) A Possible Linkage between AmpActivated Protein Kinase (Ampk) and Mammalian Target of Rapamycin (Mtor)

Signalling Pathway. Genes Cells 8, 65-79

16. Danai, L. V., Guilherme, A., Guntur, K. V., Straubhaar, J., Nicoloro, S. M., and Czech, M. P. (2013) Map4k4 Suppresses Srebp-1 and Adipocyte Lipogenesis Independent of Jnk Signaling. Journal of lipid research 54, 2697-2707

17. Ma, L., and Corl, B. A. (2012) Transcriptional Regulation of Lipid Synthesis in Bovine Mammary Epithelial Cells by Sterol Regulatory Element Binding Protein-1. Journal of Dairy Science 95, 3743-3755

18. Livak, K. J., and Schmittgen, T. D. (2001) Analysis of Relative Gene Expression Data Using Real-Time Quantitative Pcr and the 2(-Delta Delta C(T)) Method. Methods 25, 402-408

19. Appuhamy, J. A., Knoebel, N. A., Nayananjalie, W. A., Escobar, J., and Hanigan, M. D. (2012) Isoleucine and Leucine Independently Regulate Mtor Signaling and Protein Synthesis in Mac-T Cells and Bovine Mammary Tissue Slices. The Journal of Nutrition 142, 484-491

20. Bionaz, M., and Loor, J. J. (2008) Gene Networks Driving Bovine Milk Fat Synthesis During the Lactation Cycle. BMC genomics 9, 366 
21. Bauman, D. E., Perfield, J. W., 2nd, Harvatine, K. J., and Baumgard, L. H. (2008) Regulation of Fat Synthesis by Conjugated Linoleic Acid: Lactation and the Ruminant Model. The Journal of Nutrition 138, 403-409

22. Bauman, D. E., and Griinari, J. M. (2003) Nutritional Regulation of Milk Fat Synthesis. Annual review of nutrition 23, 203-227

23. Osorio, J. S., Lohakare, J., and Bionaz, M. (2016) Biosynthesis of Milk Fat, Protein, and Lactose: Roles of Transcriptional and Posttranscriptional Regulation. Physiological genomics 48, 231-256

24. McGuire, M. A., Griinari, J. M., Dwyer, D. A., and Bauman, D. E. (1995) Role of Insulin in the Regulation of Mammary Synthesis of Fat and Protein. Journal of Dairy Science 78, 816-824

25. Griinari, J. M., McGuire, M. A., Dwyer, D. A., Bauman, D. E., and Palmquist, D. L. (1997) Role of Insulin in the Regulation of Milk Fat Synthesis in Dairy Cows. Journal of Dairy Science 80, 1076-1084

26. Baumgard, L. H., Corl, B. A., Dwyer, D. A., Saebo, A., and Bauman, D. E. (2000) Identification of the Conjugated Linoleic Acid Isomer That Inhibits Milk Fat Synthesis. American journal of physiology. Regulatory, integrative and comparative physiology 278, R179-184

27. Corl, B. A., Butler, S. T., Butler, W. R., and Bauman, D. E. (2006) Short Communication: Regulation of Milk Fat Yield and Fatty Acid Composition by Insulin. Journal of Dairy Science 89, 4172-4175

28. Chiang, G. G., and Abraham, R. T. (2005) Phosphorylation of Mammalian Target of Rapamycin (Mtor) at Ser-2448 Is Mediated by P70s6 Kinase. The Journal of Biological Chemistry 280, 25485-25490

29. Rosner, M., Siegel, N., Valli, A., Fuchs, C., and Hengstschlager, M. (2010) Mtor Phosphorylated at S2448 Binds to Raptor and Rictor. Amino acids 38, 223-228

30. Sobolewska, A., Gajewska, M., Zarzynska, J., Gajkowska, B., and Motyl, T. (2009) Igf-I, Egf, and Sex Steroids Regulate Autophagy in Bovine Mammary Epithelial Cells Via the Mtor Pathway. European journal of cell biology 88, 117-130

31. Atkin, J., Halova, L., Ferguson, J., Hitchin, J. R., Lichawska-Cieslar, A., Jordan, A. M., Pines, J., Wellbrock, C., and Petersen, J. (2014) Torin1-Mediated Tor Kinase Inhibition Reduces Wee1 Levels and Advances Mitotic Commitment in Fission Yeast and Hela Cells. Journal of cell science 127, 1346-1356

32. Francipane, M. G., and Lagasse, E. (2013) Selective Targeting of Human Colon Cancer Stem-Like Cells by the Mtor Inhibitor Torin-1. Oncotarget 4, 1948-1962

33. Suzuki, Y., Haga, S., Katoh, D., So, K. H., Choi, K. C., Jung, U. S., Lee, H. G., Katoh, K., and Roh, S. G. (2015) Chemerin Is a Novel Regulator of Lactogenesis in Bovine Mammary Epithelial Cells. Biochemical and biophysical research communications 466, 283-288

34. Yonezawa, T., Haga, S., Kobayashi, Y., Takahashi, T., and Obara, Y. (2006) Visfatin Is Present in Bovine Mammary Epithelial Cells, Lactating Mammary Gland and Milk, and Its Expression Is Regulated by Camp Pathway. FEBS letters 580, 6635-6643

35. Thoreen, C. C., and Sabatini, D. M. (2009) Rapamycin Inhibits Mtorc1, but Not Completely. Autophagy 5, 725-726

36. Shao, Y., Wall, E. H., McFadden, T. B., Misra, Y., Qian, X., Blauwiekel, R., Kerr, D., and Zhao, F. Q. (2013) Lactogenic Hormones Stimulate Expression of Lipogenic Genes but Not Glucose Transporters in Bovine Mammary Gland. Domestic animal endocrinology 44, 57-69

37. Wang, Y., Vera, L., Fischer, W. H., and Montminy, M. (2009) The Creb Coactivator Crtc2 Links Hepatic Er Stress and Fasting Gluconeogenesis. Nature 460, 534-537 
38. Bi, X., Mancias, J. D., and Goldberg, J. (2007) Insights into Copii Coat Nucleation from the Structure of Sec23.Sar1 Complexed with the Active Fragment of Sec31.

Developmental cell 13, 635-645

39. Finck, B. N., Gropler, M. C., Chen, Z., Leone, T. C., Croce, M. A., Harris, T. E., Lawrence, J. C., Jr., and Kelly, D. P. (2006) Lipin 1 Is an Inducible Amplifier of the Hepatic Pgc-1alpha/Pparalpha Regulatory Pathway. Cell metabolism 4, 199-210

40. Hu, M., Wang, F., Li, X., Rogers, C. Q., Liang, X., Finck, B. N., Mitra, M. S., Zhang, R., Mitchell, D. A., and You, M. (2012) Regulation of Hepatic Lipin-1 by Ethanol: Role of Amp-Activated Protein Kinase/Sterol Regulatory Element-Binding Protein 1 Signaling in Mice. Hepatology 55, 437-446

41. Ishimoto, K., Nakamura, H., Tachibana, K., Yamasaki, D., Ota, A., Hirano, K., Tanaka, T., Hamakubo, T., Sakai, J., Kodama, T., and Doi, T. (2009) Sterol-Mediated Regulation of Human Lipin 1 Gene Expression in Hepatoblastoma Cells. The Journal of Biological Chemistry 284, 22195-22205

42. Sundqvist, A., Bengoechea-Alonso, M. T., Ye, X., Lukiyanchuk, V., Jin, J., Harper, J. W., and Ericsson, J. (2005) Control of Lipid Metabolism by Phosphorylation-Dependent Degradation of the Srebp Family of Transcription Factors by Scf(Fbw7). Cell metabolism 1, 379-391

43. Dong, Q., Giorgianni, F., Beranova-Giorgianni, S., Deng, X., O'Meally, R. N., Bridges, D., Park, E. A., Cole, R. N., Elam, M. B., and Raghow, R. (2015) Glycogen Synthase Kinase-3-Mediated Phosphorylation of Serine 73 Targets Sterol Response Element Binding Protein-1c (Srebp-1c) for Proteasomal Degradation. Bioscience reports 36

44. Smrz, D., Kim, M. S., Zhang, S., Mock, B. A., Smrzova, S., DuBois, W., Simakova, O., Maric, I., Wilson, T. M., Metcalfe, D. D., and Gilfillan, A. M. (2011) Mtorc1 and Mtorc2 Differentially Regulate Homeostasis of Neoplastic and Non-Neoplastic Human Mast Cells. Blood 118, 6803-6813

45. Jiang, S., Wang, Z., Riethoven, J. J., Xia, Y., Miner, J., and Fromm, M. (2009) Conjugated Linoleic Acid Activates Amp-Activated Protein Kinase and Reduces Adiposity More Effectively When Used with Metformin in Mice. The Journal of Nutrition 139, 2244-2251

46. Burgos, S. A., Kim, J. J., Dai, M., and Cant, J. P. (2013) Energy Depletion of Bovine Mammary Epithelial Cells Activates Ampk and Suppresses Protein Synthesis through Inhibition of Mtorc1 Signaling. Hormone and metabolic research $=$ Hormon- und Stoffwechselforschung = Hormones et metabolisme 45, 183-189

47. Appuhamy, J. A., Nayananjalie, W. A., England, E. M., Gerrard, D. E., Akers, R. M., and Hanigan, M. D. (2014) Effects of Amp-Activated Protein Kinase (Ampk) Signaling and Essential Amino Acids on Mammalian Target of Rapamycin (Mtor) Signaling and Protein Synthesis Rates in Mammary Cells. Journal of Dairy Science 97, 419-429

48. Hotger, K., Hammon, H. M., Weber, C., Gors, S., Troscher, A., Bruckmaier, R. M., and Metges, C. C. (2013) Supplementation of Conjugated Linoleic Acid in Dairy Cows Reduces Endogenous Glucose Production During Early Lactation. Journal of Dairy Science 96, 2258-2270

49. Zhang, N., Li, Q. Z., Gao, X. J., and Yan, H. B. (2011) Potential Role of Adenosine Monophosphate-Activated Protein Kinase in Regulation of Energy Metabolism in Dairy Goat Mammary Epithelial Cells. Journal of Dairy Science 94, 218-222

50. Liu, H., Zhao, K., and Liu, J. (2013) Effects of Glucose Availability on Expression of the Key Genes Involved in Synthesis of Milk Fat, Lactose and Glucose Metabolism in Bovine Mammary Epithelial Cells. PloS one 8, e66092

51. van Heemst, D. 2010. Insulin, IGF-1 and longevity. Aging Dis 1(2):147-157. 
Table

Table 5.1 Primer sequences for transcripts used in real-time quantitative PCR

\begin{tabular}{|c|c|c|c|}
\hline Transcript & Accession number & Primers (5' to 3') & \\
\hline SREBP1 & NM_001113302 & $\begin{array}{l}\text { Forward } \\
\text { Reverse }\end{array}$ & $\begin{array}{l}\text { atgccatcgagaaacgctac } \\
\text { gtccgcagactcaggttctc }\end{array}$ \\
\hline FABP3 & NM_174313.2 & $\begin{array}{l}\text { Forward } \\
\text { Reverse }\end{array}$ & $\begin{array}{l}\text { aagcctaccacaatcatcgaag } \\
\text { ttcaagctgggagtcgagttc }\end{array}$ \\
\hline SCD1 & NM_173959 & $\begin{array}{l}\text { Forward } \\
\text { Reverse }\end{array}$ & $\begin{array}{l}\text { ccctttcettgagctgtctg } \\
\text { atgctgactctctccectga }\end{array}$ \\
\hline FASN & NM_001012669 & $\begin{array}{l}\text { Forward } \\
\text { Reverse }\end{array}$ & $\begin{array}{l}\text { ctgcaactcaacgggaactt } \\
\text { aggctggtcatgttctccag }\end{array}$ \\
\hline GPAT & NM_001012282 & $\begin{array}{l}\text { Forward } \\
\text { Reverse }\end{array}$ & $\begin{array}{l}\text { attgaccttggcacgatag } \\
\text { aacagcaccttcccacaaag }\end{array}$ \\
\hline EIF3k & NM_001034489 & $\begin{array}{l}\text { Forward } \\
\text { Reverse }\end{array}$ & $\begin{array}{l}\text { gcgatgtttgagcagatgag } \\
\text { gcattttctttggcctgtgt }\end{array}$ \\
\hline B2M & NM_173893 & $\begin{array}{l}\text { Forward } \\
\text { Reverse }\end{array}$ & $\begin{array}{l}\text { tgctgaagaatcgggagaag } \\
\text { ccttgctgttgggagtgaa }\end{array}$ \\
\hline RPS15 & XM585783 & $\begin{array}{l}\text { Forward } \\
\text { Reverse }\end{array}$ & $\begin{array}{l}\text { ctctgtgcattcgggttttc } \\
\text { gggctctctgggttcctct }\end{array}$ \\
\hline
\end{tabular}




\section{Figures}

Figure 5.1 mTOR kinase affected SREBP1 levels in MacT.

a

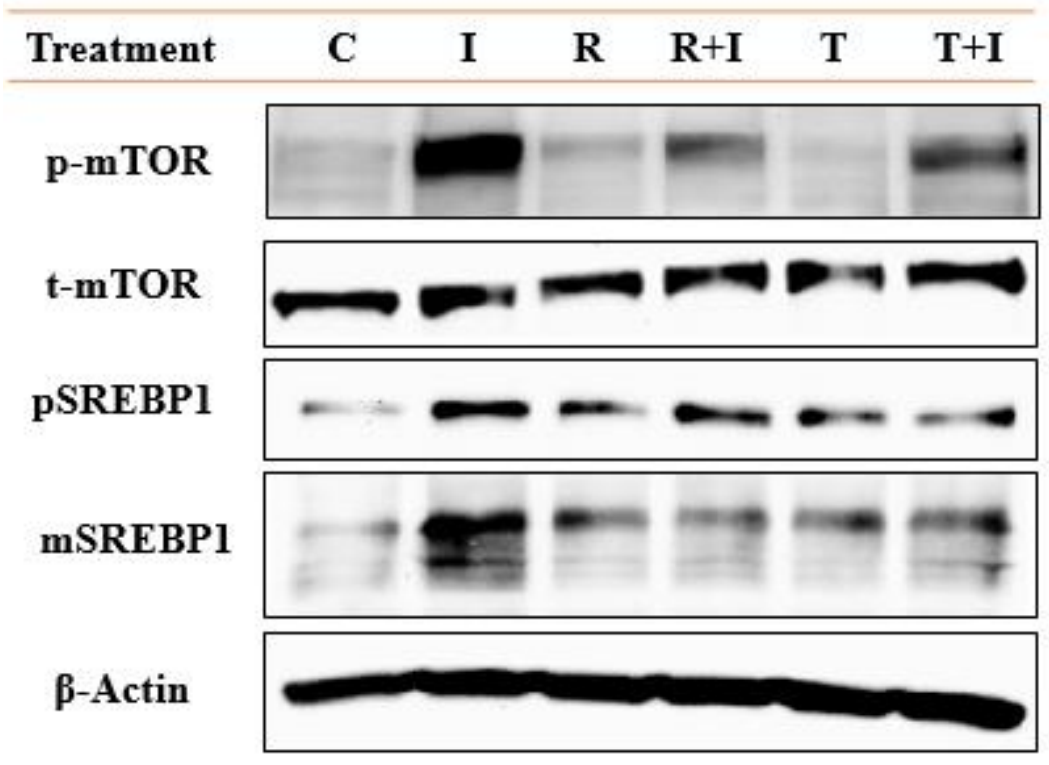

$\mathrm{b}$

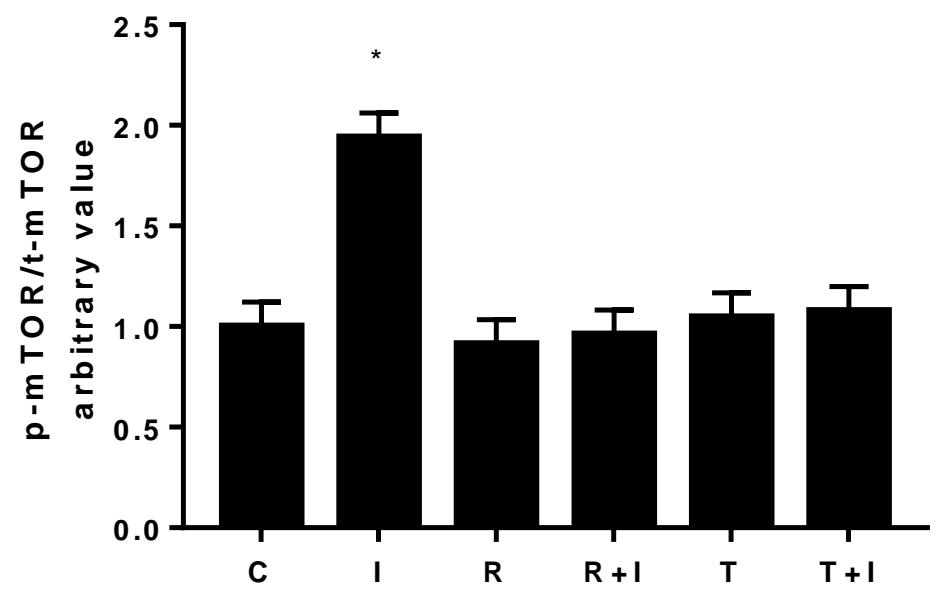




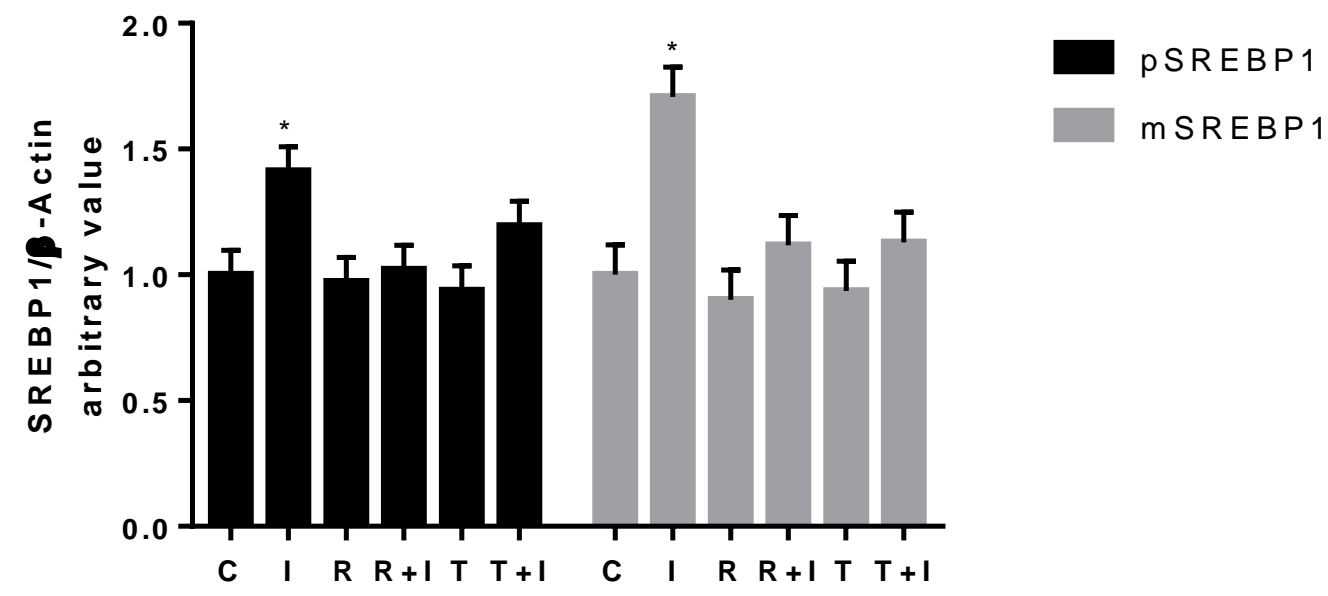

Cells were seeded at 6 -well plates with density of $3 \times 10^{5} /$ well. On the next day, after reaching $80 \%$ confluency, cells were serum-starved for $24 \mathrm{~h}$. Cells were treated with $100 \mathrm{ng} / \mathrm{mL}$ insulin, $100 \mathrm{nM}$ rapamycin, $250 \mathrm{nM}$ Torin1 or DMSO (vehicle) for $6 \mathrm{~h}$. Total protein lysates were extracted, $60 \mu \mathrm{g}$ proteins were analyzed by immunoblotting. Protein bands were visualized and densitometry was quantified and normalized to $\beta$-Actin. Mean $( \pm$ SEM) was compared using Tukey’s test and were considered significant when $p<0.05$. a. Representative immunoblots of p-mTOR/mTOR (256 kDa), pSREBP1 (125 kDa) and mSREBP1 (65 kDa). b. Data represent mean ratio of p-mTOR/ t-mTOR protein abundance $\pm S E M, n=3$. c. Data represent mean pSREBP1 and mSREBP1 protein abundance normalized to $\beta$-actin \pm SEM, $n=3$. C: control; I: insulin; $\mathbf{R}$ : rapamycin; $\mathbf{R}+\mathbf{I}$ : rapamycin + insulin; T: Torin1; $\mathbf{T}+\mathbf{I}$ : Torin1+insulin. 
Figure 5.2 mTOR kinase affected lipogenic gene expression in MacT.
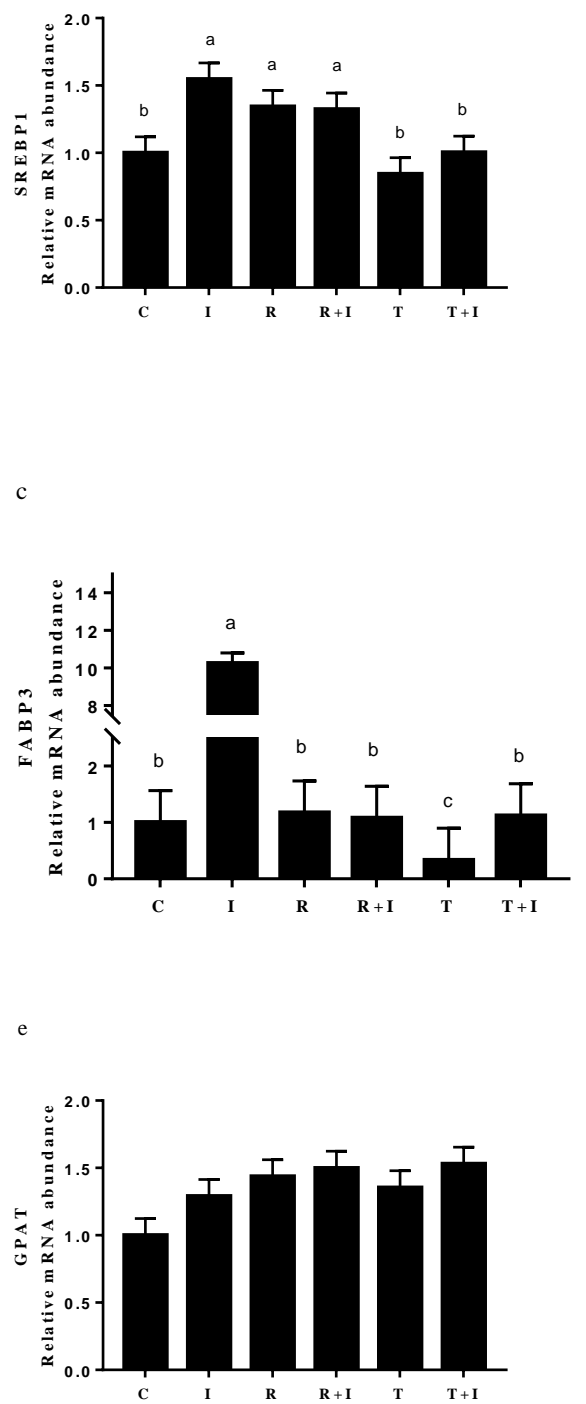

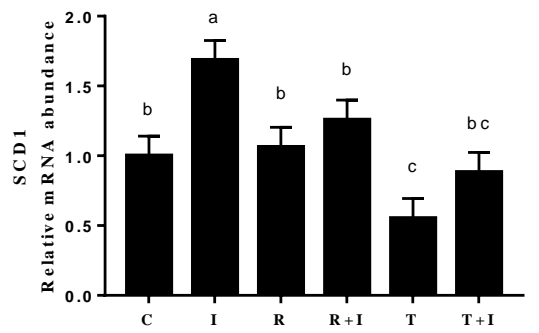

d

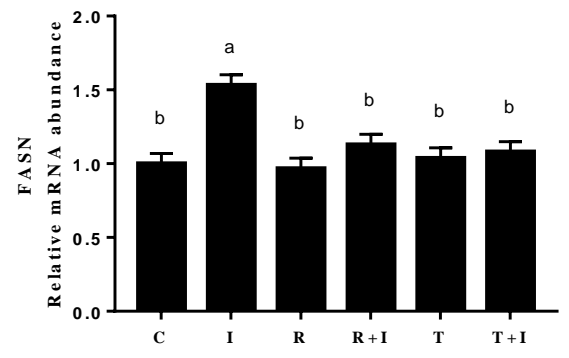

Cells were seeded at 6-well plates with density of $3 \times 10^{5} /$ well. On the next day, after reaching $80 \%$ confluency, cells were serum-starved for $24 \mathrm{~h}$ then treated with $100 \mathrm{ng} / \mathrm{mL}$ insulin, $100 \mathrm{nM}$ rapamycin, $250 \mathrm{nM}$ Torin 1 or DMSO (vehicle) for $24 \mathrm{~h}$. All mRNAs were measured by qPCR and normalized to 3 housekeeping genes B2M, RPS15 and EIF3K. Mean $( \pm$ SEM) was compared using Tukey's test. And difference was considered significant when $p<0.05$. a: SREBP1; b: SCD1; c: FABP3; d: FASN; e: GPAT. 
Figure 5.3 mTOR kinase affected lipogenic gene transcription through SREBP1.

a

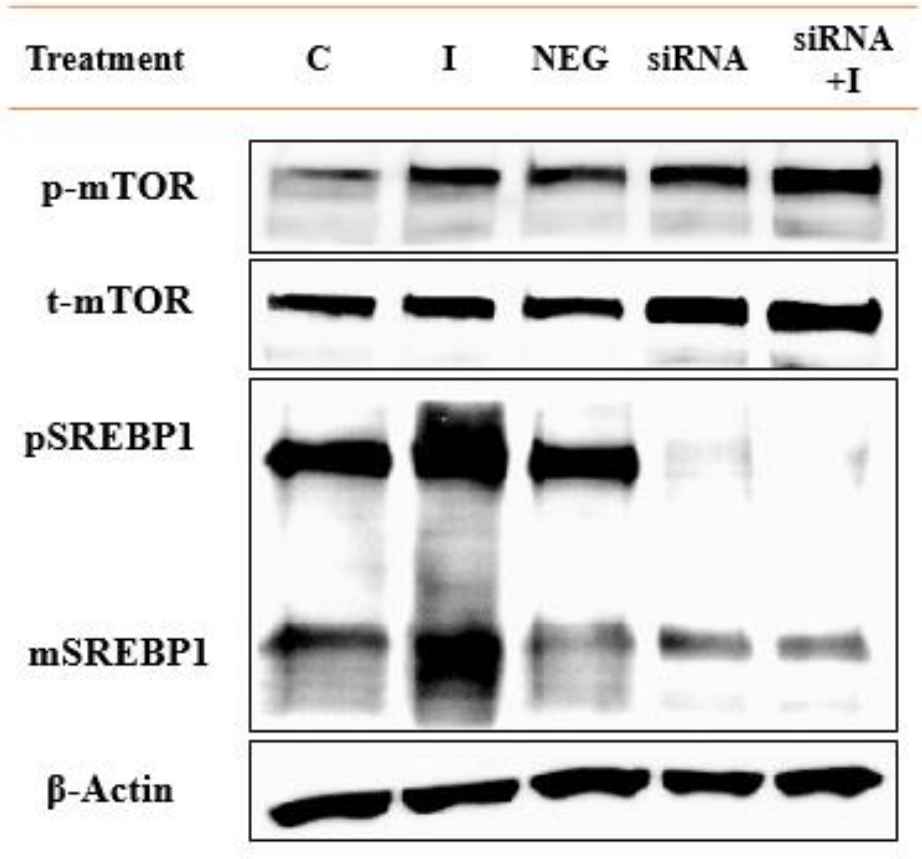

b

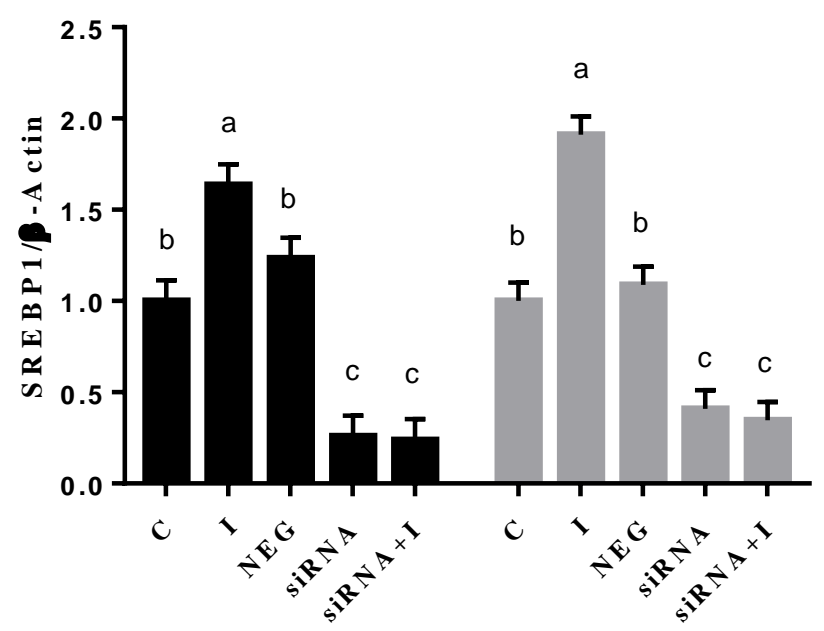

p S R E B P 1

m SREBP 1 
c

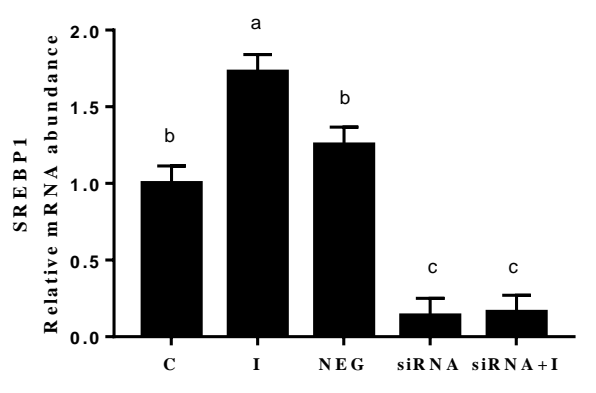

$\mathrm{e}$

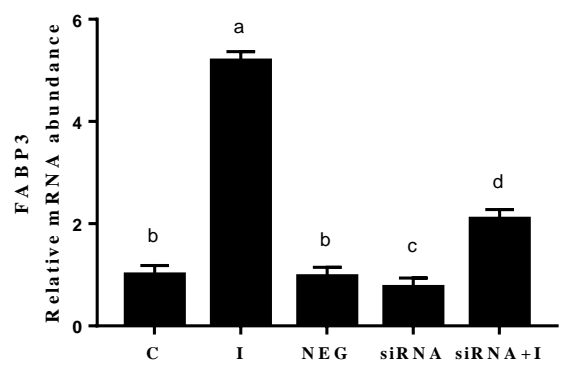

$\mathrm{g}$

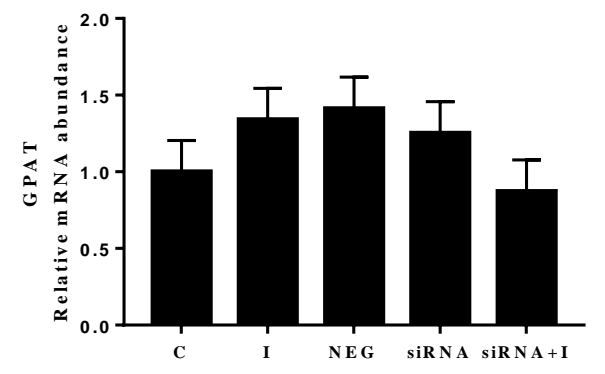

d

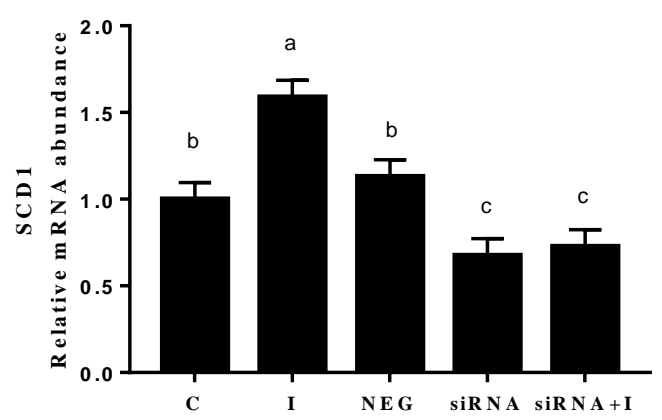

$\mathrm{f}$

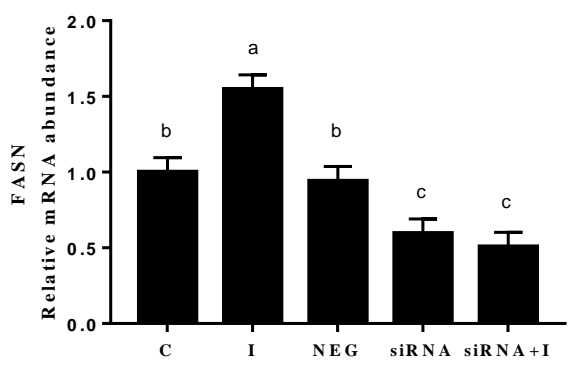

Cells were seeded at 6 -well plates with density of $3 \times 10^{5} /$ well. On the next day, after reaching $80 \%$ confluency, cells were transfected with $100 \mathrm{nM}$ pooled siRNA against SREBP1 (siRNA) or a nontargeting siRNA sequence (NEG) or with transfection reagent only (C) for $24 \mathrm{~h}$ and exchanged to serum-starving medium. Treated Cells were continued to culture for another $24 \mathrm{~h}$, 
then treated with $100 \mathrm{ng} / \mathrm{mL}$ insulin for $6 \mathrm{~h}$. Total protein lysates were extracted, and $60 \mu \mathrm{g}$ proteins were analyzed by immunoblotting. Protein bands were visualized and densitometry was quantified and normalized to $\beta$-Actin. For mRNA measurement, treatments were extended to $24 \mathrm{~h}$ before harvest. All mRNAs were analyzed by qPCR and normalized to 3 housekeeping genes B2M, RPS15 and EIF3K. a. Representative immunoblots of p-mTOR/mTOR (256 kDa), pSREBP1 (125 kDa) and mSREBP1 (65 kDa). b. Data represent mean SREBP1 protein abundance normalized to $\beta$-actin \pm SEM, $n=3$. c-g: Data represent relative abundance of gene measured by qPCR and normalized to three housekeeping genes. Mean $( \pm \mathrm{SEM})$ was compared using Tukey's test. Difference was considered significant when $p<0.05$. 
Figure 5.4 mTOR kinase affected GSK3-dependent SREBP1 degradation.

a

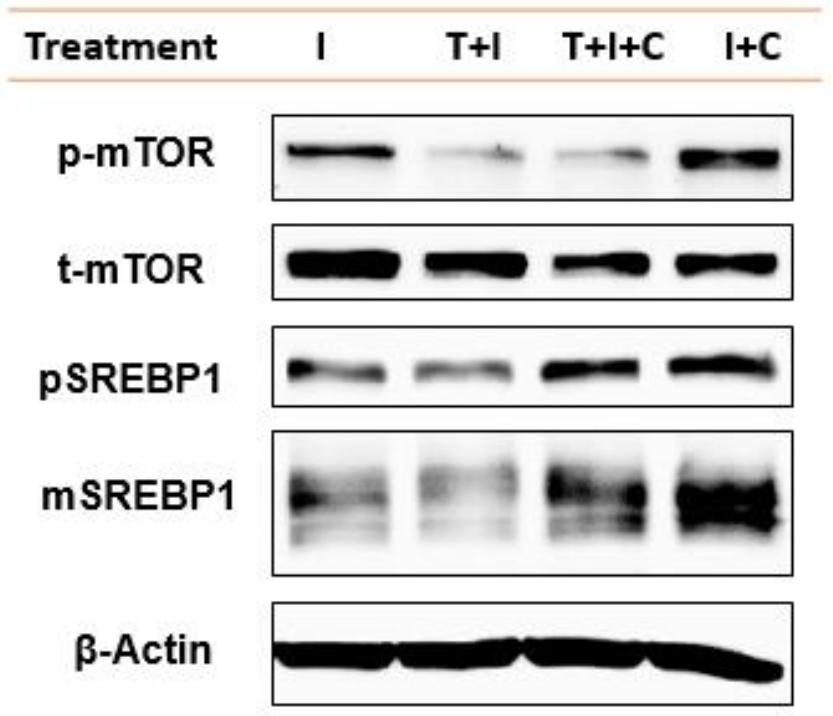

b

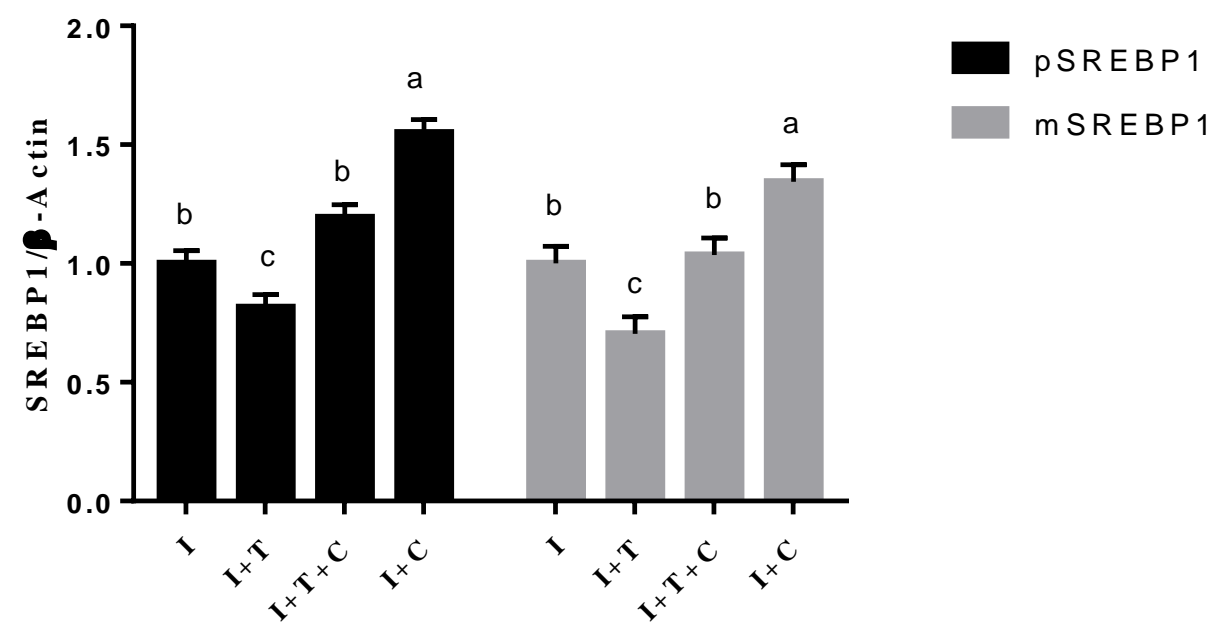

Cells were seeded at 6 -well plates with density of $3 \times 10^{5} /$ well. On the next day, after reaching $80 \%$ confluency, cells were serum-starved for $24 \mathrm{~h}$ and then treated with $100 \mathrm{ng} / \mathrm{mL}$ insulin, 250 nM Torin1 or $10 \mu \mathrm{M}$ GSK3 inhibitor CHIR99021 for $6 \mathrm{~h}$. Total protein lysates were extracted, and $60 \mu \mathrm{g}$ proteins were analyzed by immunoblotting. a. Representative immunoblots of p- 
mTOR/mTOR (256 kDa), pSREBP1 (125 kDa) and mSREBP1 (65 kDa). b. Data represent mean pSREBP1 and mSREBP1 protein abundance normalized to $\beta$-actin \pm SEM, $n=3$. Mean $( \pm$ SEM $)$ was compared using Tukey's test. Difference was considered significant when $p<0.05$. I: insulin; I+T: Torin1+insulin; I+T+C: insulin+Torin1+CHIR99021; I+C: insulin+ CHIR99021. 
Figure 5.5 mTOR kinase affected cytoplasmic CRTC2 phosphorylation and Lipin1 cellular distribution.

a

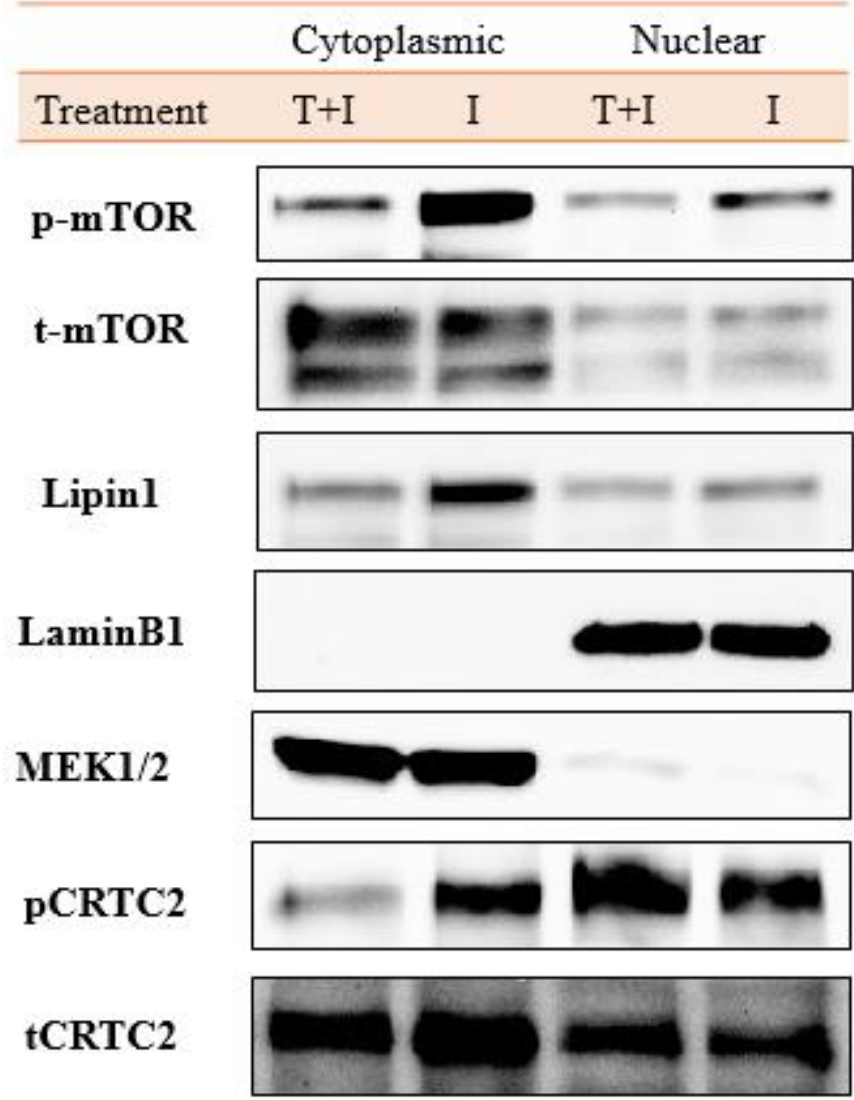

B

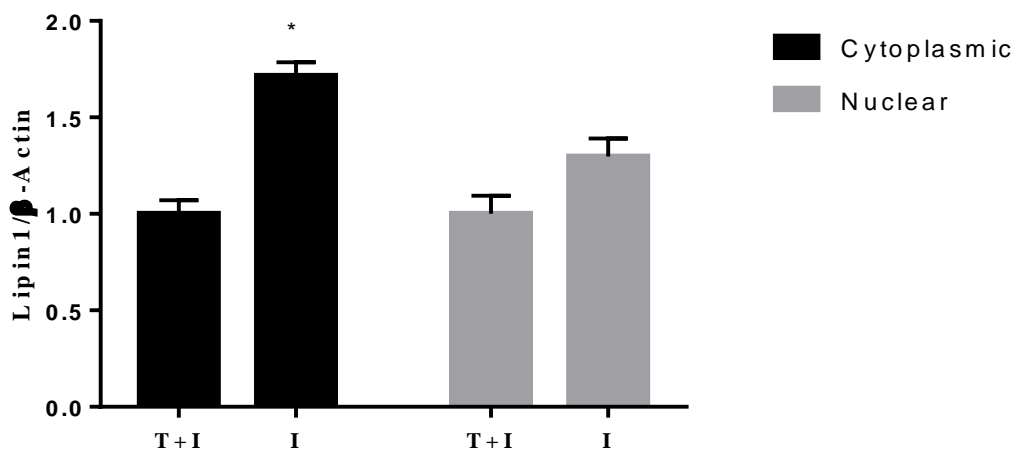




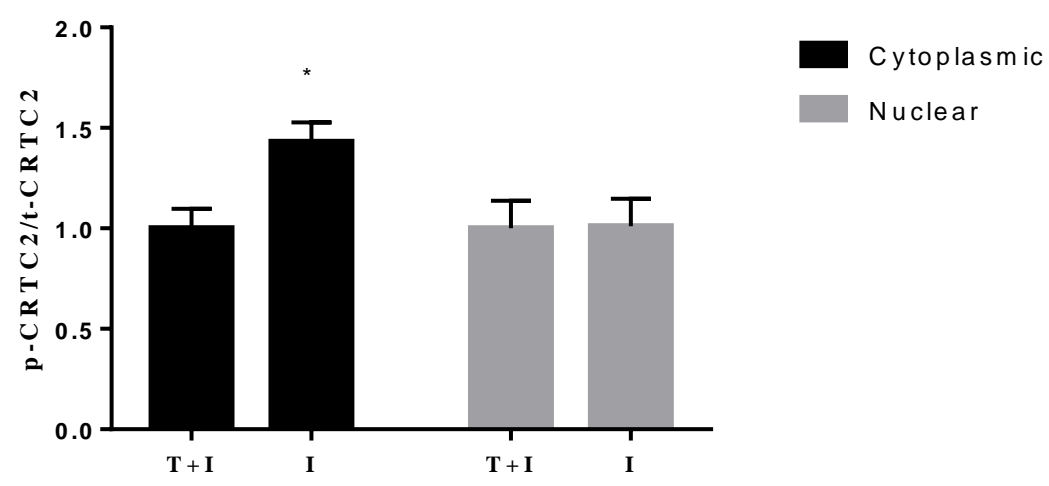

Cells were seeded at $60 \mathrm{~mm}$ dishes with density of $3 \times 10^{6} /$ well. On the next day, after reaching $80 \%$ confluency, cells were serum-starved for $24 \mathrm{~h}$ and then treated with either $100 \mathrm{ng} / \mathrm{mL}$ insulin plus $250 \mathrm{nM}$ Torin $1(\mathbf{T}+\mathbf{I})$ or $100 \mathrm{ng} / \mathrm{mL}$ insulin alone (I) for $6 \mathrm{~h}$. Nuclear and cytoplasmic protein lysates were separated and analyzed by immunoblotting. a. Representative immunoblots of pmTOR/t-mTOR (256 kDa), cytoplasmic and nuclear Lipin1 (130 kDa) and p-CRTC2/t-CRTC2 (81 kDa). b. Data represent mean cytoplasmic Lipin1 protein abundance normalized to MEK1/2 \pm SEM and nuclear Lipin1 protein abundance normalized to LaminB1, $n=3$. c. Data represent mean ratio of cytoplasmic and nuclear $\mathrm{p}-\mathrm{CRTC} 2 / \mathrm{t}-\mathrm{CRTC} 2$ protein abundance $\pm \mathrm{SEM}, \mathrm{n}=3$. Mean ( \pm SEM) was compared using Tukey’s test. Difference was considered significant when $p<0.05$. 
Figure 5.6 Glucose regulated SREBP1 through activation of SCAP.

$\mathbf{a}$

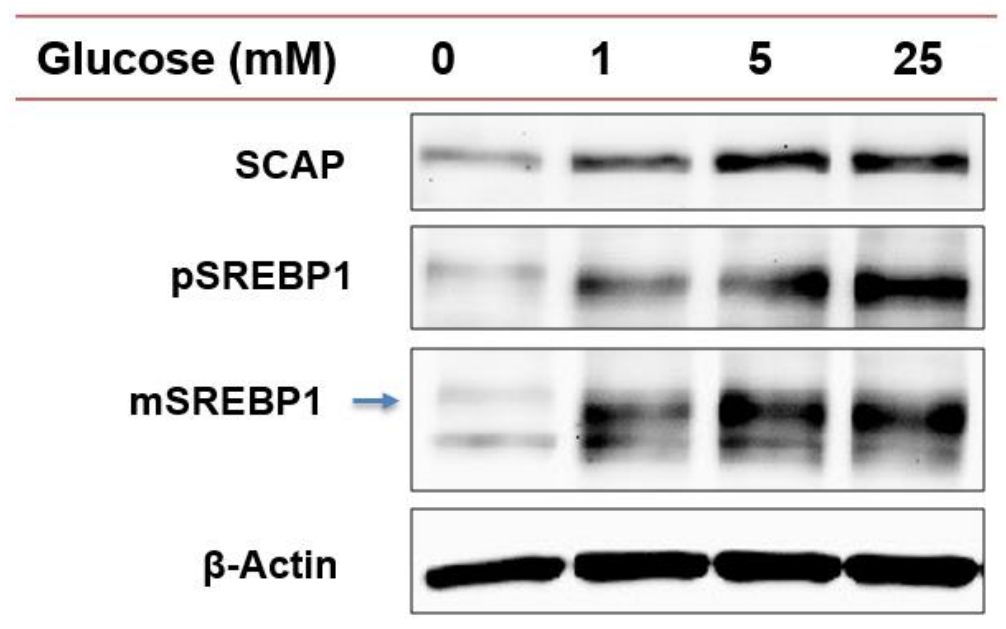

b

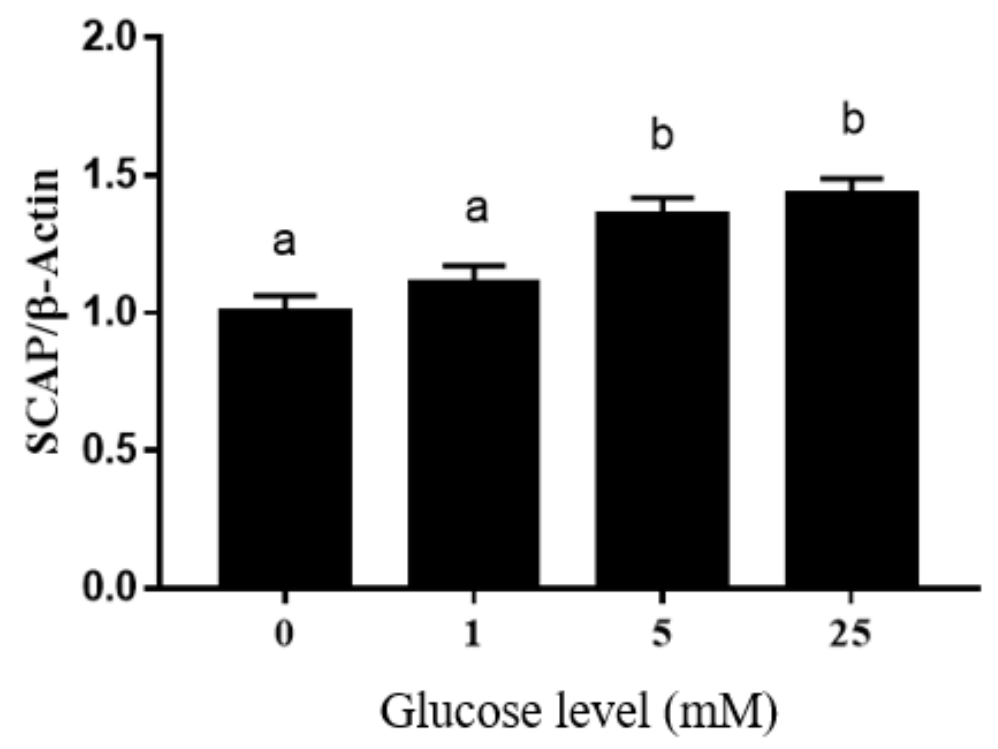




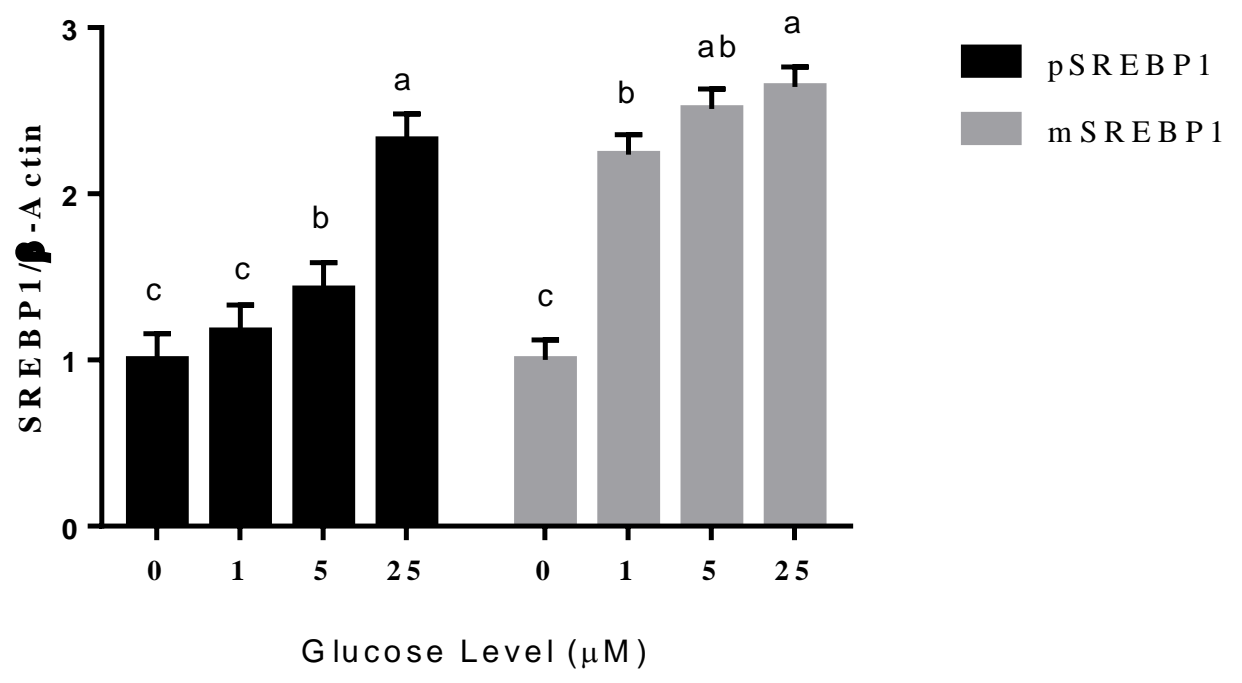

Cells were seeded at 6-well plates with a density of $3 \times 10^{5} /$ well. On the next day, after reaching $80 \%$ confluency, cells were switched to serum free medium and supplemented with or without increasing dose of glucose for $12 \mathrm{~h}$. Total protein lysates were extracted and $60 \mu \mathrm{g}$ proteins were analyzed by immunoblotting. a. Representative immunoblots of SCAP (140 kDa), pSREBP1 (125 kDa) and mSREBP1 (65 kDa). b. Data represent mean SCAP protein abundance normalized to $\beta$-actin \pm SEM, $n=3$. c. Data represent mean pSREBP1 and mSREBP1 protein abundance normalized to $\beta$-actin \pm SEM, $\mathrm{n}=3$. Mean $( \pm \mathrm{SEM})$ was compared using Tukey's test. Difference was considered significant when $p<0.05$. 
Figure 5.7 trans10, cis12-CLA induced SREBP1 inhibition through AMPK phosphorylation.

a

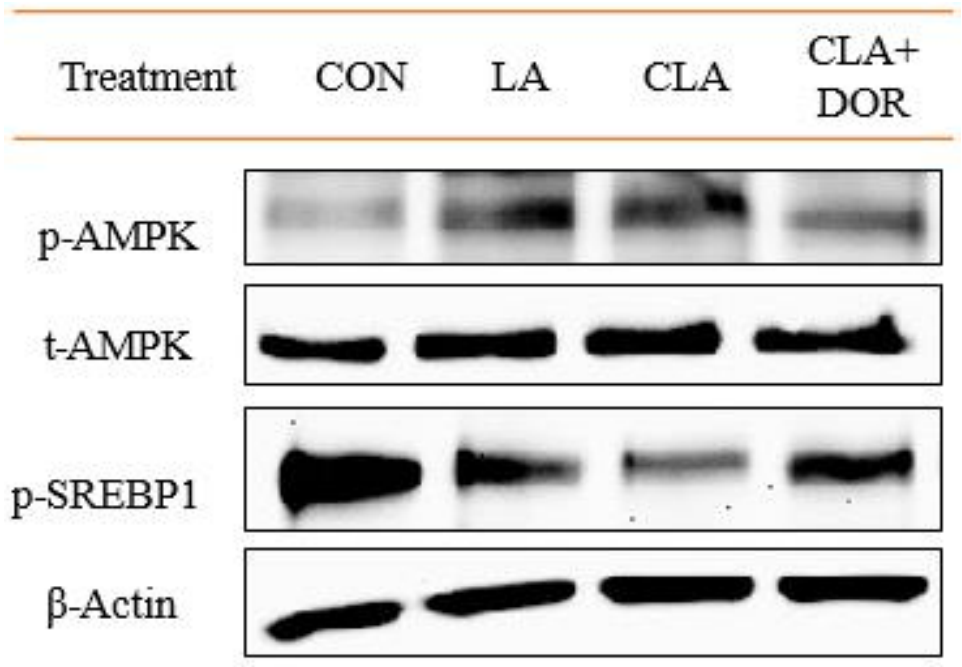

b

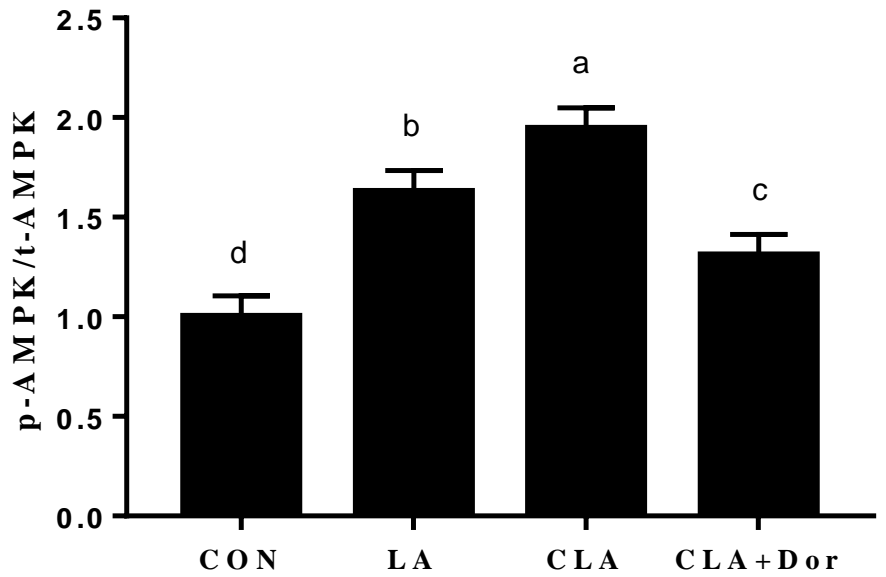




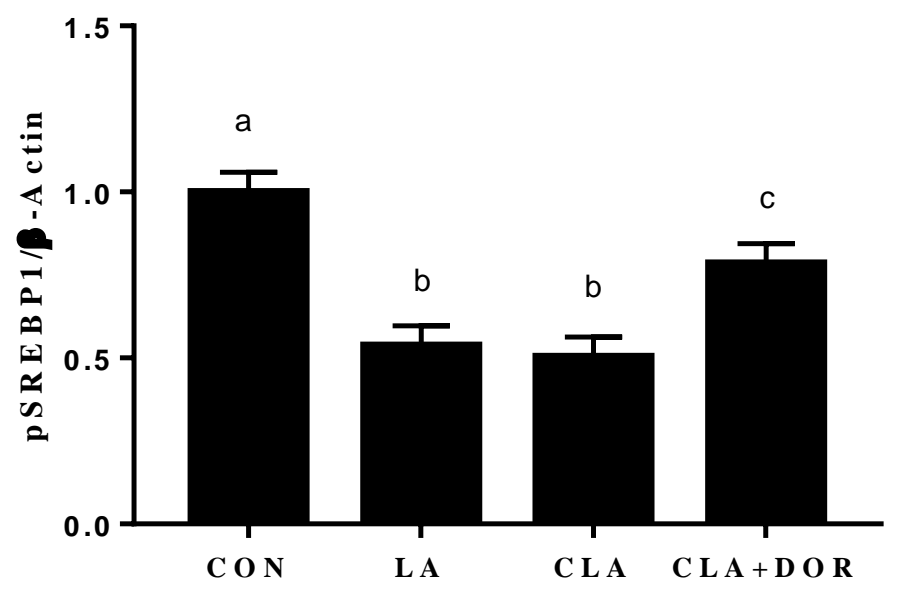

Cells were seeded at 6-well plates with density of $3 \times 10^{5} /$ well. On the next day, after reaching $80 \%$ confluency, cells were treated with either $75 \mu \mathrm{M}$ trans10, cis12-CLA (CLA), $75 \mu \mathrm{M}$ linoleic acid (LA), $10 \mu \mathrm{M}$ AMPK inhibitor Dorsomorphin (DOR) or BSA (CON) for $12 \mathrm{~h}$. Total protein lysates were extracted and $60 \mu \mathrm{g}$ proteins were analyzed by immunoblotting. a. Representative immunoblots of p-AMPK/t-AMPK (62 kDa) and pSREBP1 (125 kDa). b. Data represent mean ratio of $\mathrm{p}-\mathrm{AMPK} / \mathrm{t}-\mathrm{AMPK}$ protein abundance $\pm \mathrm{SEM}, \mathrm{n}=3$. c. Data represent mean $\mathrm{pSREBP} 1$ protein abundance normalized to $\beta$-actin \pm SEM, $n=3$. Mean $( \pm$ SEM) was compared using Tukey's test. Difference was considered significant when $p<0.05$. 
Figure 5.8 Summary diagram for proposed effects of insulin, glucose and t10, c12CLA and their regulatory pathways on SREBP1 activation in MacT.

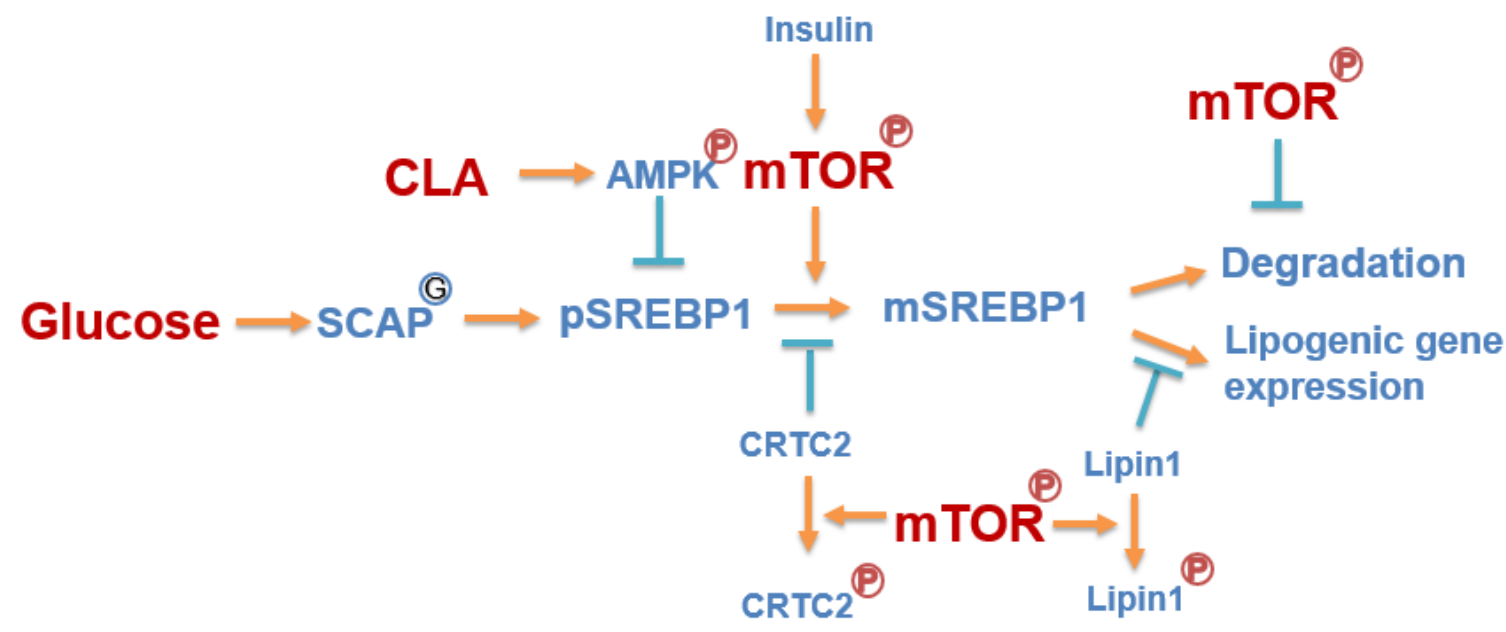

Insulin increases mTOR phosphorylation (orange arrow). Activated mTOR phosphorylates CRTC2 and Lipin1, and removes their inhibition on SREBP1 activation, mTOR signaling stops GSK3-dependent proteasomal degradation of SREBP1 (blue line with stop bar). Glucose stabilizes SCAP and thus promotes SREBP1 activation. t10, c12-CLA inhibits SREBP1 expression through increasing AMPK phosphorylation. 


\section{Chapter 6}

\section{General Conclusions}

Milk fat synthesis is a process under coordinated control of series of lipogenic enzymes. SREBP1 is the key transcription factor that regulates gene transcription, especially genes encoding lipogenic enzymes by binding specific fragments in their promoter regions, called SREs. SREBP1 activation is a multiple-step process that can be regulated by nutrients, especially t10, c12-CLA, which was claimed to be the cause of milk fat depression. SREBP1 also interacts with other major cellular signaling pathways such as mTOR, and AMPK to adapt to hormonal regulation and nutrient availability. In the first study, I concluded that SREBP1 bound to the specific SRE in SREBP1, FASN and SCD in bovine mammary epithelial cells and lactating mammary tissues using ChIPPCR. Using specific SREBP1 antibody ensured targeted-enrichment of SREBP1 binding of SREBP1, FASN using ChIP-QPCR. On top of that, the presence of SRE in 24 lipogenic genes was identified using ChIP-seq including genes that regulates de novo fatty acid synthesis, fatty acid uptake, intracellular fatty acid activation, trafficking as

well as triglyceride synthesis. Furthermore, $88 \%$ of the SRE located within 10k bp of the start of 5'-end of respective genes which could be potentially functional SREs for SREBP1-targeted transcription regulation. However, the fold-enrichment and the q-value of these peaks were low and inconsistent among samples, raising questions about the quality of the sequencing data. In addition, 11 unique peaks in the ChIP samples and three of them could be the potential SREs for the genes related to lipid metabolism were identified, which has not been reported before. the closest genes to the top peaks ranked by q-value or fold-change were involved in regulating apoptosis, immune function and 
signaling transduction were characterized, suggesting possible functions of SREBP1 in maintaining cell integrity.

In the second study, evidences were provided that t10, c12-CLA inhibited SREBP1 activation through Insig1 proteosomal degradation. Increasing t10, c12-CLA concentration increased Insig1 protein expression which was corresponded to decreasing expression and maturation of SREBP1 as well as decreased gene expression of FASN, SCD and SREBP1. Insig1 expression is not only sensitive to t10, c12-CLA but other PUFAs such as linoleic acid and c9, t11-CLA, but not to saturated FAs like palmitic acid. Further investigation showed that t10, c12-CLA decreased Insig1 degradation rather than increased its protein synthesis since the gene expression of Insig1 was also decreased by addition of t10, c12-CLA. The interaction between Insig1 and Ubxd8 was blocked by addition of t10, c12-CLA, thus the removal of Insig1 was disrupted and remained on the ER membrane, preventing SREBP1 migration to the Golgi for further processing. The retained Insig1 is the reason for t10, c12-CLA-mediating SREBP1 inhibition thus reducing lipogenic gene transcription.

In the third study, the potential effects of mTOR signaling, AMPK and glucose on SREBP1 activation were investigated. Insulin-induced mTOR activation or rapamycin/Torin1-mediated mTOR inhibition regulated SREBP1 activation thus lipogenic gene expression. Knockdown of SREBP1 by specific siRNA blocked the mTOR stimulatory effect on lipogenic gene transcription, suggesting possible mTOR regulation of SREBP1 activation. Activated mTOR phosphorylated CRTC2, a suppressor of COP II-dependent SREBP1 maturation, which inhibited the formation of COP II vesicles that deliver the SREBP1-SCAP complex from the ER to the Golgi. 
Phosphorylated CRTC2 was inactivated and dissociated from COP II subunit Sec31A. Lipin1, which suppressed mature SREBP1 entry into the nucleus, was also phosphorylated by mTOR and translocated from the nucleus to the cytosol. Lastly, SREBP1 degradation was a GSK3-dependent process which was also regulated by mTOR. Activated mTOR acted as GSK3 inhibitor to prevent SREBP1 proteosomal degradation. t10, c12-CLA increased AMPK phosphorylation in MacT cells. Inhibition of AMPK phosphorylation reduced the inhibitory effect of t10, c12-CLA on SREBP1 activation, indicating a potential regulatory pathway of t10, c12-CLA on SREBP1 via AMPK. Lastly, minimal glucose concentration was sufficient to stabilize SCAP and facilitate SREBP1 activation. No glucose degraded SCAP and inhibited SREBP1 activation, indicating a novel effect of glucose on SREBP1 activation. This is the first report to investigate the mechanisms of SREBP1 activation by mTOR, AMPK and glucose in MacT cells. More in vivo data are required to further reveal the interaction between SREBP1 and its regulators and to determine the role of those factors on milk fat synthesis. 